\title{
Embedding Medication Review in Clinical Practice Reconceptualising Implementation Using a Practice Theory Perspective
}

Ursula Reichenpfader 
Linköping University Medical Dissertations No. 1684

\section{Embedding Medication Review in Clinical Practice}

Reconceptualising Implementation Using a Practice Theory Perspective

Ursula Reichenpfader

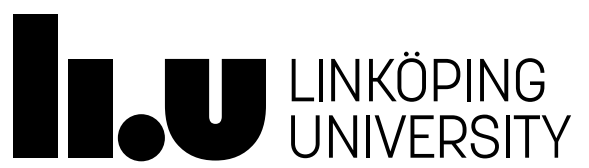

Department of Medical and Health Sciences

Linköping University, Sweden

Linköping 2019 
(c) Ursula Reichenpfader, 2019

Published articles have been reprinted with the permission of the copyright holder.

Printed in Sweden by LiU-Tryck, Linköping, Sweden, 2019

ISBN 978-91-7685-065-7

ISSN $0345-0082$ 
Für Erika

It is not a matter of turning the arrow round so that instead of the natural sciences explaining social phenomena a social explanation of molecules, cells, or bodies is being presented. Instead, another axis has been introduced, another approach taken: that of practice. The latter encompasses molecules and money, cells and worries, bodies, knives, and smiles, and talks about all of these in a single breath.

(A. Mol, 2002: 157) 



\section{CONTENTS}

ABSTRACT 1

SVENSK SAMMANFATTNING

LIST OF ARTICLES

ACKNOWLEDGEMENTS

I. INTRODUCTION 9

SCOPE AND RATIONALE $\quad 9$

Statement of the problem and focus 9

Research purpose 11

Research contributions 12

Outline of the thesis 12

MEDICATION-RELATED HARM AND ITS MINIMIZATION 13

$\begin{array}{lr}\text { Significance of the problem } & 13\end{array}$

Medication review and medication reconciliation $\quad 15$

Implementing medication review in routine healthcare $\quad 16$

Medication review in the Swedish policy context 17

UNPACKING IMPLEMENTATION RESEARCH 21

Studying implementation in the context of healthcare 22

The central role of implementation frameworks and models 23

Conceptualizing implementation in implementation research 24

Challenges to and the need to broaden theoretical perspectives in

implementation research 26

Outline for an alternative approach $\quad 27$

II. THEORETICAL PERSPECTIVE

PRACTICE THEORY $\quad 29$

A family of theories $\quad 29$

What are practices? 30

A theory-method-package 32

III. METHODOLOGICAL APPROACH \& RESEARCH DESIGN 33

METHODOLOGICAL APPROACH 33

Practice-based sensitivity using a toolkit approach 33

Theorizing practices $\quad 33$

Ethnographic approach $\quad 35$

Practice-theoretical concepts applied in this thesis 35

EMPIRICAL CONTEXT AND RESEARCH DESIGN 41

Pilot study $\quad 41$

Recruiting of cases $\quad 42$

Study setting and participants $\quad 42$

GENERATING DATA USING AN ETHNOGRAPHIC APPROACH 43 
Reflexivity and methodological quality $\quad 47$

$\begin{array}{ll}\text { Ethical considerations } & 50\end{array}$

Methodological considerations 50

ANALYTICAL PROCESSES $\quad 52$

Theoretical assumptions $\quad 52$

Analytical strategies and conceptual tools $\quad 52$

IV. FINDINGS

Article 1: 'Our surgeons want this to be short and simple': practices of inhospital medication review as coordinated sociomaterial actions

Article 2: Medi(c)ation Work in the Emergency Department: Making Standardized Practice Work

Article 3: Embedding hospital-based medication review: the conflictual and developmental potential of a practice

Article 4: 'In the hospital all is taken care of': a practice-theoretical approach to understand patients' medication use (manuscript under revision) 60

V. DISCUSSION

$\begin{array}{ll}\text { EMPIRICAL CONTRIBUTIONS } & 63\end{array}$

$\begin{array}{ll}\text { Practicing medication review } & 63\end{array}$

Practicing the embedding of medication review 68

$\begin{array}{ll}\text { METHODOLOGICAL CONTRIBUTION } & 70\end{array}$

Zooming in on practice 70

$\begin{array}{ll}\text { THEORETICAL REFLECTIONS } & 72\end{array}$

Medication review - a complex undertaking 72

Medication-related problems in everyday clinical practice 73

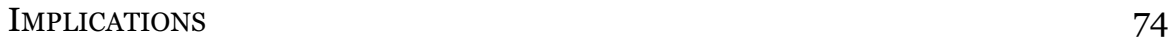

Implications for healthcare practice and policy 74

Implications for implementation research $\quad 75$

$\begin{array}{lr}\text { CONCLUDING REMARKS } & 76\end{array}$

Future research directions $\quad 76$

$\begin{array}{ll}\text { Conclusions } & 77\end{array}$

$\begin{array}{ll}\text { REFERENCES } & \mathbf{7 9}\end{array}$

$\begin{array}{ll}\text { APPENDIX } & 95\end{array}$ 


\section{ABSTRACT}

The hospital is a critical setting with respect to medication safety and quality of medication therapy. Medication review, the structured assessment of an individual patient's medications with the aim of improving therapy, has been advocated as a strategy to reduce medication-related harm. Although programs of medication review have been widely introduced, its implementation has encountered difficulties. While seemingly a rather straightforward concept, processes to identify current medication use and reconcile different medication lists have been complicated by organizational, interprofessional, or technical factors. There is, thus, a need to better understand medication review implementation. However, it is also important to critically consider how the implementation of healthcare interventions is generally understood, and what theoretical or conceptual considerations inform implementation efforts. Studying organizational and social phenomena as they unfold in practice has the potential to shed light on how these everyday activities are generated, how they are adapted over time, and what consequences this has on social and organizational processes.

The purpose of this thesis is to develop an alternative perspective on studying the implementation of a healthcare intervention in routine care. More specifically, this thesis aims to theorize the embedding and practicing of medication review in routine hospital work. Theorizing, here, refers to empirically and theoretically exploring phenomena based on cases of local medication review implementation.

Drawing on empirical case examples of medication review implementation in southeast Sweden, an ethnographic approach is employed conducting participant observation, informal conversations and semi-structured interviews with different healthcare professionals in two hospital settings, as well as semi-structured interviews with patients from three different hospital settings. A so-called toolkit approach for practice theory is employed, using a range of different practice-theoretical concepts to empirically study practice.

The empirical findings point to the centrality of dealing with medicationrelated problems when conducting and embedding medication review. Both practicing and embedding medication review were shaped by how medication-related problems and potential medication harms were constructed, contested, and negotiated in practice. Practitioners' everyday actions and practices revealed different meanings attached to the concept of 
medication-related problem bringing to the fore the contested and conflictual nature of the practice. Also, insight was provided into how practices to embed medication review in routine hospital work unfolded, revealing material-discursive and reflective practices, but also silent modes of legitimizing not practicing medication review in a highly structured way.

This thesis provides an alternative perspective on studying the implementation of a healthcare intervention and challenges various assumptions underpinning implementation research. Instead, a broadened perspective is suggested directing attention to the practical and situated knowing involved, the local processes of negotiating objectives in practice, as well as to the meaning-making required when practitioners engage with a practice. Finally, there are opportunities to learn from implementation processes, when frontline practitioners involved in embedding medication review are able to adapt medication review to make routines better fit the local context. 


\section{SVENSK SAMMANFATTNING}

Inom sluten vård finns stora utmaningar vad gäller upprätthållandet av hög kvalitet och säkerhet inom läkemedelsbehandling. Läkemedelsgenomgångar är ett strukturerat och systematiskt arbetssätt för bedömning och uppföljning av en individs läkemedelsanvändning, och har förespråkats som en strategi för att öka läkemedelssäkerheten. Läkemedelsgenomgångar har i stor utsträckning introducerats, men införandet har ofta stött på svårigheter. Implementeringen av metoden har försvårats av organisatoriska, interprofessionella och tekniska faktorer. Det finns således ett behov av att bättre förstå såväl implementeringen som genomförandet av läkemedelsgenomgångar. Det är emellertid också viktigt att få en bättre förståelse för implementeringsprocesser generellt och vilka teoretiska och konceptuella överväganden dessa baseras på. Att studera organisatoriska och sociala fenomen så som de uppträder i praktiken gör det möjligt att belysa hur vardagliga aktiviteter sker, hur de anpassas över tid, och hur sociala och organisatoriska processer påverkas.

Syftet med denna avhandling är att utveckla och tillämpa ett alternativt perspektiv för att studera implementeringen av ett nytt arbetssätt i rutinsjukvård. Mer specifikt syftar denna avhandling till att teoretisera införlivandet och genomförandet av läkemedelsgenomgångar i rutinverksamhet inom sluten vård. Begreppet teoretisera ska i det här sammanhanget förstås som ett empiriskt och teoretiskt utforskande av ett fenomen.

För att empiriskt, i form av fallstudier, studera implementeringen av läkemedelsgenomgångar vid ett antal sjukhusenheter i sydöstra Sverige, användes en etnografisk ansats. Deltagande observation, informella konversationer och halvstrukturerade intervjuer med vårdpersonal från två sjukhusenheter, samt halvstrukturerade intervjuer med patienter från tre olika sjukhusenheter genomfördes. En så kallad ‘toolkit-approach' för praktikteori, där olika praktikteoretiska begrepp och ramverk tillämpas, användes för att studera de empiriska fenomenen.

De empiriska fynden pekar på vikten av att ta hänsyn till de läkemedelsrelaterade problemen i samband med införandet av läkemedelsgenomgångar. Både genomförandet och införlivandet påverkades av hur läkemedelsrelaterade problem och potentiella läkemedelsskador konstrueras, ifrågasätts och förhandlas i praktiken. Klinikernas agerande i vardagen kan refereras till olika betydelser av begreppet läkemedelsrelaterat problem, vilket också indikerar att praktikens karaktär kan diskuteras. Resultatet il- 
lustrerade olika metoder för att införliva läkemedelsgenomgångar i rutinarbete, såsom materialdiskursiva och reflekterande praktiker, men även tysta metoder för att legitimera ett 'icke-strukturerat' genomförande av läkemedelsgenomgångar.

Empiriskt belystes kunskap relevant för det dagliga genomförandet av läkemedelsgenomgångar, praktiska frågor, syfte, uppgifter och kompetenser. Metodologiskt visade sig etnografiska metoder och olika praktikteoretiska begrepp med en 'toolkit-approach' vara användbara. De bidrog till att bredda förståelsen av begreppen kunskap, handling och förändring, som alla är centrala när man studerar implementering.

Avhandlingen erbjuder ett alternativt perspektiv på hur implementering kan studeras och utmanar olika antaganden som ligger till grund för tidigare forskning inom implementering. Ett breddat perspektiv, som riktar uppmärksamheten mot den praktiska och situerade kunskapen, de situationer i vilka mening skapas genom praktiken, samt lokala processer för att stämma av olika intressen och mål i praktiken, förespråkas. Slutligen hänvisas till den potential för lärande som reflektion över hur rutinerna bäst anpassas till den lokala kontexten, utgör bland kliniker involverade i införlivandet av läkemedelsgenomgångar. 


\title{
LIST OF ARTICLES
}

\begin{abstract}
ARTICLE I
Reichenpfader U, Wickström A, Abrandt Dahlgren M, Nilsen P and Carlfjord S. (2018) 'Our surgeons want this to be short and simple': practices of in-hospital medication review as coordinated sociomaterial actions. Studies in Continuing Education, 40:3, 323-336, DOI: 10.1080/0158037X.2018.1458710
\end{abstract}

\section{ARTICLE II}

Reichenpfader U, Wickström A, Nilsen P, Abrandt Dahlgren M, and Carlfjord S. (2018) Medi(c)ation Work in the Emergency Department: Making Standardized Practice Work. Professions \& Professionalism, 8(2), e2298. DOI: $10.7577 /$ pp.2298

\section{ARTICLE III}

Reichenpfader U, Wickström A, Abrandt Dahlgren M, and Carlfjord S. (2019) Embedding hospital-based medication review: the conflictual and developmental potential of a practice. Journal of Health Organization and Management, DOI 10.1108/JHOM-09-2018-0268

\section{ARTICLE IV}

Reichenpfader U, Wickström A, Abrandt Dahlgren M, and Carlfjord S. 'In the hospital all is taken care of': a practice-theoretical approach to understand patients' medication use (under revision, submitted to Sociology of Health and Illness) 
Embedding Medication Review in Clinical Practice 


\section{ACKNOWLEDGEMENTS}

This work was supported by the Swedish Research Council for Health, Working Life and Welfare [Forte 2014-4657], the Medical Research Council of Southeast Sweden [FORSS-476971, FORSS-568651], and the County Council of Östergötland patient safety research fund [Region Östergötlands Medel för Patientsäkerhetsforskning LIO-533151, LIO-626451].

Throughout the writing of this thesis I have received a great deal of support and assistance. I would first like to thank my supervisor Siw Carlfjord for her professional guidance through each stage of the process and her ongoing and constructive support during this research. I also wish to acknowledge the help provided by Per Nilsen, my supervisor during the first year. I would like to express my great appreciation to Anette Wickström, my co-supervisor, for providing truly valuable assistance and encouragement of this research during the entire thesis process. Finally, I am very grateful for the thoughtful advice and useful critiques given by my cosupervisor, Madeleine Abrandt Dahlgren.

I would also like to thank the Medical Education Research Group for their valuable and constructive suggestions and whose encouragement and inspiring comments I greatly appreciated and enjoyed.

I would like to offer my special thanks to Ann-Charlotte Nedlund who critically reviewed the manuscript of this thesis and provided very valuable comments and thoughtful feedback.

Inspiring discussions with Monika Nerland and members of her research group HEDWORK during my short stays at the Department of Education, University of Oslo, were greatly appreciated.

I would also like to thank my colleagues and friends at the department, specifically Agneta, Kristin, Margit, and Nadine, for giving support and lending a sympathetic ear. Particularly, Lena, thanks for not only sharing the room with me but also moments of frustration and excitement related to our research work.

I am particularly grateful for all patients and healthcare staff willing to participate in this research study. Without them this research would not have been possible.

And, last but not least, thank you, Harald, for trying to teach me patience and, among other things, reminding me that everything will work out fine, eventually. 
Embedding Medication Review in Clinical Practice 


\section{INTRODUCTION}

In this chapter I will introduce the focus of the thesis, theorizing the embedding and practicing of medication review in routine hospital work, and provide the framing for this focus. Taking as a point of departure the difficulties of implementing medication review in routine work, I will delineate the need for a better understanding of implementation, both in terms of the conceptual object and the ways of studying it. I will, then, present the purpose and research questions, as well as the intended contributions of this thesis. As a background to this research, I will then outline problems and definitions of medication-related harm, as well as measures to minimize such harms, specifically medication review and its policy context in Sweden. In the final section of this chapter, I attempt to 'unpack' implementation research; here, I will problematize several of the understandings, assumptions, and ideas relevant in the field of implementation research and subsequently provide an outline for an alternative approach to study implementation in healthcare settings.

Throughout this thesis I will be using the term embedding when referring to the processual aspect of implementation; I will use the term implementation with reference to its common usage in the academic field of implementation research. My interest in this thesis is to theorize the embedding, that is, the making of an intervention part of everyday work; further, such theorizing also includes the practicing of medication review. Briefly, and explained in more detail in chapter III, by theorizing I refer to exploring a phenomenon empirically and theoretically. As I am drawing on a practice theoretic approach, such theorizing, then, means studying and understanding 'social phenomena through their ongoing formation, accomplishment, and alternation' (Schmidt, 2017: 5).

\section{Scope and rationale}

\section{Statement of the problem and focus}

This thesis theorizes the embedding and practicing of medication review in routine hospital work. Drawing on case examples of the implementation of medication review in routine care at two regional hospitals in Sweden, ethnographic methods are used to reconceptualize implementation from a practice theory perspective. 
Medication prescription and utilization have been growing over the last decade in industrialized countries (Charlesworth et al., 2015), partly related to an aging population with a growing proportion of age-related diseases (Prince et al., 2015) as well as an increased availability of medicines (Lim et al., 2013). Pharmaceutical expenditure constituted the third largest item of health care spending across OECD countries in 2015 accounting for $16 \%$ of health expenditure (OECD, 2018). Notwithstanding the great health benefits of medicines, inappropriate medication therapy, medication errors and preventable consequences such as increased risk of medicationrelated harm are a significant cause of morbidity and mortality and are associated with considerable excess costs (WHO, 2017).

The hospital setting is of particular relevance to efforts of preventing medication harm as this is the site where complex medication regimes are used often, patients with more serious or acute clinical conditions are treated, and where transitions of care occur frequently (WHO, 2017). Prescribing of inappropriate medicines in the hospital setting is common (Juliano et al., 2018) and particularly the elderly are at higher risk of medication-related harm due to increased vulnerability (Cossette et al., 2016). Also, transitions of care, that is, a hospitalized patient's moving between different healthcare staff, healthcare settings, or sectors, have been found to be associated with unintended medication discrepancies and medication-related errors due to fragmented or incorrect communication of medication information (Kerstenetzky et al., 2018).

Medication review, the structured assessment of an individual patient's medications with the aim of improving therapy, has been advocated as a strategy to reduce medication-related harm (Sjöberg and Wallerstedt, 2013). Conduct of medication review in hospitalized patients has been associated with reductions of emergency department (ED) visits after discharge, yet not with relevant health outcome improvements (Christensen and Lundh, 2016; Huiskes et al., 2017). Nevertheless, the Swedish National Board of Health and Welfare introduced medication review as a mandatory service in 2012, to be undertaken at each hospital or ambulatory care episode and offered to all patients aged 75 years and older with five and more medications (Socialstyrelsen, 2012; Socialstyrelsen, 2013a). County councils are responsible for regional implementation of regulations and guidelines allowing for local adaption at the clinical unit level (Region Östergötland, 2015).

Although programs of medication review have been widely introduced, its implementation has encountered difficulties. Previous studies have identified challenges such as unclear task distribution or poor communication as barriers to successful integration (Sanchez et al., 2014). Both, how identified medication problems are followed-up, and how recommenda- 
tions regarding medication therapy changes are carried out, constitute critical elements when implementing medication review (Huiskes et al., 2017). Further, patient involvement in medication review is poorly understood and described (Willeboordse et al., 2014), as is the involvement of patients in implementation in general (Boaz et al., 2016).

There is, thus, a need to better understand medication review implementation. However, it is also important to critically consider how the implementation of healthcare interventions is being understood in general, and what theoretical or conceptual considerations inform the design, planning, conduct and evaluation of implementation efforts. As has been shown, only a minority of these studies are based on explicit theory or theoretical constructs, and in even less studies a theoretical justification for its use is provided (Davies et al., 2010; Kirk et al., 2016; Strifler et al., 2018). What is more, theories and constructs, when used, are selected haphazardly and based on prior exposure (Birken et al., 2017b). An important question to ask, then, is whether current conceptualizations of implementation and extant views on how to study implementation are useful for generating questions that enable us to better understand implementation problems.

It has been argued that a deeper understanding of the intervention to be implemented, including its context, is needed to embed a new way of working in everyday clinical care (May et al., 2007). Integrating new work routines or changing organizational structures can alter existing work practices and need 'situated studies of work', ideally applying ethnographic methods (Barley and Kunda, 2001: 87). Such questions require approaches that study organizational practices as they unfold in its context, thus, in practice (Nicolini, 2012). Therefore, choosing a theoretical approach based on practice theory using ethnographic methods seems warranted as practice-based approaches afford to capture the 'dynamics of everyday activity' (Feldman and Orlikowski, 2011: 1241). Studying organizational and social phenomena as they occur in practices has the potential to shed light on how these everyday activities are generated, how they are reproduced and adapted over time, and what consequences this has on social and organizational processes (Blackler, 1995; Gherardi, 2000; Schatzki, 2005).

\section{Research purpose}

The purpose of this thesis is to develop an alternative perspective on studying the implementation of a healthcare intervention in routine hospital work. Drawing on empirical case examples of medication review implementation in Sweden and using a practice-theoretical approach, this thesis aims to theorize the embedding and practicing of medication review in routine hospital work. 
The following overarching research questions are guiding this thesis research:

1. How is medication review being understood and enacted? What are the ways of embedding medication review into routine hospital work?

2. What does a practice-based perspective offer to better understand the challenges of embedding a new practice into routine hospital work?

Theorizing in this thesis refers to empirically and theoretically exploring these phenomena based on cases of local medication review implementation in Swedish hospital settings. Here, I am drawing upon Alvesson and Kärreman (2007) who view theorizing as a dialogue between theoretical assumptions and the empirical material. A central element in such a dialogic process is problematization, that is, the challenging of the value of a theory, idea, theoretical framework, or preunderstandings relevant in a domain (Alvesson and Sandberg, 2011). A concern of this thesis, therefore, is to challenge the, often implicit, assumptions made in implementation research.

\section{Research contributions}

This thesis research aims to contribute to the fields of implementation research and professional development. First, I want to make an empirical contribution by providing deeper insight into how medication review is being understood and practiced, particularly with respect to the relevant knowledge involved, the practical concerns, as well as the ends, tasks, and competencies considered acceptable. Further, I want to broaden the understanding of how practices to embed medication review in routine hospital work unfold. In doing so, the ways in which medication-related problems are constructed, contested, and negotiated in practice are brought to the fore.

Second, I want to make a methodological contribution by providing an alternative way of studying the complexity of implementation. Using ethnographic methods combined with a methodological practice-based sensitivity represents a novel approach to study and understand implementation in a healthcare context.

\section{Outline of the thesis}

This thesis comprises two parts, an extended abstract, and, second, four separate articles. In the extended abstract the first and introductory chapter describes the purpose and rationale of the research and provides a brief background related to medication-related harm and the current policy measures in Sweden; this chapter also includes a subsection problematiz- 
ing implementation research and the implications of such a problematization for this thesis. This is followed by presenting the theoretical approach and its affordances in the second chapter. The third chapter provides an overview of the methodological approach, including the practice-theoretical concepts selected for this thesis, as well as the research design, the data generated, and the analytical strategies employed. In the fourth chapter the findings of the four articles are summarized, and, finally, the overall empirical and methodological contributions of the thesis will be discussed in the fifth chapter.

The second part of the thesis comprises four separate articles. Although each represents a separate research contribution, the articles are interconnected in the sense that a practice-theoretical perspective, albeit with different concepts, is used to study medication review implementation. Thus, the articles should not be viewed as the results of separate substudies, rather, they represent different 'practice arenas' and different analytical 'cuts' based on a 'joint' ethnographic dataset.

\section{Medication-related harm and its minimization}

\section{Significance of the problem}

Medications are essential and indispensable elements in healthcare, utilized not only for the treatment, but also for the prevention and diagnosis of disease (Angamo et al., 2016). Prescription and use of medications have been increasing over the last decades, particularly in the elderly population (Craftman et al., 2016; Franchi et al., 2014). As part of a growing demand for prescription medications due to increased aging-related diseases, higher accessibility of medicines, expanded drug indications, and increasing availability of new drugs, drug utilization and the total number of prescribed drugs used per adult patient continue to grow (Guthrie et al., 2015). Notwithstanding their various beneficial effects, medicines also possess a considerable harmful potential. Inappropriate prescribing, errors in the medication process, or inadequate use of medicines can cause serious problems and negatively affect health outcomes (WHO, 2017; Zhou and Rupa, 2018). Both increased age and the combination of multiple medications are associated with a higher risk of medication-related harms, besides other factors such as type of medication, patient adherence problems, or inadequate monitoring of medications (Johnell and Klarin, 2007; Leendertse et al., 2008; Shah and Hajjar, 2012).

Medication-related harm poses a significant public health concern given its clinical significance and considerable economic consequences (WHO, 2017). As a broader concept, the term adverse drug event (ADE) 
refers to harms as a result from medication-related interventions. Estimates of $\mathrm{ADE}$ incidence rates from international studies range from $0.17 \%$ to $65 \%$ (Meier et al., 2015). While ADEs can be a result of inappropriate dose increase or reduction, or the discontinuation of a drug, the term adverse drug reaction (ADR) refers to a narrower concept. An ADR is defined as any harmful and unintended response to a medicine which occurs under conditions and doses normally used (WHO, 2002). Occurrences of ADRs associated with hospitalization vary widely due to differences in detecting, assessing, or reporting ADRs, ranging from $0,2 \%$ to $55 \%$ across countries (Goedecke et al., 2016).

Some, but not all ADEs or ADRs may be caused by medication errors. A medication error, defined as an unintended failure in the medication process with the potential to cause patient harm, can occur at any stage related to medication use. This ranges from prescribing (choosing an inappropriate medicine, writing the prescription), storing, preparing and manufacturing, dispensing, or administering medicines (WHO, 2016). Due to highly variable detection methods and definitions, there are difficulties to estimate the exact frequency of medication errors with prevalence rates ranging from $2 \%$ to $70 \%$ and about $15 \%$ of errors resulting in patient harm (Lisby et al., 2010). It is argued that mistakes identified and corrected can contribute to learning (Sutcliffe, 2004) although still a large number of errors are considered to go unnoticed (Aronson, 2009). According to the seminal Harvard Medical Practice Study, medication errors were the most frequent errors with one in five of the identified medical errors in hospitalized patients, estimates that were later confirmed in studies conducted in other hospital settings (Leape et al., 1991; Lisby et al., 2005; Karthikeyan and Lalitha, 2013).

The hospital is a critical setting with respect to medication safety and quality of medication therapy. Unintended medication discrepancies were found to be common among hospital patients, although they do not automatically lead to clinically relevant patient harm (Kwan et al., 2007). Such medication discrepancies occur in connection to transitions of care when patients are being hospitalized (Redmond et al., 2018). Here, critical trajectories associated with unintended medication discrepancies involve all forms of transitions, such as a patient's admission to the hospital, transfers between different hospital units or between healthcare staff, and discharge from hospital to home (Redmond et al., 2018; Freyer et al., 2018).

Although an important step, only ensuring a correct medication list through medication reconciliation is not enough to provide for appropriate medication therapy. Thus, identifying potential inappropriate medicines (such as incorrect indication or dosage, or unfavorable medicine combination) and adjusting medication regimes are further essential steps for minimizing harms and optimizing medication therapy outcomes (Zimmerman 
et al., 2017). It has been suggested that engaging patients in medication safety should be added as a patient safety intervention in its own right, for example by providing them with information about the purpose and sideeffects of their medications, and encouraging them to monitor medicine effectiveness and to discuss their medications with healthcare professionals (Gruman et al., 2010). However, studies also indicate that opportunities to engage patients in medication management during hospitalization are often not recognized and patients' attempts to participate are not facilitated (McTier et al., 2015); also, patients could not effectively learn about their medications as communication about medications took place in distracting, stressful situations during the hospital stay, potentially affecting the quality and safety of medication therapy (Manias et al., 2014).

\section{Medication review and medication reconciliation}

Given the harmful potential of medication therapy with the risk of adverse events leading to unplanned healthcare visits or hospitalization, compromised health, or death (Dechanont et al., 2014; Patel and Patel, 2018), evidence-based strategies to improve processes and outcomes of medication therapy are called for (Cohen et al., 2018). One of the possible strategies to optimize medication therapy and improve medication safety is medication review (Acheampong et al., 2014). Although no generally accepted definition of medication review is available (Griese-Mammen et al., 2018), medication review is commonly understood as the systematic assessment of an individual patient's medication therapy by a healthcare professional with the aim of optimizing treatment benefit, minimizing potential medication harm, and improving health outcomes (Christensen and Lundh, 2016).

Medication review is a complex intervention requiring different steps including collecting patient-specific information on medicine use, assessing medication therapy, and recommending or directly making medication therapy changes. A basic component of medication review is medication reconciliation. A complex intervention itself, medication reconciliation means developing a complete and accurate list of a patient's current medicines, clarifying and reconciling any discrepancies, and documenting potential changes (McNab et al., 2018; Mekonnen et al., 2016; Cheema et al., 2018). Several different sources of information on medicines may be available, such as the electronic medical record, a patient's own notes, or pharmacy records which may contribute to potentially discrepant medication lists (Redmond et al., 2018).

More comprehensive concepts of medication review encompass additional interventions such as tailored patient education or counselling, telephonic follow-up and advice on medications after discharge, or written medication summaries for patients at discharge (Christensen and Lundh, 
2016). It is hypothesized that medication review results in more appropriate prescribing which then positively affects effectiveness and adherence to medicines, reduces adverse events (for example by ensuring correct treatment indication or drug-therapy monitoring), and, ultimately leads to reduced morbidity and mortality (Christensen and Lundh, 2016).

There is no conclusive evidence with respect to the basic elements required for medication review to be effective (Huiskes et al., 2017), a result of the intervention components not being well theorized and the inappropriate study designs used for evaluating effectiveness (Cadogan et al., 2016b). Findings across different systematic reviews and meta-analyses showed positive effects with respect to several process outcomes (such as the number of medications, the number of medication changes, the number of medication-related problems), yet only small or no effects with respect to patient-oriented health outcomes and mortality (Christensen and Lundh, 2016; Hohl et al., 2015; Huiskes et al., 2017). Also, very little is known how patients view their participation in medication review (Willeboordse et al., 2014). Patients have expressed resistance towards advice by pharmacists conducting medication review, referring to the higher valued authority of their general practitioners or hospital doctors (Salter et al., 2007). Findings from a study conducted in primary care showed that patients were overall positive towards medication review provided by pharmacists and healthcare assistants; however, study authors point to potential barriers such as concerns about patient autonomy, or being uncomfortable to disclose information on the use of specific medications (Uhl et al., 2018).

\section{Implementing medication review in routine healthcare}

As briefly described above, various programs of medication review have been introduced internationally (Bulajeva et al., 2014). However, implementation of medication review or medication reconciliation has faced several challenges (Huiskes et al., 2017). The most commonly named obstacles were the complexity of medication review processes, difficulties in collaborating with other healthcare professionals, high staff turnover, or lack of feedback (Chen and de Almeida Neto, 2007; Sanchez et al., 2014; Jubraj et al., 2015). Similarly, medication reconciliation, both central part of medication review or as a stand-alone intervention, has proven difficult to put into practice in the hospital setting (van Sluisveld et al., 2012; Vogelsmeier et al., 2013). While seemingly a rather straightforward concept, processes to identify current medication use and reconcile different medication lists at admission, in-hospital transfers, or discharge have been complicated by organizational, interprofessional, or technical factors (Clay et al., 2008; Lee et al., 2015). 
Of the few studies examining the structured facilitation of implementing medication review, a majority has been carried out in primary care (Jäger et al., 2017; Uhl et al., 2018; Willeboordse et al., 2018), or in community pharmacy (Ocampo et al., 2015). The strategies used were academic detailing, various education formats, patient treatment algorithms, patient information leaflets, or paper bags for so-called brown-bag review of a patients' medicines (Jäger et al., 2015). Other strategies focus on external pharmacist-physician teams and explicit methods to increase patient involvement (Willeboordse et al., 2018), physician peer support, allocating sufficient consultation time, or using prompts within electronic medical record systems (Sinnott et al., 2017). Most of these strategies are time-consuming, consist of multiple components, and target clinicians' behaviour change (Jäger et al., 2015; Sinnott et al., 2017). They encompass checklists (Mahler et al., 2014) and screening tools to assess medication appropriateness (O'Mahony et al., 2015; Sennesael et al., 2018); also, electronic decision-support tools are offered, for example to check for drug-drug interactions, appropriate medication dosages, or recommended monitoring intervals (Muth et al., 2018).

\section{Medication review in the Swedish policy context}

\section{National regulation and guidance recommendations}

National regulation on medication review in Sweden came into effect in 2012 aimed at reducing inappropriate prescribing and to prevent medication-related problems. According to the regulation, it is the ultimate responsibility of physicians to conduct medication review, yet other healthcare professionals can contribute to its provision (Socialstyrelsen, 2012). Based on the binding national regulation, a subsequent guidance document with recommendations specifically addressed healthcare management and physicians (Socialstyrelsen, 2013a). According to this guidance, medication review shall be conducted with patients aged 75 years or older with five or more prescribed medications at each ambulatory care visit, or when admitted to the hospital or nursing home care. Additionally, this patient group should be offered medication review once a year in primary care. The national recommendations on medication review, thus, focus particularly on groups at higher risk for medication-related problems. Polypharmacy, i.e. the concurrent use of multiple drugs, has been associated with an increased risk for adverse events, poorer medication adherence, higher health care costs, and increased hospitalizations (Lenander et al., 2018). Use of more than a single medication also carries the potential of drug-drug interactions. Complex medication regimes may also cause problems with drug adherence, thus contributing to sub-optimal therapy. Also, due to physiological changes and increased morbidity, older persons 
are more vulnerable to drug-related problems (Lamy, 1991). The guidance, therefore, addresses medication safety and medication therapy optimization in a particular patient group. However, it is emphasized that the recommendations were equally applicable to all patients with suspected or identified medication-related problems. Thus, the specification of patients with suspected medication-related problems somewhat implies a process of assessment of a patient's symptoms or medication therapy.

Lack of clear communication and errors when transferring medicationrelated information at transitions of care are particularly addressed as risks for medication-related problems. The guidance, therefore, highlights the importance of effective communication of medication information and of collaboration between several healthcare providers in order assure adequate follow-up. Also, it is recommended to clarify at the local level how responsibility for medication therapy and follow-up shall being realized. Hospital-based medication review in the Swedish context requires the identification of a patient's current medicines, comparing them to the current list in use (usually the available information based on medical record documentation), documenting any discrepancies, and assessing the appropriateness of medication therapy. Further, to minimise medication error at discharge, any medication changes during hospitalisation shall be documented and the discharge medication list be checked against all changes. This updated list, together with a paper discharge summary, shall then be provided to, and discussed with the patient; at the same time this information is accessible to other providers via the electronic medical record (Socialstyrelsen, 2012). Here, the regulation and national guidance refer to general principles so that care and treatment should be carried out in consultation with the patient; further, medication-related information should be tailored to the patient's needs (Socialstyrelsen, 2012).

Overall, recommendations in the guidance document are intended to provide only general principles, allowing the adaptation of processes in order to fit the local conditions of each healthcare unit (Socialstyrelsen, 2013a). The regulation and national guidance, further, do not specifically define medication-related problems. Examples of possible medication-related problems are given, such as incorrect medication dosages, interactions and side-effects, but also inappropriate medications or patient-related problems related to medication use. Once a (potential) medicationrelated problem has been identified, further procedures for assessing and managing the problem are being specified. According to the regulation, a systematic assessment with respect to the indication, therapeutic effect, and dosage of each of a patient's current medication shall be conducted; also, potential side effects or risk of drug-drug interactions shall be evaluated in relation to potential benefits of a medication (Socialstyrelsen, 2012). Following-up on the national guidance, electronic training materials 
intended for physician interns and to be administered at the regional level were developed; these web-based training modules focused on medicationrelated problems in elderly patients and used patient vignettes; different case scenarios were available, supplemented by content information, electronic links and resources, self-tests and examples of appropriate medication documentation (Socialstyrelsen, 2013b).

\section{Regional implementation in southeast Sweden}

Based on the regulation and guidance recommendations, a regional implementation structure had been established in the study region in 2013. It was specifically aimed to establish region-wide, uniform procedures in order to reduce the risk of avoidable medication-related problems (Region Östergötland, 2015). The systematic conduct of medication review, as well as improved medication documentation and the provision of structured medication information to patients at discharge were considered essential elements to accomplish the objectives. It was hoped that these efforts would result in increased patient benefits; these were defined in terms of more appropriate medication therapy, improved patient-experienced quality of medication therapy, and increased percentage of patients which received medication discharge information (Region Östergötland, 2015).

A small pilot study was conducted to test and adapt medication-related modules, templates and forms within the region-specific medical record system. As part of the implementation activities and with some input from primary care, nursing care and hospital pharmacy, the project group developed regional guidelines; while based on the national recommendations, these were broader in scope in that it required medication review to be conducted with all patients irrespective of age or number of medications (Region Östergötland, 2014).

Information related to the implementation of medication review was communicated, first, to the head of department at each local clinical unit level, both in primary and hospital care. After these initial meetings, key personnel at the clinic level received information and training regarding medication review documentation in the medical record system; further, local information, 'educational', meetings were held, separately for physicians and nurses, where issues concerning the practical conduct could be discussed. Web-based training modules were adapted and offered via the electronic training system after 2014 (Region Östergötland, 2015).

Finally, implementation progress was followed up with brief structured interviews with heads of the departments, conducted up to a year after initial dissemination. In this context, it was found that about half of all clinical units had established local medication review routines, yet several of them had not understood the actual purpose of such routines. Also, only about $40 \%$ felt that they had some influence during the implementation period. 
Also, at more than half of the hospital units participating in follow-up interviews, had medication routines changed towards being more structured after implementation; however, about half of them made use of the electronic medication review tools and templates or routinely provided medication discharge information to patients as required by the guidelines (Region Östergötland, 2015).

\section{Medication review in the wider policy context related to medi- cations in Sweden}

Issues relevant to medication review, such as the need to establish an upto-date medication list that corresponds to all medication prescribed and in use by a patient, as well as making this information accessible to all relevant healthcare providers, are being addressed in other policies relevant to medicines. Access to a common medication list has been a concern over the last decade as several different sources of information on a patient's medicines are in use. In addition to the prescribing module of electronic medical record (EMR) which contains the medication list and inpatient drug list, a multi-dose drug dispensing list ('ApoDos'), lists from the national pharmacy register ('Läkemedelsförteckningen'), and the national prescription repository ('Receptdepån') are available sources of medication information. However, information from these different medication databases is not automatically synchronized between these different sources, and information is not equally accessible to all healthcare providers. In summary, data from different medication information sources do often not correspond, are therefore not always correct when accessed by healthcare providers, and, thus, pose a patient safety risk (Hammar et al., 2014).

The need for a shared medication list has been repeatedly articulated by physicians, as shown in two Swedish qualitative studies (Hammar et al., 2014; Sveriges läkarförbund, 2016). The patient safety risks resulting from current weaknesses in providing accurate and complete information on medication therapies have been pointed out in a qualitative study based on focus groups with physicians (Sveriges läkarförbund). A specific difficulty stems from the various region- or provider-specific electronic systems that do not allow transfer between prescribers from different healthcare providers. Also, physicians often lack the possibility to invalidate prescriptions recorded in other databases not synchronized with medication lists in the EMR. This can lead to situations where a patient still is able to fill her prescription at a pharmacy although it already has been terminated by a prescriber, yet registers are not fully synchronized (here, the national prescription repository) is not. Further, the manual transfer of medication information between different sources has been found to be prone to error, and, thus, can have an impact on patient safety (Sveriges läkarförbund). 
Efforts to provide the legal pre-conditions for implementing a shared medication list have been intensified over the last years and as part of the national e-health strategy. The proposal for a new legislation on the socalled national medication list has been approved in 2018 (eHälsomyndigheten, 2018). The realization of the national medication list has encountered several technical and legal difficulties and, as reiterated in the national pharmaceutical strategy, remains one of the measures proposed to secure effective and safe use of medicines (Government Offices of Sweden - Ministry of Health and Social Affairs and Swedish Association of Local Authorities and Regions, 2015). Other proposed measures include the expanded use of electronic prescribing tools for prescription support, but also for monitoring and investigating prescription of medicines not in accordance with scientific evidence or proven experience. Although physicians stressed that a shared medication list would be highly beneficial for patient safety, some areas of concern were recognized (Hammar et al., 2014). Besides issues of confidentiality, physicians were aware that a shared and, thus, more likely to be correct and updated medication still left important questions unsolved as it does not address the complex issue of how responsibility for a patient's entire medication list should be dealt with. This, for example, included the need to position oneself in relation to the appropriateness of all medications contained on the current list. Also, physicians emphasized that patients should be explicitly addressed as active users of such a shared medication list as they often lacked up-to-date information on prescribed medications (Hammar et al.).

\section{Unpacking implementation research}

While a comprehensive overview of the state of implementation research is beyond the scope of this thesis, this section aims to provide a brief outline of the research field in terms of its central assumptions, concepts, and methodological orientation.

Mindful of the difficulty in clearly demarcating the boundaries of a research field or defining its exact scope, in the context of this thesis I refer to implementation research as defined by implementation scholars in relevant scientific publications. Based on such descriptions, implementation research has been characterized as the scientific study of methods to bring about the adoption and integration of proven health-related or clinical interventions into routine practice. Implementation research (interchangeably used with implementation science) can be located in the applied health research field and addresses implementation interventions ranging from policies, programs, or ways of working, to single interventions (Thomas et al., 2017). Despite overlaps with respect to implementation as research ob- 
ject, knowledge exchange and conceptual overlaps between the fields of implementation research and policy implementation research were found to be small (Nilsen et al., 2013). Briefly, policy implementation research, an academic field located in public administration and political science, has been described as the scientific study of public policies, comprising the range of policy development to the impacts of such policies (O'Toole, 2000). On the other hand, implementation research rather deals with socalled 'small-p' policies, such as clinical guidelines, healthcare guidance, or organizational procedures. Despite its roots in the evidence-based medicine movement (Pope, 2003) and its focus on so-called evidence-based practices aiming to maximize healthcare value, implementation research sees itself as an inter-disciplinary endeavour (Eccles et al., 2009; Bauer et al., 2015).

In this thesis, I am limiting myself to the field of implementation research as this is the research field primarily relevant to study the implementation of healthcare interventions, such as medication review. Here, I will be drawing on the literature published in the field of implementation research, with a specific focus on published and frequently utilized implementation frameworks and concepts. My interest, here, is to problematize, not criticize, assumptions and pre-understandings prevailing in implementation research as an academic field. How the phenomenon of implementation is constructed and studied matters as this also affects how implementation problems are being practically approached. A supposition, here, is that the ways an object of inquiry is constructed affects how it is analyzed and understood (Shotter and Gergen, 1994; Cohn, 2014). Thus, challenging assumptions and ideas can be useful as it may lead to novel questions to investigate and understand a phenomenon (Alvesson and Sandberg, 2011).

\section{Studying implementation in the context of healthcare}

Broadly, the purpose of implementation research in healthcare is to understand the 'complexities of making change in real-world care settings' (Birken et al., 2017a: 2). Understanding how implementation processes can be scaled up, or why specific programs fail or succeed in everyday clinical settings, are some examples of relevant problems when studying implementation (May et al. 2016). More specifically, implementation research is driven by an interest to advance knowledge about how to effectively adopt and integrate 'proven' or evidence-based interventions in routine practice (Wandersman et al., 2012); a central assumption is that successful implementation ultimately improves the quality of healthcare services (Eccles et al., 2009). Implementation has been defined as 'any deliberately initiated attempt to introduce new, or modify existing, patterns of action in health care or some other formal organisational setting' (May et al. 2007: 3). 
Equally relevant to effective implementation are the processes of subsequently making a new practice part of the everyday work, also referred to as embedding (May and Finch, 2009).

Implementation research is considered a still emerging, yet rapidly growing research field (Albers et al., 2017). Development of the field has been fueled by an interest to improve the understanding of implementation processes and to guide the design and evaluation of implementation studies in healthcare settings (Nilsen 2015). So, the question I will be turning to in the next section is: where does implementation research currently stand in terms of conceptualizing and investigating the phenomenon of implementation?

\section{The central role of implementation frameworks and models}

I am focusing on the frameworks, models, and theories used in implementation research since, I want to argue, I regard them as important tools to express ideas and concepts relevant to the field as well as to define research problems. According to implementation research scholars, these frameworks, models, and tools, are thought to provide a common language and can facilitate the consistent articulation of actions and behaviours considered necessary and relevant for successful implementation (Lynch et al., 2018), thereby advancing the scientific development and promoting shared understanding within the community (Birken et al., 2018: 2). Within the implementation research field, models and frameworks also reflect efforts to consolidate its research base, particularly through refining terminologies and definitions, standardizing and unifying constructs, and synthesizing knowledge in the field (Birken et al., 2017b).

A variety of frameworks, often providing quite comprehensive taxonomies of potential determinants, have been proposed and are currently being utilized (Glasgow et al., 1999; Michie et al., 2005; Glasgow et al., 2006; Kitson et al., 2008; Damschroder et al., 2009; Michie et al., 2011; Harvey and Kitson, 2016). While the boundaries between frameworks and models, are fluent, models usually include more explicit assumptions about the mechanisms of implementation processes, or more narrowly specify variables considered most relevant to the model (Lynch et al., 2018). However, as the research field expanded, the number of taxonomies, classification schemes and implementation frameworks continued to grow, as have the efforts to promote a uniform terminology and a simplified overarching framework (Colquhoun et al., 2014; Lokker et al., 2015; Slaughter et al., 2017). A growing body of implementation frameworks, models and theories has been published over the last decade (Skolarus et al., 2017), resulting in numerous different, partly overlapping tools with varying degree of comprehensiveness (Moullin et al., 2015). About 60 different frameworks models and theories utilized in studies of healthcare implementation were 
identified in an earlier review conducted in 2011 (Tabak et al., 2012), and about 160 different frameworks, conceptual models or theories in a further scoping review covering relevant studies published between 2000 and 2016 (Strifler et al., 2018). Implementation frameworks, models, and tools have been described as 'cognitive tools' to help researchers or implementers with planning, guiding, or evaluating implementing a service or program (Lynch et al., 2018: 3). However, based on a recent scoping review it was found in the majority of implementation studies no justification for their selection was given, or utilization was not in line with the intended use or purpose (Strifler et al., 2018). Also, findings from an international survey among implementation researchers indicated that they made use of theories, models and frameworks 'driven by convenience or prior exposure', and it was warned that this might lead to 'silos in the field', thus, impeding the further advancement of implementation research (Birken et al., 2017b: 7).

Implementation frameworks have been recognized to function as implementation strategies, thus shaping and enhancing implementation processes (Albers et al., 2017). They are utilized for designing and planning implementation studies and relevant for all implementation stakeholders (Strifler et al., 2018), as well as for making the understanding of implementation processes more explicit. Thus, the frameworks, models and theoretical concepts proposed and utilized in the field of implementation research provide a frame of reference for organizing thinking about implementation, including what is considered salient in implementation processes. How, then, is implementation conceptualized based on extant frameworks, models and theories in the field?

\section{Conceptualizing implementation in implementation research}

Based on the implementation research literature, there is an acknowledgement that factors contributing to effective implementation 'interact in rich and complex ways to influence implementation effectiveness' (Damschroder et al., 2009: 4); however, here I want to argue that studying implementation clearly privileges deterministic and outcomes-oriented views.

Such conceptualizations involve some form of linking factors that influence (successful) implementation with an (often behavioural) outcome (Fleuren et al., 2014). Variably these factors are referred to as implementation determinants or determinants of innovation (Fleuren et al., 2004), implementation drivers (Metz and Bartley, 2012), or barriers or facilitators to change (Rycroft-Malone et al., 2002; Baker et al., 2010). Generally, implementation determinants are understood as modifiable factors that prevent or enable the adoption and implementation of an innovation (Flottorp et al., 2013). Within the implementation research field, determinants are also understood as essential constructs with respect to how potential change in 
the sense of adopting an evidence-based intervention can be facilitated (Fleuren et al., 2004; Powell et al., 2012).

According to conceptions in the implementation research literature, effective implementation or transfer of evidence-based knowledge into practice can be achieved by overcoming barriers to its adoption or supporting enablers of its use (Jäger et al., 2017). In order to support such a transfer, implementation strategies, understood as systematic methods or techniques to support the adoption and integration of evidence-based health innovations into usual care', are needed (Powell et al., 2012). These strategies are viewed as the active component, or, "the "how to" component of changing healthcare practice' (Proctor et al., 2013: 1), presupposing a hypothesized or experimentally tested causal mechanism (Michie et al., 2011). A structured approach for designing 'tailored interventions' is recommended, choosing strategies responding to identified 'determinants of practice' (Baker et al., 2015). Overall, there is a clear orientation towards framing implementation strategies as behaviour change interventions, similar to efforts in the controlled clinical trials field, in guidelines for standardizing reporting of these interventions have been proposed (Albrecht et al., 2013).

Based on implementation research literature and borrowing from terminology used in quantitative clinical models, implementation outcomes are viewed as the ultimate endpoints of 'successful', or effective, implementation. Conceived as distinct from (clinical) treatment effectiveness outcomes, implementation outcomes are understood as the 'effects of deliberate and purposive actions to implement new treatments, practices, and services', and serve as 'indicators of the implementation success' (Proctor et al., 2011: 65). Several core implementation outcomes have been proposed and the need to further advance the conceptual and measurement properties is emphasized (Proctor et al., 2011). Also, with respect to the epistemological commitment of implementation research, there has been lending from clinical trial research methodology, using hybrid designs with randomization and multilevel data that allow for testing both implementation (i.e. the implementation strategy) and clinical interventions; such designs involve quantitative methods to evaluate intervention or program effectiveness, and mixed methods to identify potential implementation barriers and facilitators (Brown et al., 2017). Other approaches, including case-study approaches using qualitative and mixed-method designs, are also advocated with the aim of integrating outcomes- and process evaluation (Southam-Gerow and Dorsey, 2014; Palinkas, 2014). In this context, qualitative approaches such as 'clinical ethnography' are suggested, that is, using participant observation and less structured interview techniques within pragmatic clinical trials, yet under conditions that minimise cost and time in the field (Palinkas and Zatzick, 2018). Ongoing developments in the field 
point towards increased standardization and operationalization with a continued orientation towards behaviour change theories (Patey et al., 2018) and building causal pathway models (Lewis et al., 2018a).

Drawing on the implementation research literature, implementation as a phenomenon appears to be mainly conceptualized in terms of socio-cognitive behavioural constructs (Strifler et al., 2018) where implementation is understood in terms of behaviour change, to be enhanced by so-called behaviour change techniques (Michie et al., 2011). Most frequently applied in conceptualizing implementation as used in frameworks, models and theories are the Social Cognitive Theory by Bandura (1986), the Transtheoretical Model of Behavior Change (Prochaska and DiClemente, 1983), and the Health Belief Model (Rosenstock, 1990), either used in isolation, or integrated in a growing number of implementation frameworks and models (Strifler et al., 2018).

Thus, despite the rhetoric of the complexity and context-dependent nature of implementation processes, there seems to be a tendency to focus on implementation outcomes framed as intermediate outcomes, that is, as the 'necessary preconditions' for desired changes in clinical or service outcomes (Proctor et al., 2011: 66). Such a conception also is in line with the objective of implementation research, that is, to promote the systematic uptake of evidence-based practices in order to ultimately improve healthcare quality (Eccles et al., 2009). Thus, a better understanding of the implementation of a clinical intervention is needed when clinical interventions proven to be effective are found to be not working 'in the real world' as these interventions might have been poorly implemented (RycroftMalone et al., 2002); but a corollary, then, is that for understanding implementation it is being approached from a perspective that treats implementation as an 'intermediary' phenomenon between an 'intervention' and a clinical (or healthcare service) 'outcome.'

\section{Challenges to and the need to broaden theoretical perspectives in implementation research}

There is some debate within the implementation research field over current research approaches and conceptualizations; critics have argued that these were based on understandings that would not adequately represent the complexity surrounding common implementation problems, particularly the relationship to implementation context (Greenhalgh and Stones, 2010; May et al., 2016; Braithwaite, 2018).

Yet on a more general level, I want to argue here, there is a different problematic in implementation research, concerned with the notions of knowledge and practice. A central metaphor used in the field is the knowledge-practice gap which I consider problematic as it suggests a clear separation between the spheres of knowledge and action. Viewing theory 
and practice as separate realms, firstly, conceives of theory as a precursor to action (Antonacopoulou et al., 2011); consequently, this then necessitates 'interventions' which 'put' the knowledge 'required' 'into practice'. The 'gap'-metaphor, thus, treats (scientific) knowledge (or theory) as preceding action (Zundel and Kokkalis, 2010); it treats, further, knowledge as a commodity to be stored, transferred, and replicated, and to be moved to recipients or 'targets', a process thought of as to be facilitated by opinion leaders or knowledge champions (Waeraas and Nielsen, 2016). The knowledge-practice gap is also problematic because it rests on conceptions of disseminating knowledge viewing the spheres of policy, healthcare organizations, and frontline clinical activity as distinct levels across which knowledge can be shared in a straightforward way; such a view was criticised as too simplistic as it presumes a flow of communication from policy (or research) to practice (Davies et al., 2008; Greenhalgh and Wieringa, 2011; ; Greig et al., 2012). Thus, the above assumptions are problematic as they carry with them specific modes of intervention of change, or, put simply, different ways to 'do' implementation.

Greenhalgh and Wieringa (2011) call for a social practice view of knowledge providing alternative metaphors to the knowledge-translation concept; such a view recognizes different forms of knowledge and knowing such as personal and tacit knowledge (Polanyi, 1958), embodied knowledge (Reckwitz, 2002), but also alternative conceptions of sharing knowledge (Brown and Duguid, 2001). The authors argue that a continuing propagation of the knowledge translation metaphor 'inadvertently (will) close our minds to alternative framings which could add to the illumination and analysis of this complex field' (Greenhalgh and Wieringa, 2011: 507-8). They call for ethnographic research designs and micro-analyses of the situated clinical encounters, but also for the use of organizational case studies. The authors conclude that conceptualisations of knowledge (and practice) should be broadened 'before the assumptions behind (the knowledge translation metaphor) become too entrenched' (Greenhalgh and Wieringa, 2011: 508).

\section{Outline for an alternative approach}

As laid out in the previous section, current dominant conceptualizations of how implementation processes can be understood need to be broadened. Studying implementation has to contend with an inherent tension between the need to provide testable explanations using causal models to identify effective implementation strategies and the interest to understand how processes of implementation work in 'real-world settings'. While the former requires experimental approaches using robust methods, uniform terminologies, and operationalization of constructs, the latter needs interpre- 
tive approaches that take into account the dynamic and recursive relationships between the processes to embed an intervention and the context it is embedded in. This thesis has problematized mainstream assumptions underlying conceptions of implementation research. Consequently, it aims to provide an alternative perspective by theorizing the practicing' of medication review and its embedding into routine work. Theorizing in this thesis refers to empirically and theoretically exploring these phenomena and will focus on the following two aspects:

(1) With relevance to embedding a healthcare intervention, alternative conceptualizations are required to better understand the contextual and situational nature of its dynamics. I argue here that an alternative perspective is necessary to take into account the social and processual dimensions of implementation in its everyday routine context. This entails exploring the notions of knowledge, action, and change using an alternative lens.

(2) In addition, a different conception of the intervention to be embedded, medication review, is required. Moving beyond behavioural conceptions of medication review means paying attention to the daily work practices of healthcare professionals, to access practitioners' practical understandings of the abstract concepts of patient and medication safety, and how these understandings are bound up with concrete situations. This usein-context concerns practitioners' understandings of roles, task boundaries, organizational routines, professional identities, as well as their commitments and interests. An exploration of these issues in relation to concrete instances can help to understand their connections to different medication-related practices. 


\section{THEORETICAL PERSPECTIVE}

Selection of the theoretical perspectives was guided by the objectives to study medication review and its embedding as practiced in situ. My interest to examine the doings and sayings of healthcare professionals and patients when enacting medication review with a focus on the material and social aspects and the processual character was best served with a theory-method approach offered by practice theories. This chapter provides a brief overview on practice theories and of their affordances and limitations.

\section{Practice theory}

\section{A family of theories}

Practice theories, also labelled as practice-based standpoint, practice-lens, practice-based studies, or practice-based approaches (Corradi et al., 2010) have been increasingly utilized to study human activity. Practice-based approaches have been used in order to understand a variety of social and organizational phenomena, such as professional learning (Billett et al., 2005; Fenwick et al., 2012), organizational learning (Blackler, 1993; Gherardi, 2011), strategizing and managerial activities (Jarzabkowski, 2003), studies of science and technology (Suchman et al., 1999), healthcare practices (Nicolini, 2006), but also everyday practices related to consumption, such as eating (Warde, 2005), or showering (Hand et al., 2005).

Briefly, practice theory builds on practice concepts in the Marxist and phenomenological tradition (Schütz, 1980) and the work of Wittgenstein (1967) and Heidegger (1978); influenced by philosophical and sociological orientations from symbolic interactionism (Blumer, 1969) and ethnomethodology (Garfinkel, 1967), practice-theoretical concepts were further advanced by Bourdieu (1977), de Certeau (1984), Giddens (1984), Ortner (1984), and Lave and Wenger (1991). More contemporaneous practice theory variants include actor network theory (Latour, 1992; 1996; 2000; Callon, 1986) and science and technology studies (Latour and Woolgar, 1986; Knorr Cetina, 1999; 2001), activity theory (Engeström, 1995; 2000; Engeström, 2001; Engeström and Blackler, 2005), and practice-based organizational studies. The latter can be traced back to studies on situated learning and knowing by a range of different practice theory scholars (Lave and Wenger, 1991; Brown and Duguid, 1991; Cook and Brown, 1999; Brown and Duguid, 2001; Gherardi, 2000; 2006; 2011; 2017). Last, but not least, building on the work of Wittgenstein (1967) and Heidegger (1978), practice 
theory scholars such as Theodore Schatzki (1996) or Joseph Rouse (2001) have significantly contributed to the contemporary social science literature.

Although different strands of practice theories exist, the label practicebased studies can be considered an umbrella concept which encompasses a variety of differences and similarities (Corradi et al., 2010). However, practice-based approaches have been described as departing from traditional ways of understanding and examining social phenomena and are considered distinctive. Despite many different scholarly traditions, they share common assumptions and ideas. These 'family resemblances' (Nicolini, 2012: 214) can be summarized as follows:

(1) Practice theories foreground human activity and performative aspects and the recurrent, ongoing work to create and reproduce the world and social orders (including social structures, organizations, or institutions). The body and materiality play a central role in these creative and reproductive processes.

(2) Practice rests on something not subject to be expressed in words, something that predates reflexive thinking, or something inscribed in the body or artifacts (Nicolini, 2012).

(3) Everyday actions are consequential in producing and reproducing the social orders (such as structures, routines, or institutions) that constrain and enable actions. These relations of mutual constitution are constantly produced, transformed, and reproduced (Feldman and Orlikowski, 2011).

(4) Dualisms, that is, oppositions between body and mind, action and cognition, structure and agency, micro- and macro-level, object and subject, are rejected. Human agency is conceived as individual performance composing a practice, yet against the background of practices, or in relation to other performances (Rouse, 2007).

\section{What are practices?}

Owing to the various different practice theory traditions, there are several notions of practice (Nicolini, 2017). Important features of the practice concept are that they are not composed of a specific number of activities, the so-called open-endedness of practices (Schatzki, 2012), the organized nature of practices, and the existence of practices in interconnections or configurations (variously termed as knots, networks, nexuses, assemblages, textures) (Engeström, 2000; Schatzki, 2002; Warde, 2005; Shove et al., 2012; Gherardi, 2012a). In organization studies two different orientations of practice concepts have been described, a performative one focusing on 'what actors do' and a second, epistemic-normative orientation (Geiger, 2009). In the first approach, performative aspects of practices are fore- 
grounded with the concepts of routines as cycles of plans and actions, focusing on how these actions are carried out in organizations, how they function, and how they are changed (Feldman, 2000; Orlikowski, 2000). Practices conceived with such a performative orientation tend to focus on micro-phenomena and the more concrete aspects of 'what actors do', claiming to be located closer to the problems relevant to practitioners (Geiger, 2009).

Such a performative concept can be contrasted with practice as an epistemic-normative concept which emphasizes the social and collective nature of practice (Geiger, 2009). The notion of practice as a way of seeing (Corradi et al., 2010), or as 'ways of knowing' (Cook and Brown, $1999^{\circ}$ : 383) brings to the fore the work occurring in and through practices and the knowledge generated in and through practicing (Cook and Brown, 1999). Practices, here, refer to coordinated actions imbued with meaning and positioned in a particular place and time. Practice conceived as a normative construct points to the mutual accountability of performances of a practice, the ways norms of appropriate conduct of a practice are established and reproduced, the working out what is at issue and at stake in a practice (Rouse, 2007). Taking into account the epistemic-normative dimensions and the performative character of practice, Nicolini (2017) points to practices as having 'a history, social constituency and hence, a perceivable normative dimension' (: 21) as well as having a directionality that drives the carrying out of a practice forward.

The above epistemic-normative dimensions of practice have implications for the ways in which other phenomena, such as knowledge and meaning, are being conceptualized. Knowledge, then, is understood as mastery and capability to carry out an activity and has strong processual qualities as knowledge-in-practice. Contrary to metaphors of knowledge as possession, knowledge as a practice is shared with others and connected to the creation of meaning (Cook and Brown, 1999); it is concrete in that it is tied to objects, artifacts, bodies, or discursive activity; knowledge, thus, is only partially articulable in language and always in-the-making (Gherardi, 2001; Reckwitz, 2002; Schatzki, 2002; ). Similarly, from a practice-based view, learning is conceived less as the acquisition of knowledge, but rather as the participating in practices (Lave and Wenger, 1991; Brown and Duguid, 1991; Gherardi, 2006; Kemmis, 2009; Hager et al., 2012 ; ). Learning, it was argued by Schatzki (2017), 'does not just happen to take place in social practices: it is integral to them' (: 26). This also extends to processes of organizational learning and change where practice is seen as the source of innovation with professionals engaged in the sharing of knowledge when adapting, refining, and improving practices (Gherardi, 2001). 


\section{A theory-method-package}

Nicolini (2012) argues that rather than a 'fully formed theory of how the world is' (: 218), practice theory shall be viewed as a theory-method package, or 'methodology-vocabulary orientation' (2017: 26). This means that practices should be studied with a coherence of the methodological approach chosen, the epistemological stance taken, and the ontological assumptions about the phenomenon studied. Nicolini (2012), thus, calls for methods that examine practices with an 'ethnography of practice approach', or, what he calls 'proximal research methods' to get 'close enough to the activity at hand' (: 218). Stemming from an ontological conception of practices as the fundamental unit of analysis to understand 'the social', and the conception that practices only exist to the extent that they are continuously performed, examining practices entails studying the 'real-time doing and saying in a specific time and place' (Nicolini, 2012). Practice theory should therefore be conceived as 'ways of understanding the social that gives handles to empirical researchers' (Nicolini, 2017: 26).

Consistency, further, requires to study not only practices as they unfold, but also their wider relationships in time and space, a move called 'zooming in' and 'zooming out' of practice (Nicolini, 2009). Here, zooming in draws on a ethnomethodologist tradition and its orientation towards practitioners' methods to accomplish everyday activity (Garfinkel, 1967). Zooming in builds on concepts of practical understanding as the ways practitioners recognize what makes sense to do and how they understand to carry out specific actions (Wittgenstein, 1967; Heidegger, 1978; Schatzki, 1996; 2002); it, further, builds on the stance developed in organizational ethnography practiced by a 'disengaged fieldworker' balancing distance and thinking 'from within' (Ybema et al., 2009). Zooming in, then, means paying attention to the moment-by-moment instances of mundane work activities (Llewellyn, 2008) by focusing on the real-time instances of sayings and doings, the discursive and material practices. This includes attending to the micro-level of practices, the timing and sequence of doings and sayings, the use of a particular vocabulary, how artifacts are positioned, or how tools and materials are used in performing a practice (Nicolini, 2009). A further methodological strategy, 'zooming out', is required to uncover the wider connections of a practice; here, associations between practices of wider networks and the relationship between local and more distant practices and effects can be traced (Nicolini, 2009). Zooming in and out of practices can be understood as iterative moves between data and theory: starting in the midst of action and focusing on the practical accomplishments, and then zooming out on the relationship of these practices, moving to trail the connections between practices and their possible effects. 


\section{METHODOLOGICAL APPROACH \& RESEARCH DESIGN}

\section{Methodological approach}

In the following sections, I will lay out the specific approach used, particularly with respect to theorizing, the different practice-theoretical concepts utilized in this thesis, and the ethnographic sensibility employed. I will, further, provide information on study design, and details on how data were generated. In this context, I will then describe how I engaged with the concept of reflexivity and address ethical and methodological considerations. Finally, I will describe the assumptions and strategies used in analyzing the data.

\section{Practice-based sensitivity using a toolkit approach}

Work on this thesis is being done with a practice-based, so-called toolkit approach, that is, using a range of different practice-theoretical concepts to empirically study practice (Nicolini, 2012). Nicolini (2012) sees merits in such a programmatic eclecticism arguing that given the 'complex web of similarities' of practice theories, these can 'be mobilized together to enrich [the] understanding of practice, and to provide an understanding of everything social (and organizational)' (:215). I found the different practice-theoretical concepts useful in empirically studying my 'research object', looking at it from different angles, formulating different questions, and interrogating the data. Thus, the intention was not to synthesize or unify the different approaches, but to let them complement each other.

\section{Theorizing practices}

In this thesis I attempt to theorize both, the embedding, and the practicing of medication review, using a practice-based perspective. By theorizing I refer to exploring a phenomenon empirically and theoretically. Drawing on a practice theoretic approach, such theorizing, then, means studying and understanding 'social phenomena through their ongoing formation, accomplishment, and alternation' (Schmidt, 2017: 5). Here, I am also drawing on Alvesson and Kärreman (2007) who conceive of theorizing as the developing of theory based on a critical dialogue between the empirical material and theoretical concepts. Such an approach of theorizing implies a different conception of the relationship between theory and the empirical material, one that stresses the role of the empirical material as a 'resource 
for developing theoretical ideas through the active mobilization and problematization of existing frameworks' (Alvesson and Kärreman, 2007: 1265). Theorizing, then, emphasizes the processual character of developing theory, yet where theory is not understood as a finished or final product after theory formulation (Swedberg, 2016). Theorizing, further, does not rest on an understanding that views theory as methodologically preceding its application, or as separate from practice but, rather, means 'proceeding from within an activity, making its "grammar" explicit' (Eikeland and Nicolini, 2011: 169).

Theorizing in the context of this thesis research, thus, meant a strong empirical orientation using ethnographic methods of observation, shadowing, informal discussions, and conducting interviews when studying medication review and its embedding; but it also involved the use of various practice-based conceptual tools (as described in more detailed further below) in a critical dialogue with the empirical objects. This meant, for instance, observing a physician's assessing a patient's medication therapy and its interconnections with the artifacts, rules, texts, discourses, other actors, and contexts in order to study 'knowledge in its making' (Gherardi, 2016: 685). Theorizing, lastly, also included critically exploring and 'irritating' the theoretical assumptions incorporated in generating the empirical data; this, meant, for example challenging the conception of carrying out knowledge-based work practices as cognitive schemes or individual behaviours, as common in implementation research.

Research work was informed by interpretivist and constructivist presuppositions, acknowledging that in studying the research phenomena I am also, collectively and intersubjectively, constructing these phenomena. (Berger and Luckmann, 1966; Yanow and Schwartz-Shea, 2014). Such a position argues that a separation between the researcher and the object (or phenomenon) studied is not tenable as (research) knowledge is viewed as the cumulative outcome of ongoing construction (Yanow and SchwartzShea, 2014). Similarly, this means viewing theory and practice as fundamentally interlinked where empirical evidence always is constructed and impregnated with theory (Alvesson and Kärreman, 2007; Alvesson and Sköldberg, 2009). Critical, therefore, become processes of reflexivity where the interconnectedness of researcher, theoretical framework and social phenomena studied are subjected to inquiry, as are the processes of my own meaning-making (Alvesson and Sköldberg, 2009; Ybema et al., 2009). This meant, for instance, challenging and reflecting on the extent the vocabulary specific to a chosen approach shaped my research practice, both with respect to observing, but also to analyzing. Further, it included reflecting on the potential risk of reifying the doings and sayings of practitioners as a clearly defined, and thus no longer open-ended, practice, instead of viewing practice as a fluid phenomenon. 


\section{Ethnographic approach}

While using practice theory is not directly connected to specific methods, ethnographic methods are considered a mainstay in practice-based studies (Gherardi, 2012a; Nicolini, 2009; 2017; Schatzki, 2012). Work on this thesis was conducted with a 'sensibility for practice', an approach that allows conducting ethnographic fieldwork with a focus on immersion and openness while being consistent with a practice-based ontology (Sedlačko, 2017: 47). Such a sensibility for practice included an orientation to the 'observable material doings' of practitioners (Sedlačko, 2017: 54); this meant I attended to the situated doings, focusing on sequences of interactions and conversations, and paying attention to the specific role of materials in such doings. This included an attention to bodies, spaces, and, particularly, artifacts and material objects. I tried to follow the use of artifacts, such as forms, templates, and checklists, or notes 'in situ', and the variations in use over time. Further, such a sensibility meant, a focus on everyday actions and occurrences, particularly paying attention to the routinized and ordinary doings and sayings, and how practitioners make sense of these situations. This would include informal discussions with practitioners on, for instance, a specific sequence of an activity, or the use of specific terms used for repeated actions.

Additionally, and somewhat related to the former, it meant a focus on the work of assembling and ordering, that is, a sensibility for how different elements of a practice are brought into connection, how they are interlinked, or kept interconnected; this requires paying attention to the work of ordering and stabilizing, but also to the role of breakdowns, conflicts, tensions challenging such ordering. This would mean to pay attention to deviations from routinized doings or unexpected 'disturbances' and practitioners' reactions to them. Here, I tried to explore such occurrences in direct temporal relation to such events. Finally, a sensibility for practice requires reflexivity in the sense of paying attention to my own participation, as researcher and 'fieldworker', in 'a larger assemblage that also includes the observed practice with all its elements' (Sedlačko, 2017: 56). This meant reflexivity with respect to the potential effects my presence or the research project might have had on the observed practice-assemblage (and vice versa), but also the ways I brought my presuppositions of the phenomenon into this 'assemblage'.

\section{Practice-theoretical concepts applied in this thesis}

This sub-section presents the key theoretical concepts frameworks utilized for analyzing data in the four different articles. My intention here is not to recount or summarize these concepts but rather to show some of their affordances with respect to analyzing the phenomenon studied. 


\section{Practice-arrangement bundles}

In the first article I was drawing upon practice theory concepts of Schatzki (1996, 2002, 2012), aiming to examine how medication review is accomplished with respect to coordination of its actions. Here, practices are defined as organized, 'open-ended, spatially-temporally dispersed nexus of doings and sayings' (Schatzki, 2012: 14). Briefly, the actions composing a practice are conceptualized as organized by practical understandings of how to do things, rules (such as explicitly formulated directives, guidelines, or regulations), teleoaffective structure, and general understandings. Teleoaffective structure is the combination of ends, projects, affects, and activities that are enjoined or acceptable in a given practice (Schatzki, 1996; 2002).

Applied to the case of the implementation of medication review in a surgical ward setting, actions that make up medication review practices are organized by, among other things, practical understandings how to use the medical record system, or how to talk to patients; examples of rules would be national and regional guidelines of medication review, or regulations for prescribing; further, a teleoaffective structure guiding medication review could encompass an array of ends in avoiding medication errors, acceptable uses of medication formularies, and affects such as concern about the dangers of particular medicines. Finally, actions are organized by general understandings which can be understood as broader and more abstract understandings of concepts or 'the overall projects in which people are involved (Nicolini, 2012: 167), such as a sense of the value of patient safety or quality improvement, or an intervention's benefit to a patient.

Central for exploring the local implementation and conduct of medication review was the notion of practice-arrangement bundles (Schatzki, 2010; 2012). In this context, arrangements refer to 'interconnected material entities' which are made up by 'humans, artifacts, organisms, and things of nature' (Schatzki, 2010: 129), for example, medical records, electronic prescribing systems, but also paper forms, the spatial placing of objects, or patients' medicines. Since activities composing a practice are thought of as intimately bound with material entities, bundles of practices and material arrangements are considered fundamental to analyzing social phenomena (Schatzki, 2012). That practices and arrangements bundle means that practices use, are inseparable from, and give meaning to arrangements; here, relationships work both ways where arrangements channel, are essential to, and prefigure practices (Schatzki, 2012). Thus, material arrangements are relevant to practices as spaces and configurations of objects within these spaces where practices unfold; these material arrangements are intertwined with practices and 'house' them (CecezKecmanovic et al., 2014: 815). 
Practices and arrangements bundle up through five types of relations: causality, prefiguration, constitution, intentionality, and intelligibility. Prefiguration is construed as a the ways material arrangements shape or affect the course of practices (Schatzki, 2010), such as making a particular option of how an action proceeds or a practice is perpetuated, easier or harder, or more or less time consuming. Closely related to the notion of prefiguration is the relationship of intelligibility, referring to the ways material entities have meaning for participants in a practice, and intentionality, the thoughts and ideas participants have about these entities (Schatzki, 2002). Both these relationships reflect the teleological and affective attachments participants hold towards material entities involved in an activity. Artifacts, for instance a patient's medication list and the progress notes displayed during pre-ward round briefs, have different meanings for participants with respect to what it makes sense to do, such as using or not using them. As such, how these artifacts are used and approached during discussions in ward round briefs, is being established and determined in practice.

I was particularly interested in the notion of coordination as a key feature of successful conduct of medication review. According to Schatzki (2009), coordination is understood as a joining of actions through which a result ensues' (: 44) when practices, interwoven with arrangements, bundle up. Thus, medication review as a coordinated or bundled practice is made possible when material arrangements, the normative organization of the practices (i.e. the rules, goals, ends, intelligibility inherent in practices that are bundled together), and the practices interweave. Further relevant to coordination, practices are connected through common organizations when they share the same element, such as the same end, rule, or understanding (Schatzki, 2005; 2012). Practices further link through chains of actions, thought of as sequences of actions, each responding to its predecessor or leading to actions 'that induce people to hold up, divert, alter' (Schatzki, 2002: 42). Practices, also between bundles, are further connected through links among arrangements where such connections are influenced through how a spatial layout at a setting is formed, how materials are positioned, and artifacts, organisms, things, and people are set up within arrangements; also, a greater density of relations characterizes the existence of a bundle (Schatzki, 2005).

\section{Knowing-in-practice}

In the second article I was drawing on the concept of knowing-in-practice (Gherardi, 2000; 2001; 2006; 2008) with the aim of analyzing the practical knowledge necessary to perform medication review in everyday ED practice. In this practice-based approach, the notion of knowing-in-practice is used as a methodological lens that, assuming a mutual constitution of practice and practicing, and of knowing as a practical accomplishment, allows 
the analysis of a practice by studying knowledge as an observable phenomenon (Gherardi, 2008). Knowing-in-practice as a situated activity rests on thinking in the ethnomethodologist tradition with its focus on practitioners' methods to accomplish everyday activities; in this tradition, the feature of reflexivity of actions, or their making themselves meaningful to actors, allows the analysis of practices as these meanings are not abstract or decontextualized, but always established in a concrete situation. Also, social actions have a moral quality in that certain actions are recognized as correct, legitimate and adequate in a particular context (Garfinkel, 1967). A focus on work as the practical accomplishment pays attention to the social processes that support and reproduce a practice as a 'collective knowledgeable doing' (Gherardi, 2015: 16) where practitioners share and negotiate the understandings of how to appropriately conduct a practice.

A central notion in an approach focusing on knowing-in-practice is practical knowledge, understood as knowledge constructed in ordinary work activities and as knowledge which is recognized by or made recognizable among participants in the practice. Knowledge (as process, or knowing) is tied to and generated in performing a practice and involves a knowing-how-to-see, knowing-how-to-speak, and knowing-how-to-act in a specific situation and in connection with human and non-human elements (Gherardi, 2006). When analyzing work practices, the approach is useful for understanding the logic of the situation by examining how practitioners' seeing, saying, and acting is situated, or embedded in a particular situation; situated is the knowing in bodies, materials, but also in language and in the dynamics of interactions between practitioners (Gherardi, 2015). Understanding practice with the methodological approach using the concept of knowing-in-practice shifts from an understanding of knowledge as a commodity to one that views it as a process (that is, as knowing); as an epistemology it requires a looking at how the various sets of knowledge are entangled with meaning and how situated activities are accomplished collectively. It means looking at the discursive practices, the ways how practitioners make sense of what occurs in a situation through talk in and about practice as well as how the practical knowledge is anchored in material objects and how it is mediated by learning from and in experience (Gherardi, 2012a).

\section{The role of tensions as manifest contradictions in activity sys- tems and}

In the third article I utilized the concept of contradictions in activity systems (Engeström, 2001; Engeström and Sannino, 2011) in order to explore the embedding of hospital-based medication review. I found the concept useful as it affords the use of the conflictual and developmental nature of 
practice. How these contradictions play out in professional practice and local embedding processes directs attention to the object-orientation or directedness of a practice, as well as to the historical development and mediated character of a practice.

Activity theory highlights the collective, historically and culturally mediated, and the transformative character of human actions. Drawing on roots in Russian cultural-historical child development psychology (Vygotskij and Cole, 1978), a specific variant, called cultural and historical activity theory (CHAT) was further developed for studying organizational learning and work practices (Engeström, 1995; 2000; Engeström, 2001; Miettinen and Virkkunen, 2005). According to CHAT, activity (that is, practice within an activity system) is viewed as the primary unit of analysis when examining human conduct. Rules, patterns of relationships, and how actors orient themselves towards an object in an activity system are foregrounded when analyzing actions, instead of focusing on individual behaviour. Central is the object of activity which is shared by practitioners and which provides meaning to their ongoing interactions. This object is constantly developing through ongoing practice, is considered partly given, partly constructed, and is oriented towards the intended outcome(s) of the activity (Engeström and Blackler, 2005). All activity is mediated through tools, rules and a particular division of labour. All elements composing an activity system, that is, the object, subjects, and the community forming around the object, are constantly reconfigured in the evolving activity system (Engeström, 2000).

Contradictions are considered inherent in activity systems, since activity systems are seen as fundamentally heterogeneous and dynamic. According to CHAT, contradictions are understood as structural tensions that accumulate over time and emerge within and between activity systems; they can be manifest as different understandings, conflicts, dilemmas, or disturbances, breaks, and disruptions in activities. Contradictions can emerge within the elements of an activity system, such as differing understandings of the object of an activity system, or of how norms and rules shall be interpreted. Also, contradictions can arise between elements of an activity system, for instance as a result of the modification of existing elements or adding of new elements; this can give rise to a mismatch between the newly established mode of activity and remainders of the previous mode of activity, for example how work is being divided up (Engeström and Sannino, 2010). These contradictions can 'trigger generative and expansive processes' in terms of organizational development and learning (Engeström, 2001; Avis, 2009), and are therefore viewed as drivers of transformation and change. Thus, CHAT not only emphasizes the constant presence of contradictions and disturbances in all activity systems (and, therefore, every- 
where human activity unfolds), but it equally points to the generative quality of such contradictions in order to achieve change. Thus, the concept of contradictions can be used within an interventionist approach, that is, utilizing and discussing these disturbances as a prerequisite for then jointly transforming an activity (Engeström, 2000). However, as in my case, the concept can also be utilized analytically.

\section{Practice-as-entity of elements and as performance}

In the fourth article I utilized the theoretical framework developed by Shove et al. (2012) for exploring patients' everyday medication practices in connection to hospital-based medication review. According to this approach, practices can only be established and sustained through the integration of three 'generic elements', that is, materials, meanings, and competences. Materials encompass all kinds of objects, tools, or infrastructures, and meanings refer to socially shared meanings, conventions, expectations, but also embodied understandings of the social significance of the practice and past experiences of participation; competences, lastly, include skills, techniques, but also practical know-how, background knowledge, and understandings of appropriate practice, such as understandings of the situation. These elements are understood as comparably stable entities, whereas the practices composed by these elements are viewed as undergoing constant transformation. It is through the integrative and ongoing performances that practices are reproduced (but also changed).

The framework synthesizes and simplifies different practice-theoretical approaches and has a focus on everyday practices and on how practices can be changed. Specifically, the framework builds on concepts by Schatzki (2002), such as the notion of practical understanding as 'a skill or capacity that underlies activity' (: 79); it also draws on work by Reckwitz (2002) who sees practices as 'blocks' of several, non-reducible practice elements whose specific interconnectedness makes it recognizable as a practice. According to Reckwitz, further, individuals are 'carriers' of many different practices and each individual agent can be conceived of as 'the unique crossing point of practices' (: 256). I found the framework by Shove et al. useful for exploring if and in what ways medication review practices, observed in healthcare settings and accounted for in interview talk, interconnect with patients' everyday medication practices; thus, this integrated sites beyond the healthcare settings the patients (and, to some extent, I as a fieldworker) were attending, in looking at what makes up patients medication practices. Particularly, I found the notion of recruitment into as well as defection from a practice (Shove and Pantzar, 2007) interesting as an analytical tool to examine what makes certain practices to 'live on' or to be abandoned. Also, the notion of individuals as 'carriers' of a multitude of practice(s) allows the conception of practitioners' (here, patients') sayings and doings in 
terms of participation in a practice, instead of viewing them as behavioural constructs of individual properties. Thus, using such an approach made it possible to analyze patients' medication use as social practices which, albeit individually enacted, are collectively constructed, shared and reproduced.

\section{Empirical context and research design}

\section{Pilot study}

Study design of this research was informed by insights gained during a pilot study, conducted in two medical hospital wards (a general internal department, a nephrology ward) at two different hospitals in southeast Sweden during spring 2015. Observation methods with a focus on shadowing individual physicians were employed, supplemented by informal discussions and brief field interviews. Direct observation enabled studying the conduct of medication review in two rather different settings. The former with a very broad spectrum of patients in terms of age, medications taken, and types of conditions treated; also, physician staff differed between the two with the latter dominated by a relatively small team of highly specialized clinicians providing tertiary care for a narrowly defined patient group. Medication review routines differed considerably, for example with respect to how a medication history was obtained, medication issues were discussed with patients and among staff, or how medication risks were identified and managed.

Based on my experiences in the pilot study, I found ethnographic methods extremely valuable to study the 'ways of doing' medication review in context. Physicians emphasized that medication review was highly relevant in conducting routine patient care; however, to perform comprehensive medication review was seen the main responsibility of primary care clinicians. Physicians had varying understandings with respect to whether and how medication review tasks should be best distributed where it was found suitable to divide up medication review in components and having junior doctors conduct more 'simple' ones. Also, differing views were held with respect to whether medication review can be conducted in a standardized manner (as practiced by the tertiary care clinicians). Thus, applying field methods enabled me to explore physicians' meaning-making of the newly introduced practice in everyday hospital work, the varying ways physicians made sense of the aims, objectives, and expected benefits of medication review as well as how they conceived of medication safety in general. Therefore, it was decided to use ethnographic methods as the principal approach in the thesis research. 


\section{Recruiting of cases}

Between February 2015 and September 2016, a total of seven different clinical departments in southeast Sweden were contacted for participation in the study; contacts were made by e-mail and letter with telephone followup and resulted in four clinical departments willing to participate. Finally, two hospital clinical units in southeast Sweden (a department of surgery, and the ED) were willing to participate in the thesis study. Nevertheless, due to difficulty in recruiting patients into the interview study, two further clinical units at two different hospitals were contacted. Finally, one of these units, a department of orthopedics, entered the study in September 2016. Participation in the study, though, only included access for approaching patients for participation in the interview study. Ethical approval was granted by the Regional Ethics Board (ref 2015/194-31).

\section{Study setting and participants}

With respect to the organization of the Swedish healthcare system, the state is responsible for overall healthcare policy, whereas the funding and provision of healthcare services rest with the county councils and regional bodies; at the level of the single healthcare facility, clinical management is responsible for day-to-day clinical activities (Anell et al., 2012). Over the last decade, strategies to base clinical and political decisions on best evidence have increasingly gained influence in Sweden; national guidelines and regulations form the basis for implementation and allow for regional specification and local adaptation of such policies (Kalkan et al., 2015).

Three different clinical units located in two different hospitals in southeast Sweden participated in this research. Regarding the work structure in the participating ED, care is being provided by small teams, usually composed by an ED physician, a nurse, and 1-3 nursing assistants. During dayshifts at weekdays several of such teams are distributed on the ED floor, with a few teams directed at more specialized issues (such as orthopaedics and traumatology, or patients with complex geriatric problems). Work during night shifts and on weekends is provided by fewer and smaller teams. A group of several triage nurses initially assesses all patients visiting the $\mathrm{ED}$, grading them according to clinical priority and distributing them to the different ED teams. The ED is open 24 hours a day and is the location where the initial assessment and acute care for a broad spectrum of conditions and injuries is being provided.

The second clinical unit participating in the study was a surgical department situated at a hospital in the same region. The department comprises two wards with each 28 hospital beds providing specialized surgery, and a smaller ward offering day case and short stay surgery (the study was conducted at the two larger wards only). Care at the surgery department is provided by surgical ward teams comprising surgeons, residents, interns, 
nurse practitioners, nurses, and assistant nurses; three clinical pharmacists were contracted to perform basic medication review at admission. As the third clinical unit, a department of orthopaedics, located in the same hospital as the department of surgery, was included. Here, patients hospitalized for planned knee-or hip surgery were approached at two wards, yet no observations or interviews with staff were involved.

\section{Generating data using an ethnographic approach}

Fieldwork was initiated first at the ED, starting in October 2015 and concluded in May 2016, with a total of 160 hours spent on 21 different workdays. The main methods employed were participant observation and informal field interviews. Observation meant shadowing of usually one ED physician during his or her entire work shift; during fieldwork I observed, among others, ED team interactions, documentation practices, clinicianpatient encounters, and consultations with other healthcare professionals. Shadowing included following a practice (Nicolini, 2012), that is, focusing first on the doings of the ED physician, and then, switching to following the ED teams nurse(s), when practice tasks were handed over or divided up among team members. Observation episodes were supplemented by brief informal discussions with ED staff (usually the physicians, nurses, assistant nurses of that team shadowed on that day), less often with staff on the ED floor on that workday. Only a few of the scheduled semi-structured interviews with ED physicians ( $\mathrm{n}=14$ in total) were conducted after completion of a work shift; the majority, though, (that is, 11 of the 14 interviews) were conducted shortly after completion of the field phase. A brief overview of the methods employed is given in table 1 in this section.

Fieldwork at the second case, a department of surgery, was started in February 2016 and lasted 11 months, involving a total of 130 hours of direct observation in two wards over 27 different weekdays. Again, participant observation including informal discussions with staff was utilized. Here, observation and shadowing enabled me to study how medication review practices were organized interprofessionally where different healthcare practitioners (physicians, hospital pharmacists, nurse practitioners, and nurses) enacted medication review. Further, being in the field over an extended time period allowed observing medication review longitudinally, that is, following different medication review tasks from admission to discharge of a patient. During, as well as after completion of the fieldwork period, I conducted semi-structured interviews with 17 different healthcare professionals engaged in clinical work at both wards.

In both settings, observation was overt, that is, announced each time at the beginning of the shift, and once again after assignment to the respective 
ward or ED team. Also, I was required to wear the hospital clothes customarily used by physician staff along with a name identifier (and, being a certified physician, followed by the term of 'legitimerad läkare'). Oral consent was obtained from clinicians prior to starting fieldwork on each day; it was also offered to obtain written consent but the majority of clinicians preferred to give oral consent only; a written information leaflet was always provided.

Participant observation in ethnographic field research involves direct, ongoing interaction with people in a natural social setting (Emerson et al., 2011). However, nature and degree of my participation varied depending on the context and situation; this meant, for example, moving from more explorative and unstructured observations at the beginning of the fieldwork period to more focused ones; this involved switching from a position as a mere observer during clinician-patient interactions, to more active modes of participation when engaging with team members, such as during pre-ward round briefings where patients were not present.

I made handwritten fieldnotes of observation episodes and informal discussions in a paper notebook directly on site and then transcribed and expanded texts to full fieldnotes on the same or subsequent day. Early on I became aware that writing fieldnotes directly during an observation episode could affect interaction and relationships with participants in the field, as described by ethnographic scholars (Wolfinger, 2002). After being asked by a physician I was shadowing whether 'something was wrong' and another physician jokingly commented that she wanted to check my notes for comments on potential mistakes she might have made, I either briefly explained what I was jotting down in a specific situation, or waited until I could write down a few words unobserved later on. Ethnographic fieldwork in the hospital has been found to irritate staff as they feel being watched, monitored, or policed by the observer (Wind, 2008).

Participants for semi-structured interviews with healthcare professionals at both sites were selected to ensure diversity with respect to seniority and work experience, gender and professional group. Interviews were focusing on practitioners' practical understandings of their overall work tasks, of doing medication review, ways to ask about medication use, and their understandings of and managing of medication risks; also, their understanding of and participation in local implementation efforts, as well as the strategies to support medication review integration into routine work. A topic guide with broad, open-ended questions was used (see Appendix), with room for complementing questions to explore issues emerging in observations or informal discussions. All semi-structured interviews took place on hospital premises, in a room at the choice of the interviewee. Interviews were digitally recorded and transcribed verbatim by me. 
Recruiting of patients for semi-structured interviews began at the first fieldwork site, the ED, early in November 2015. To be eligible for participation in the interview study, patients were required to have sufficient Swedish language proficiency and to take at least one medication regularly. However, partly due to the severity or acuity of the patient's health condition, but also due to practical reasons (for example were some patients temporarily moved within the ED or away for diagnostic procedures) I was able to approach only a few patients. The stressful situation and pressing environment in the ED complicated the process to inform patients about the study and negotiate the conditions of their participation. Therefore, interviews with only three patients from the ED were conducted. Recruiting of patients in the department of surgery began in May 2016 and continued up until November 2017. Patients hospitalized were approached at the ward, both on days when I was conducting observations, but also on separate occasions (resulting in eight semi-structured interviews from that site). As previously described, my efforts to recruit patients from this site progressed only slowly as many of the patients initially willing to participate later declined (many due to health reasons). Therefore, additional patients were approached at two wards at the department of orthopaedics at the same hospital in from September 2016 onwards. There, I contacted patients on-ward after meeting with a nurse contact who had pre-selected eligible patients, so that finally interviews with nine patients were conducted by me.

A topic guide was used exploring, among other things, patients' views on processes related to dealing with medications at home and in the hospital, prior and current medicine use, and their experience and understanding of medication review (for more details, see Appendix). Irrespective from study site, I provided all patients with oral and written information about the study; I contacted those willing to participate by telephone about 10 days later to agree upon date and location of the interview. All interviews were conducted at the location preferred by the patient, in the majority of cases at the patient's home. 
Table 1 Study design: setting, aim and methods by article

\begin{tabular}{|c|c|c|c|c|}
\hline & I. Article 1 & II. Article 2 & III. Article 3 & IV: Article 4 \\
\hline Setting & $\begin{array}{l}\text { Dept. of Surgery } \\
\text { (two wards) }\end{array}$ & ED & $\begin{array}{l}\text { ED, Dept. of Surgery } \\
\text { (two wards) }\end{array}$ & $\begin{array}{l}\text { ED, Dept. of Surgery } \\
\text { (two wards), Dept. of } \\
\text { Orthopaedics }\end{array}$ \\
\hline Aim & $\begin{array}{l}\text { To analyze how med- } \\
\text { ication review is be- } \\
\text { ing sociomaterially } \\
\text { accomplished with } \\
\text { respect to coordina- } \\
\text { tion of its actions }\end{array}$ & $\begin{array}{l}\text { To analyze the prac- } \\
\text { tical knowledge nec- } \\
\text { essary to perform } \\
\text { medication review in } \\
\text { everyday ED practice }\end{array}$ & $\begin{array}{l}\text { To explore the em- } \\
\text { bedding of hospital- } \\
\text { based medication re- } \\
\text { view attending to the } \\
\text { conflictual and de- } \\
\text { velopmental nature } \\
\text { of practice }\end{array}$ & $\begin{array}{l}\text { To explore patients' } \\
\text { everyday medication } \\
\text { practices in connec- } \\
\text { tion to hospital- } \\
\text { based medication re- } \\
\text { view }\end{array}$ \\
\hline $\begin{array}{l}\text { Generat- } \\
\text { ing data }\end{array}$ & $\begin{array}{l}\text { Participant observa- } \\
\text { tion: } 11 \text { months, with } \\
\text { a total of } 130 \text { hours } \\
\text { over } 27 \text { weekdays } \\
\text { Semi-structured in- } \\
\text { terviews with } 17 \\
\text { healthcare profes- } \\
\text { sionals (10 physi- } \\
\text { cians, of which } 5 \\
\text { specialists in sur- } \\
\text { gery, } 2 \text { residents, } \\
\text { and } 3 \text { interns; } 2 \\
\text { nurses, } 3 \text { nurse prac- } \\
\text { titioner, } 2 \text { clinical } \\
\text { pharmacists; } 15 \text { of } \\
\text { the interviewees also } \\
\text { shadowed) }\end{array}$ & $\begin{array}{l}\text { Participant observa- } \\
\text { tion: } 5 \text { months, with } \\
\text { a total of } 160 \text { hours } \\
\text { over } 21 \text { weekdays; } \\
\text { Semi-structured in- } \\
\text { terviews with } 13 \text { ED } \\
\text { physicians; } 7 \text { special- } \\
\text { ist physicians, } 6 \text { at } \\
\text { various stages of ED } \\
\text { speciality training; } 5 \\
\text { of the interviewees } \\
\text { were previously } \\
\text { shadowed) }\end{array}$ & $\begin{array}{l}\text { Participant observa- } \\
\text { tion as in I. and II. } \\
\text { Semi-structured in- } \\
\text { terviews with } 31 \\
\text { healthcare profes- } \\
\text { sionals (data from } \\
\text { interviews as in I. } \\
\text { and II, including ma- } \\
\text { terial from interview } \\
\text { with specialist physi- } \\
\text { cian/director of clin- } \\
\text { ical education at ED } \\
\text { not working clini- } \\
\text { cally in ED at that } \\
\text { time) }\end{array}$ & $\begin{array}{l}\text { Semi-structured in- } \\
\text { terviews with } 20 \text { pa- } \\
\text { tients ( } 3 \mathrm{ED}, 8 \text { surgi- } \\
\text { cal wards, } 9 \text { ortho- } \\
\text { paedic wards) }\end{array}$ \\
\hline $\begin{array}{l}\text { Analyzing } \\
\text { data }\end{array}$ & $\begin{array}{l}\text { Thematic analysis } \\
\text { (Braun and Clarke, } \\
\text { 2006); concept of } \\
\text { practice-arrange- } \\
\text { ment bundles as ana- } \\
\text { lytical tool (Schatzki, } \\
\text { 2012) }\end{array}$ & $\begin{array}{l}\text { Constructivist } \\
\text { grounded theory } \\
\text { (Charmaz, 2014); } \\
\text { concept of knowing- } \\
\text { in-practice as analyt- } \\
\text { ical tool (Gherardi, } \\
\text { 2008) }\end{array}$ & $\begin{array}{l}\text { Thematic analysis } \\
\text { (Braun and Clarke, } \\
\text { 2006); concept of } \\
\text { contradictions in re- } \\
\text { lation to activity ob- } \\
\text { jects as analytical } \\
\text { tool (Engeström, } \\
\text { 1995) }\end{array}$ & $\begin{array}{l}\text { Thematic analysis } \\
\text { (Braun and Clarke, } \\
\text { 2006); concept of } \\
\text { practice elements ac- } \\
\text { cording to Shove et } \\
\text { al. (2012) as analyti- } \\
\text { cal tool }\end{array}$ \\
\hline
\end{tabular}

Note. ED, Emergency department 


\section{Reflexivity and methodological quality}

The notion of negotiated interactive observation was proposed by Wind (2008) to acknowledge the specificities of conducting ethnographic fieldwork in hospital settings. Here, it is argued that the hospital setting allows for only some degree of participation, hereby setting limits to the fieldworker's amount of interactions, agency and 'authority over the filed' (Wind, 2008: 84). However, such a specific way of observation in hospital fieldwork can be distinguished from other notions, such as 'nonparticipation' or 'passive participation' as levels of participation proposed by Spradley (1980); instead, Wind argues that participant observation in hospitals, albeit seemingly 'passive', still requires an active, ongoing negotiation of the conditions of participation and interaction. Given the highly differentiated social space of the hospital (van der Geest and Finkler, 2004), continuous negotiations with respect to when, where, and how observations can take place and to what degree of participation is deemed acceptable; therefore, negotiated participation in hospital fieldwork also requires the fieldworker to constantly reflect upon and openly discuss the conditions of observation and how these negotiations are done (Wind).

On both sites, healthcare professionals (physician or the head nurse) decided at the beginning of each day of fieldwork which team or ward would be suitable to select for observation. However, more situated negotiations took place and involved briefly discussing whether patients would be distressed by my presence; further, it included situations where my participation, specifically my shadowing, would be a burden to the healthcare professionals present. The term shadowing has been used to describe a range of different approaches and techniques (Gill, 2011) and has been defined as 'researcher closely following a member of an organization over an extended period of time' (McDonald, 2005: 456). Shadowing, however, does not mean being invisible or unobtrusive.

I, thus, tried to be attentive to the situation and potential signals, and, for example, withdraw when I sensed that healthcare professionals were in stressful situations. Only once it was necessary to negotiate access to a different team as my presence obviously was felt as 'added' stress by the junior physician I was shadowing. I am aware that my presence or my shadowing can have affected the way participants acted and interacted; for example, triggered my brief explanations about the study a few discussions about 'the importance of the medication list', thus, I might have acted as a prompt in that situations. Equally, my attentiveness and thoughts about being obtrusive might have led to abstaining from conducting observations. The latter, a potential reactiveness on my part, also relates to the issue of being 'too close' as a researcher as I (as a trained physician) was familiar with the set- 
ting and the phenomena I studied. Reflexivity, therefore, requires to address the challenges of closeness in such forms of 'self-ethnography' or insider-ethnography (Alvesson, 2003); this meant, for example, that I tried to pay attention to possible taken-for-granted understandings of a situation (or phenomenon) that I had experienced as a physician. I was critically aware that patients might have misunderstood my role, potentially seeing me as a physician involved in their care, which might have affected their willingness to participate in the study. Therefore, both in oral and written information, I explained my role as a researcher (although with a physician background) to no extent involved in clinical care, and that they could withdraw from participation at any time without any consequences for their clinical care. I noticed, further, that shadowing nurses in the surgery wards proved practically impossible, meaning that nurses did not principally object to my shadowing them but providing a series of reasons why it was difficult or not possible 'at this point in time'. I did not explicitly explore this issue with nurses, but hypothesized that I was perceived as a physician, not as a researcher, by the nurses in this setting. Although I could not resolve these difficulties of access, the extended time spent in the field provided numerous opportunities to observe these healthcare practitioners (albeit not one-on-one) in diverse contexts.

My fieldnote taking on-site evolved over time with more comprehensive note-taking in the initial phase and more focused notetaking later on. Throughout note-taking of the more expanded fieldnotes, my writing preserved the temporal logic of observations; over time, I became particularly aware of the interconnectedness of the observation, writing, and analysis modes (Emerson et al., 2011). I reflected on my strategies of observing, selecting what and when to observe, describing, and making sense of what I observed and wrote down. This involved, for instance, memo writing on the 'salience hierarchy' implicated in the cases or observations I selected, what made deviant cases to stick out, or in what ways they deviated from 'normal' or mundane activities (Wolfinger, 2002: 90).

Additionally, I kept a reflective journal describing interview and participant observation processes and the respective context information. Writing and then sharing these reflections with my supervisors facilitated the development of critical awareness of the research process, particularly researcher-participant interactions during fieldwork and how they might have affected data analysis and interpretation. This involved, for instance, reflecting on potential observer effects, such as reactivity of actions on the part of shadowed or observed research participants (Atkinson et al., 2007). While I doubt that research participants staged (or faked) activities in my presence, I am fully aware that my presence could have triggered participants' reflecting on their practices which otherwise might not have occurred. In this context I also noticed that my presence was less and less 
commented on the longer I was present 'in the field'. However, with more time spent in the field, a closer relationship evolved between some of the people I 'observed' and me; thus, reflecting also involved how to walk a fine line between developing 'too close ties' and staying too distant (Monahan and Fisher, 2010). Nevertheless, I was aware that despite the familiarity of the participants with my role and the study, there was the possibility that some of them might have consented although they were not comfortable with my being there. Also, I had to deal with practical limitations of the informed consent concept in ethnographic research (Watts, 2011) as there were situations where it was not practicable to obtain full consent from all participants, for example, from healthcare professionals or patients that were present very briefly in a situation I observed.

With respect to interviewing of healthcare staff, I mostly contacted interviewees after having spent some time in the field with them. Except for one interview, interviewing proceeded undisturbed. However, a few of the interviewees pointed out that they 'had lots of work to do'; this somewhat affected my interviewing in that it, in a few cases, made me end the interview earlier so that issues could not be explored to an extent that I felt was appropriate. Nevertheless, I tried to follow-up on some issues in informal conversations whenever I had the opportunity during subsequent fieldwork episodes. Generally, I am aware of the character of interviews as social encounters and situated activities (Warren, 2012). Thus, I reflected on the potential effects of impression management or role-playing, both on my own part and on part of the interviewees. What proved challenging was to develop a sensitivity for healthcare practitioners' use of what is being called institutional discourse, that is, the language practices that organize 'ways of knowing the world in institutionally actionable ways' (Smith, 2006: 122). This meant that healthcare practitioners, particularly more senior ones, put strong emphasis on general statements of the 'importance of medication review', their dedication to patient safety, and the need to set up specific routines. I, therefore tried to move interview talk beyond such institutional language and used probing questions to explore practical instances that would illustrate these assertions. Interview talk of some healthcare practitioners also showed signs of accounting for specific actions (Baker and Johnson, 1998) where I then tried to explore the particular situated nature of the actions they accounted for.

On several occasions during data collection and data analysis I was engaging in peer debriefing with one of the thesis co-supervisor (a social anthropologist with about 15 years of ethnographic research experience in the health field) discussing my fieldnotes, conceptual maps, commentaries, memos and analytic themes. 


\section{Ethical considerations}

In addition to considerations related to obtaining consent from patients for participating in interviews, I encountered challenges with respect to obtaining consent from patients participating in field observations. It turned out to be difficult for me to approach patients prior to situations that involved routine patient-clinician interactions. Particularly in the ED, it appeared to cause distress to the patient when I visited him or her before the ED team saw this patient. Thus, my explaining the study for obtaining consent generated confusion and discomfort, as some patients took me for an ED clinician and were pressed to tell me about their health problem. Similar problems occurred at the surgery wards when I initially tried to inform patients present on that day of my taking part in the ward round and obtain their consent.

However, obtaining oral and written consent in ethnographic research is not entirely unproblematic. It is unknown whether methods, such as informed consent in ethnographic studies can minimize potential harm (Murphy and Dingwall, 2007). Also, potential harms and their likelihood of occurrence in participant observation are difficult to predict and it is challenging to communicate such hypothetical risks beforehand. It is often first during fieldwork one can assess an individual research participant's vulnerability or one becomes aware of potential negative or distressing effects of the research process on research participants. We discussed this issue within the research group as I was troubled by the difficulty to reconcile a research participant's right to decide on participation and the potential risks of causing further distress by engaging in obtaining consent. I specifically reflected on an experience where my asking a patient for written consent seemed to generate anxiety and discomfort; signing an informed consent form also required that the patient had to identify herself by giving her name which seemed to intimidate the patient. Nevertheless, she gave her consent. I reasoned that requiring written informed consent in every research situation could transform an exploratory research context to a contractual and very formal situation, potentially putting pressure on the patient where she or he already is in a very vulnerable position. In accordance with the ED team I was assigned to (or the physician responsible for the surgical ward, respectively) it was, then agreed that I would participate in first encounters in the ED (ward rounds, respectively) without prior obtaining written or oral consent.

\section{Methodological considerations}

Critique regarding particular practice-theoretical assumptions also applies to this research. The assumption of the collective sharing of knowledge and how such shared knowledge can be accessed has been criticized (Turner, 1994). Particularly the conception of the publicness (or observability) of a 
practice and its accessibility to other practitioners, central tenets in practice-theoretical methodology, have been questioned (Schmidt, 2018). This, thus, fundamentally challenges the possibility to empirically analyze practices as practices need to be recognized by researchers observing a practice. The critique of the 'publicness assumption' also echoes similar criticism of ethnographic approaches (Schmidt and Volbers, 2011).

Particularly the critique of the publicness assumption, specifically arguments incorrectly understanding 'publicness' as 'immediate visibility', has been addressed by Schmidt and Volbers (2011). The authors pose that the publicness assumption is not so much based on physical perceptibility; rather, publicness has to be understood as 'social visibility, which is always already practically produced and embedded in overarching contexts of sense and meaning' (: 423). Therefore, I was dealing with these 'limitations' by reflecting on my 'seeing', 'perceiving' and 'observing', but also my meaning-making in my research practices throughout this thesis research. Thus, in connection with fieldwork, but also during my engaging with practicetheoretical concepts and the empirical material, I was examining my own preconceptions; also, I tried to reflect on potential linkages of the 'locally' observed with the wider context it was embedded in. Attending to the social visibility also included a sensibility towards the practical intelligibility of 'things' (including abstract concepts) in use and analytically focusing on the connections of these objects with objects and practices not immediately present in an observed situation (Barnes, 2001; Schmidt and Volbers, 2011).

I tried to address the difficulty of 'recognizing a practice' by critically reviewing several of the suggested approaches for 'capturing' a practice (Warde, 2014). These approaches include making use of instructive texts (such as relevant guidelines, regulations, local instructions, or training material), disputes or discussions about appropriate practice conduct between participants, observation of everyday work practices, and the use of objects tightly connected to the practices, such as the medication list, or electronic templates in the medical record.

Finally, limitations related to the study design need to be acknowledged. With respect to the theorizing of practicing and embedding medication review, this research is based on two cases. All settings participating in the research were self-selected and observations were only done on only workday shifts. However, no claims are being made with respect to the formal generalizability of the findings; also, even single or 'small-N-case studies' can contribute to valuable insight when they are based on carefully selected examples and encompass multiple 'within-case' comparisons (Flyvbjerg, 2006). As previously stated, work on this thesis is not based on presuppositions of an objective 'knowability' of social realities. Nevertheless, various efforts to uphold trustworthiness of the research approach 
were employed. These included, aside from the previously described reflective moves, being in the field over an extended period of time in both settings, as well as the use of a range of comparative techniques, such as 'shadowing' and comparing multiple actors and objects, or texts, and balancing familiarity with strangeness in diverse encounters (Yanow and SchwartzShea, 2014)

\section{Analytical processes}

\section{Theoretical assumptions}

A central assumption for studying practices is that a practice is being understood as a 'publicly available accomplishment' (Nicolini, 2009: 1400) which can be captured through zooming in on the situated discursive and non-discursive activities of practitioners (Nicolini, 2012). Although practices can be fluid and transient occurrences and cannot be uncovered through direct experience, they become accessible through 'doings and sayings': here, language can be a guide as ' $(\mathrm{t})$ he use of words for activities and practices is built into practices' (Schatzki, 2012: 24), and can be explored using ethnographic observation, informal conversations, and formal interview techniques. Capturing a practice through a focus on discourse, though, does not mean privileging language but equally attending to the bodily and material interconnections of discursive practices; this includes gestures, postures, interactions around the use of tools, or actors' engagements with materials (Iedema, 2007). Talk among practitioners can, then, be examined with respect to how meaning is negotiated in discourse, and, how practitioners transform artifacts and objects through talk, or how they position themselves and others through talk (Hermansen, 2015).

\section{Analytical strategies and conceptual tools}

Given the research interest in studying practices as they unfold, my 'zooming in' on the 'real-time accomplishments' (Nicolini, 2009: 1392) were tightly connected to the use of a range of conceptual tools and analytical resources in the interpretive processes of the data analysis. In the abductive data analysis process, iterative cycles of the interplay between the data and different theoretical conceptualizations were employed (Timmermans and Tavory, 2012). This involved alternating phases of sorting, comparing and interpreting the material (utilizing thematic analysis in articles 1,3, and 4, and constructivist grounded theorizing in article 2), with interrogating the data using diverse practice-theoretical concepts and analytical strategies. 


\section{Focus on accountability and legitimacy}

Zooming in meant focusing on how practitioners made sense of what 'counts' as a practice, including the problem(s) the practice is oriented at. Focusing on what makes a practice recognizable also taps into practitioners' sense of how a practice should be best performed, what differentiates one practice from another, what constitutes 'good practice,' or where the boundaries of a practice can be drawn.

Here, the notion of medication-related problems served as a springboard to explore how 'practitioners' (not only healthcare practitioners, but also patients) made sense of concerns related to medications. The term medication-related problem figures prominently in all formal documents relevant to medication review in Sweden. It commonly refers to an event connected to the use of medications and which potentially, or actually, affects health outcomes (Ruiz-Millo et al., 2017). Again, several similar terms, such as drug-related problem, medicine-related problem, or medication problem, are in use (Meyboom et al., 2000). Medication-related problems range from problems of treatment effectiveness, or inappropriate choice of a drug, to patient-associated problems of medication use, and adverse drug reactions (Blix et al., 2006). The national regulation and the guidance document (Socialstyrelsen, 2012; 2013a), regional guidelines (Region Östergötland, 2014), and documents of the regional implementation group (Region Östergötland, 2015) all refer to this term when defining the scope and purpose of medication review. Thus, as policies can be understood as 'dynamic processes that include texts, practices, and decisions that organize action across contexts' (Canary, 2010: 24), policy terms are relevant in implementation contexts as practitioners give meaning to, sometimes ambiguous, terms in order to apply them in concrete contexts. Organizations, specifically, are of interest as sites where policies are produced, reproduced and adapted through processes of interpretation and negotiation (Kirby and Krone, 2002).

Thus, the broad scope and the various nuances in the usage of the term medication-related problem made the exploration of the different meanings in everyday situations worthwhile. I was therefore interested in the term's use-in-context; this also tapped into practitioners' understandings of their roles, task boundaries, organizational routines, professional identities, their commitments, and interests vis-à-vis medication-related issues. Exploring these issues in relation to concrete instances, for example in informal conversations and field interviews was useful to understand connections to different medication-related practices. 


\section{Focus on practical concerns: exploring 'ordinary troubles' and 'breakdowns'}

Bringing to the fore the orientation and direction of a practice (i.e. what to do and what ought to be done, the goals and rules, the practical concerns) requires one to focus on how practitioners experience this directedness or orientation while being engaged in a practice; this involves attending to practitioners' talk, their explanations, justifications, or accounts about motives or goals of their object of work (Nicolini, 2009). However, this does not mean that such practical concerns are easily articulated while practicing; they are not articulated partly because certain practice aspects are taken-for-granted features of familiar to practitioners, partly because they belong to pre-reflexive or un-reflexive qualities of a practice (Greig et al., 2013). The notion of 'ordinary troubles' has been suggested as an approach for exploring the disruptive qualities in ethnographic research; this implies a heightened sensitivity to ordinary routines, social and normative order and a focus on the interactional processes through which such troubles are expressed, recognized, and dealt with (Emerson, 2009).

Similarly, these practice qualities and 'the significance of the internal workings of a practice' can become accessible by exploring breakdowns or disruptions in the practice (Sandberg and Tsoukas, 2011: 347). The concept of breakdowns is grounded in Heideggerian thinking (Koschmann et al., 1998) that conceives of ongoing and ordinary practice as a nonreflective mode of activity where certain aspects (such as tools used in that practice) can be 'lit up' through interruptions; prompted by an interruption, one then switches from an absorbed mode of practice to a deliberating and reflecting mode (Heidegger, 1978). Similarly, 'temporary breakdowns' can emerge in organizational routines in the form of thwarted expectations, deviations and boundary crossings, as well as awareness of differences (Sandberg and Tsoukas, 2011). With respect to my zooming in on practices and subsequent analytical processes, I therefore attended to practitioners' reactions to and deliberations on such temporary breakdowns which made them switch from an absorbed to a more reflective mode of practicing. Practitioners reacted to unmet expectations, for instance, when facing unintended outcomes of their actions; temporary breakdowns could also occur when healthcare practitioners became aware of a different practice, for example, of a different way to document a medication order. In short, examining how practitioners respond to 'naturally occurring' breakdowns or ordinary trouble was useful for accessing what they view as significant in their professional practices. 


\section{FINDINGS}

In this chapter, the findings of the research conducted in the context of this thesis are summarized; here, they are presented in the order of publication of the article. As different practice-theoretical concepts were used in each of these articles (or substudies), this results in an analytically separate structure. However, in the subsequent chapter, these findings will be discussed in a more integrated manner.

\section{Article 1: 'Our surgeons want this to be short and simple': prac- tices of in-hospital medication review as coordinated socio- material actions}

The aim of this article was to examine how medication review is sociomaterially accomplished with respect to the coordination of its actions. A focus was put on coordination as this is a crucial aspect in the conduct of medication review, being composed of various interdependent actions and conducted by multiple practitioners. Schatzki's practice theory was utilized (1996, 2002), particularly the concept of practice-arrangement bundles (Schatzki, 2002; 2010; 2012). Here, material arrangements are understood as configurations of interconnected material entities, that is, human bodies, organisms, artifacts, or things. These arrangements are conceived as being entangled or bundled with practices in various ways, as practices are carried out amid material arrangements, are affected by and affecting them. The notion of practice-arrangement bundles, therefore, is useful for analyzing a social phenomenon, coordination, or the hanging together of actions, peoples, material entities that compose medication review.

Data based on observations of routine work in two surgical wards of a Swedish regional hospital as well as interviews with staff were analyzed. Applying a sociomaterial lens for analyzing medication review and its coordination involved two distinct tasks. First, identifying the actions composing in-hospital medication review, and, second, identifying the practicearrangement bundle(s) these actions were involved in. In doing so, two different inpatient medication review practices were uncovered: a practice concerned with comparing and evaluating medicines (that is, the practice of medication reconciliation), and another concerned with choosing and keeping track of medications (that is, the practice of inpatient medication management). In each practice, several medication-related actions were bound up with material entities in characteristic ways. Tasks such as estab- 
lishing a medication list together with the patient, comparing and evaluating these medicines with other sources in the medical record, and generating recommendations, composed the medication reconciliation practice. In this practice, mainly pharmacists were participating, and, initially actions and materials involved in this practice showed only a few connections or overlaps with the second practice. In the inpatient medication management practice, composed by actions of choosing and tracking medication orders along the trajectory leading to hospital discharge, all other healthcare professionals participated. Thus, surgeons, junior physicians, nurse practitioners and nurses were involved; basically, the same material entities as in the medication reconciliation practice were utilized.

However, based on interviews and observations, including shadowing of physicians, pharmacists, and nurse practitioners, it could be shown that the 'bundling up', that is, the coordination of the practices, was difficult to accomplish under certain conditions: such a coordination was 'harder' to accomplish when the material entities (such as the electronic medical record, or the medication list) connected with different medication-related actions were organized by different teleoaffective structures and were not linked by the same practical intelligibility, that is, what makes sense to do for a practitioner).

An important precondition of coordination of medication review practices, though, was also how actions within a practice were hanging together. An example of the latter was illustrated pointing at the importance of the continuous documentation of medication changes in the medical record and its contribution to the discharge discussion on medications. Also, between-practice coordination could be achieved by establishing overlaps between actions or material entities from each of the two practices. Such connections, for example, the regular tracking whether recommendations of pharmacists were followed up by nurse practitioners during pre-ward rounds were only built up over time and required the ongoing negotiation of the understandings of tasks and of the ends toward which the healthcare practitioners acted; however, it was also shown that building and maintaining such relations for bundling-up medication review and, thus, its coordination, was tied to other local arrangements that affect the conditions under which practitioners acted: here, the restricted composition of ward rounds, frequent staff rotations between wards, or tight surgery schedules, all made coordination of medication review actions more difficult.

By attending to the material arrangements and their interconnectedness to the practices, the dynamics of coordinated actions composing medication review could be traced; in doing so, it could be shown that ongoing efforts were necessary to generate and sustain such interconnections for coordinating medication review in everyday work. 


\section{Article 2: Medi(c)ation Work in the Emergency Department: Making Standardized Practice Work}

The aim of this article was to examine the practical knowledge necessary to accomplish medication review in the ED. Drawing on the concept of knowing-in-practice (Gherardi, 2000; 2001; 2006; 2008), a focus was placed on ED physicians' work practices and on the ways the knowing becomes manifest in different, ordinary, situations. The concept was particularly useful for paying attention to how physicians mobilized knowledge in conncetion with human and non-human elements (Gherardi, 2006).

Based on observations and semi-structured interviews with physicians, several examples of practical knowledge relevant to conducting medication review were provided. For instance, the embeddedness of knowledge in a heterogenous network was illustrated by how an ED physician brought together various forms of knowledge; these forms of knowledge were distributed among different artifacts (the medical record, several medication lists) and the patient. By skilfully resolving inconsistencies between the codified knowledge embedded in the artifacts, the knowing-in-practice involved a situated production of knowledge in order to obtain the best possible medication history. In the case illustrated, the situatedness stemmed from a self-medicating and non-cooperative patient in the sense of not actively contributing information about his past medication use; yet, while the skilful accomplishment, displayed in the sensible knowledge and interaction between the physician, the artifacts, and the patient, was embedded in this socio-material network, a further competence was required. Required, here, was a competence difficult to standardize or specify in advance but highly relevant when performing medication review; this physician's 'knowing-how-to-see' and 'knowing-how-to-speak' (and act) (Gherardi, 2015) and the situated construction of medication risk were required for identifying such a patient as 'at risk' for a medication-related problem.

Further, the emerging and provisional nature of the knowing-in-practice was illustrated; this involved the assessment of a patient's clinical condition, the mobilization of abstract knowledge on potential side effects of specific medications, and the face-to-face interaction between ED physician and patient. Here, the collective and practical accomplishment rested on the relational competence unfolding between a knowledgeable physician and a, likewise, knowledgeable patient; the knowing-in-practice relevant, then, was co-constructed in the situation between patient and physician and developing in the practice, requiring the sensible knowing for judging a patient's ability to follow medication instructions.

Third, the back-and-forth between two ED physicians when negotiating 'good' practice was shown following-up a junior physician's encounter with a young patient presenting with a 'long' medication list. Here, what 
was considered a 'medication-related problem' and how to deal with such a potential problem in the ED were established in practice. Empirical examples of two discursive practices, 'talk in practice' and 'talk about practice' (Gherardi, 2012b), were provided; talking in practice simply occurred as the verbal exchange between the practitioners engaged in inquiring, checking, and answering when reviewing the patient case. Here, talking in practice functions as a discourse mode that carries the action forward. Talk about practice, on the other hand, represents a reflexive discourse modality, negotiating about what 'ought' to be done and how to conduct medication review appropriately with this patient. Through talk about practice, ED physicians not only negotiated the ED-specific view of accepted ways of doing medication review (thus, of a practice), but also the competences required to perform the practice.

Using the concept of knowing-in-practice for analyzing ED physicians' work practices related to medication review was useful for understanding the micro-dynamics and local contexts of practitioners' actions to investigate or deal with a suspected medication-related problem. Discursive and material practices were used to establish, contest, and legitimize what was considered 'good' and practicable medication review practice, as well as its boundaries and necessary competencies. In doing so, practitioners not only reproduced medication review in routine ED work, they also continuously adapted the practice to make it fit to the local context.

\section{Article 3: Embedding hospital-based medication review: the conflictual and developmental potential of a practice}

The aim of this article was to explore the embedding of hospital-based medication review paying attention to the conflictual and developmental nature of practice. Using the concept of contradictions in activity systems (Engeström, 2001; Engeström and Sannino, 2011) it was examined how these contradictions surfaced in professional practice and local embedding processes. Data from participant observation (in total 290 hours over 48 different workdays) and 31 semi-structured interviews with different healthcare professionals in two hospital-based settings (ED, department of surgery) were utilized.

Drawing on the concept of contradictions with respect to the activity or work objects, the analysis focused on discursive manifestations of contradictions, including expressions of irreconcilable issues, conflictual topics, emotionally and morally charged accounts, or explicit criticism comments (Engeström and Sannino, 2011), arising in talk (both during interviews and observations). Further analyzed were contradictions manifest in breakdowns or disruptions of actions (during observations). According to activity theory, such manifestations of contradictions are considered to trigger 
reflection and learning and carry with them a generative potential for change when practitioners try to resolve these contradictions (Engeström, 2001). Various examples of tensions related to the object of work (that is, the 'problem' that is being transformed towards an outcome in the context of medication review) are given, pertaining to three different aspects of activity systems.

First, related to the motives of work, tensions with respect to how 'medication problems that matter' were understood by clinicians were manifest when setting up a routine for checking patients' medications at the surgical department. Consequences of pharmacists' identifying medication problems became apparent to surgeons in terms of affecting other work routines, such as discharge processes and follow-up or referral routines, thereby 'adding to the workload' of surgeons. Tensions, then, surfaced in how surgeons dealt with pharmacists' recommendations, written after reviewing a patient's medicines on admission; for example, surgeons were not sharing reasons for not agreeing with pharmacists' understandings of medication problems expressed in these recommendations, which left uncertainties about which of the recommendations had been followed up. However, pharmacists then adapted their practice and either met with the surgeon in the ward or junior physicians shortly after the ward round had finished. Also, pharmacists learned about specific medication-related problems as ward nurses came to seek their advice on practical medication matters.

Second, tensions arose with respect to the appraisal of work. Specifically in the ED, tensions related to the conduct of medication review became manifest for physicians as not being aligned with their sense of purposeful work; although a medication-related problem was considered as a potential and not uncommon reason for visiting the ED, an obvious connection between physicians' immediate practices, those in neighbouring activity systems (such as receiving hospital wards), and the more distant outcome (an optimized medication therapy, improved patient health) was not evident. This required ongoing conceptual reconstructions by ED physicians in order to attribute worth to carrying out medication review. This included casting the conduct of medication review, or, rather, medication reconciliation, in terms of error minimisation. However, the conflictual tension between the requirement of performing medication review in all patients, and, applying, as it was felt, a 'standardized approach' to managing often 'non-routine' problems in the ED proved difficult to dissolve.

Third, tensions were manifest with respect to the division of work at both sites. According to a contractual agreement, clinical pharmacists were responsible for initiating medication review after a patient's admission to the ward at the surgical department. However, the actual task division in everyday work was not always aligned with formal rules, local conventions 
or with what professionals sensed 'needed to be done', for example, when pharmacists were not present on certain days. Also, the task division for checking a patient's medication was less straightforward than envisioned by local implementers. Although how to go about this task division was meant to be deliberated by each ED team at shift start, how work was divided up proved vulnerable to disturbances under higher workload and dependent on team composition.

Concluding, despite numerous differences in how practitioners understood the object, appropriate conduct, and outcome of work, organizational routines to collectively accomplish medication review were established at both sites. Tensions arose primarily between, but also within, professional groups, and practitioners struggled with, or only partly resolved tensions. However, many of the modifications of work routines to deal with medication-related problems emerged in absence of specific implementation-related meetings or structures, but instead evolved in practice.

\section{Article 4: 'In the hospital all is taken care of': a practice-theo- retical approach to understand patients' medication use (man- uscript under revision)}

The aim of this article was to examine patients' medication practices in the context of hospital-based medication review. Drawing on the framework by Shove et al. (2012) it was explored how these practices are constituted in terms of different practice elements and how patients' medication practices relate to healthcare professionals' medication review practices.

Data from participant observation in two clinical settings (ED, department of surgery) and interviews with patients recruited in three hospital settings (the former two and a department of orthopaedics) were analyzed. Three medication practices were described, according to whether they centered on accepting, challenging, or appropriating medication orders. Different forms of agency, or of being knowledgeable or enabled to act in relation to other actors and arrangements, were made possible in each of these practices.

First, in the practice of receiving and accepting medication orders forms of silent acceptance of medicine orders, predominantly located in the hospital were apparent. This included listening to medication-related information provided and was often limited to instances when nurses administered medications. Practice elements to be integrated included competences such as an understanding of the situation and a knowledge how to 'appropriately' receive and take medications in the hospital. These elements were attached to specific meanings, such as viewing the medications provided as indisputable, and the activities of health professionals as au- 
thoritative. To merely comply with medication-orders became more accentuated in situations where a patient's condition was compromised by intense pain, sickness, or fatigue. However, accepting healthcare professionals as authoritative was also common irrespective of experiencing bodily distress. Here, normative engagements of what ought to be done and how were actively integrated with symbolic practice elements related to past practices; particularly understandings, such as being the 'exemplary patient', one expected not to mistrust, or not 'having the required knowledge to ask'. Specific to the hospital setting, 'a practice-specific emotionality' (Reckwitz, 2002: 254) was employed in the hospital ward as patients considered themselves as lacking control, and as 'completely at the mercy of healthcare personnel'.

Second, in the practice of questioning and challenging medication orders, competences such as embodied knowledge of how to interpret current bodily sensations, signs, or symptoms were integrated with prior knowledge related to medications. Questioning medication orders as a practice presupposed that patients made sense of medication practices, including how they recognized and understood others' medication practices; yet, questioning medication orders did not necessarily mean to outright challenging others' medication practices. Not once during fieldwork observations did I witness that patients openly questioned or challenged medication orders; however, based on patients' experiences recounted in interviews, such a practice required abstract, but also practical knowledge in the form of knowing one's medications and how one's medicines look like, especially for keeping track of (often substituted) medicines. Engaging in this practice also required the knowledge of a specific medication, and the specific time it has to be taken. Explicitly 'defecting' from the practice of accepting and complying with medication orders, though, necessitated other forms of 'competences, that is, a motivational know-how and a strong normative engagement of 'taking back' responsibility, as well as a capacity to stand one's ground.

Finally, third, the practice of appropriating and monitoring medication orders heavily rested on the meanings and understandings of regaining control and taking care of one's medicines after hospitalisation, that is, in the home. According to interview accounts, these practices were represented by activities of probing, testing, and of appraising the consequences of these doings. Such appraising included ongoing cycles of observing, monitoring, comparing, documenting and re-evaluating actions and results; patients also referred to acts of recording where they diligently documented bodily reactions and signs, functional states, as well as types and dosages of medications utilized. Monitoring and appraising could also result in a patient's adapting medicine taking intervals, or, less often, medicine type. 
Overall, patients' medication practices required an active integration of their understandings of the situation, embodied, affective, and experiential forms of knowledge, as well as their understandings of what was considered acceptable. However, advice on medicines was actively sought by patients, not regularly provided in healthcare encounters. Knowing how to interpret bodily symptoms or signs related to medication side effects drew on patients' prior experiences, less often on information provided by healthcare professionals. Thus, only weak links were seemed to be stablished between patients' medication practices and healthcare professionals' medication review practices. 


\section{DISCUSSION}

The purpose of this research was to theorize the practicing of medication review and its embedding into routine hospital work. Guided by a practicetheoretical approach and an ethnographic 'sensibility for practice', empirically it was aimed to deepen the understanding of how medication review was enacted and understood, but also how the embedding of medication review evolved. Methodologically, it was aimed to examine what a practicebased can afford with respect to the taking into account the complexities of implementation in a routine hospital setting.

In the following sections, the above questions will be addressed by discussing the main empirical findings and the methodological contributions; subsequently, brief theoretical reflections and the implications of this research will be put forth. Finally, future research suggestions will be outlined and conclusions will be drawn.

\section{Empirical contributions}

The empirical contributions are twofold: first, the empirical evidence provides insight into the practicing of medication review, and it is shown how medication use is understood and practiced by patients. Second, insight is offered into how the embedding of medication review in routine hospital work is unfolding. Below these two forms of practicing are discussed which despite being interconnected are presented separately for analytic reasons.

\section{Practicing medication review}

In the following subsections, I will discuss the ways in which medication review is being understood and practiced. With this in mind, I have organized this discussion according to the central features through which they represent the practicing of medication review. In this way, the practicing of medication review can be characterized in two different ways, featuring the situated and embodied character of the practice, and the concerned and conflictual character of the practice.

\section{The situated and embodied character of the practice}

As presented in article 2 on the situated and practical knowledge mobilized by ED physicians, the practical accomplishment lies in the skillful handling of fragmented knowledge contained in various artifacts, or in transforming the 'known' into 'knowing' (Bruni et al., 2007). Such knowing-in-practice, then, involved the subjects participating in the practice (the physicians and 
other ED staff, the patient) and the objects of knowledge (the artifacts and the updated medication list) conceived as mutually produced within a situated practice. That is, how medication review is being accomplished rests on the situated and competent knowing, 'a knowing-how in situation' (Gherardi, 2012a: 206) which integrates fragmented knowledge differently and pragmatically, depending on the problem at hand. Thus, practicing medication review also represents the indeterminacy of such practical and situated knowing, a knowing that evolves in the course of practicing. This meant, at times following a standardized approach which privileges knowledge based on formal rules embedded in diagnostic algorithms and ED treatment procedures in one situation; other situations required a practice that put more weight on assessing situational factors of a patient's presenting a problem when assessing the appropriateness of medication therapy; still other situations foregrounded material entities, where several cycles of taking stock of the current medication use were required; here, the printed medication list was equally 'involved' in the practice, along with the participation of the patient and a relative, a nurse and assistant nurse, the ED physician, all adding and editing the list.

In doing so, ED physicians and nurses, partly implicitly, constructed the boundaries of the practice of medication review; situated knowledge was implicated in determining what was falling inside or outside the boundaries of medication review in a specific situation. This was connected to how physicians defined a patient as 'suitable' for receiving medication review. Also, situated knowledge was involved when judging a patient's risk for medication-related harm which lead to modifications of the thoroughness and duration of certain medication review components when asking about and documenting a patient's medications. Such local and contextually informed constructions of risk focused on medication complexity, medicines of narrow therapeutic range, and on patients with multiple conditions. Despite the collective character of the knowing-in-practice involved in medication review, ED physicians used their clinical authority, both, to negotiate the boundaries of the practice of medication review, but also to establish how to perform it competently in the ED.

However, practice boundaries also came to the fore when approaching medication review from a different angle. As shown in article 4, examining patients' medication practices and using data from observations and interviews, only weak links were established between these practices and medication review practices; to a very limited extent only participated hospitalized patients in medication review, such as by providing information on their medication use at home, participating in ward round or discharge discussions about medication therapy, or when nurses were administering medicines. 
Patients' competences required the integration of different forms of knowledge and were often tied to the symbolic sphere. Patients' medication actions in the hospital, here, were guided by embodied knowledge of how to carry out a practice in the sense of tapping shared symbolic structures or routinized ways of understanding (Reckwitz, 2002). Knowing what to do and how in such shared understandings required the integration of affective or normative engagements (Warde, 2005). Not challenging the authority of healthcare professionals by asking questions about medications, or quite uncommon, to call into question a medication order, represented a specific form of knowledge pertinent to a practice of accepting and receiving medication. This kind of knowledge, a knowing-how, an understanding of oneself (as a patient), others (that is, healthcare professionals) rested, further, on a practice-specific emotionality (Reckwitz, 2002), for example being the 'exemplary patient' or not to mistrust a healthcare professional. Identified as the third medication practice, practices of appropriating and observing medication orders, on the other hand, was based on an embodied know-how-knowledge directed at a 'certain way of wanting' (Reckwitz, 2002: 254), as patients engaged in actions of monitoring, evaluating and adapting as they desired to regain their bodily capacities. Such a knowhow-knowledge, however, did not heavily draw on resources provided by medication review. In fact, current ways to conduct medication review, particularly discussions involving medications, made it difficult for patients to engage with healthcare professionals in meaningful ways. Examining patients' medication practices from a practice-theoretical perspective shed light on the distinct embodied and affective character of the knowledge involved, the specific symbolic structures these practices were connected to, and the ways they enabled or restricted patients' capacity to engage in medication review practices.

\section{The concerned and conflictual character of the practice}

The findings shown in articles 1 and 3, both represent the practical concerns, that is, what mattered to practitioners engaged in a practice. Foregrounded in article 1 were the sociomaterial dynamics of coordination when practicing medication review, whereas in article 3 an analytic focus was put on the object toward which work efforts were directed and on tensions related to these objects. Findings in both articles also revealed the ends and tasks considered acceptable to practitioners engaged in medication review.

In article 1, findings point at the importance of the entanglement of materiality with intelligibility (Schatzki, 2002; 2010; 2012). Here, how a specific object or artifact is used can only be understood in relationship to the 'fields of action intelligibility' constituted by practices (Nicolini, 2012: 
172); what makes sense to do with an artifact, for example an entry on medications in the medical record, is not simply determined by that artifact. Based on observations in the two surgical wards, several social mechanisms of connecting actions, healthcare practitioners, and the materials used were exemplified through which coordinated action was accomplished. This required, inter alia, the identification of overlaps and the creation of linkages between the ends or the directedness of carrying out medication reconciliation with the ones preparing a discharge medication list. Here, the pharmacist recommendation was a critical artifact bridging the practices of medication reconciliation and inpatient medication management. Although pharmacists and surgeons did not agree on the meanings attributed to certain objects (for example, the types of medication-related problems laid out in pharmacist recommendations), their actions were orchestrated as they shared the same directedness, that is, to assist patients to better understand medication therapy.

The pharmacist recommendations, thus, evolved to express what mattered in the two practices making up medication review. As an object of materialized understanding (Reckwitz, 2002) of the practice of medication reconciliation, the artifact incorporated what mattered to pharmacists, that is, to identify a patient's medication use, the potential problems with their medications, and to establish a 'correct' medication list. What mattered most to surgeons with respect to medications was taking responsibility for both, the medications ordered and the patient's wellbeing in relation to the surgical treatment. Although pharmacists' understandings of medicationrelated problems were not aligned with surgeons' understanding of such problems, the recommendations 'were made to matter' to surgeons through pharmacists' (re)actions. They became meaningful in connection to pharmacists' directedness towards solving an individual patient's problem, expressed in pharmacists' individualized discussions with physicians. Thus, actions of both practices became orchestrated by a shared directedness towards a specific patient's need to understand the purpose of his/her medication therapy and to take the medicines as prescribed. However, the concerns, ends, and tasks that mattered in these actions only emerged from and through practices of medication review and, thus, were not pre-determined.

Still the same artefact - the pharmacist recommendation - can be discussed examining it as a source of conflict and tension, as it was shown in article 3. Viewing the embedding of medication review as taking place in an activity system with practitioners working on a common object, the conflictual nature of the interconnected elements of an activity system can be used as a point of departure. As briefly described in chapter III on the methodological conceptions used, tensions and conflicts that surface can reveal 
the directedness of practitioners' activities and practitioners' practical concerns (Engeström, 2001; Engeström and Sannino, 2011). Hospital pharmacists in the department of surgery, commissioned to prepare and conduct parts of medication review for patients admitted to the ward, entered a 'system', and, in a way, generated tensions with the newly created artifact, the pharmacist recommendation. These artifacts, however, 'disturbed' a system with a hitherto accepted way of dealing with medications.

Revealed were different beliefs and motivations with respect to what 'mattered' in 'value-laden practices' (Edwards and Daniels, 2012) of each professional group. This meant that surgeons' work practices were guided by a more processual and 'evolving' view of medication-related problems, with some problems expected to naturally resolve themselves over time; thus, some of the 'problems' potentially related to medications were integrated in an equally developing clinical trajectory and, thus, 'normalized'. Pharmacists' contributions, although valued with respect to the specific pharmacologic knowledge employed, were not considered sufficiently grounded in the specific clinical context by surgeons. Surgeons' practical concerns were not always made accountable to others and surgeons did commonly not legitimize their doings. Thus, disagreements between surgeons and pharmacists on medication-related problems were initially not often addressed, and, were not negotiated in practice. Over time, though, pharmacists who could not participate in many of the ward activities (such as ward-round briefings, ward rounds, or hand-overs) by design, came to learn about these tensions. Discussing these tensions and conflicts between practitioners and reflecting on them in the context of what was considered 'accomplishable', made the differing practical concerns accessible, although not all of them were resolved.

Analyzing a practice (here, for that matter, termed an activity) from this perspective also shed light on the conflictual nature of a system with shared responsibility of a patient's medication therapy, both in the ED and the surgery department. As prescribing often is a collective accomplishment (with multiple, often sub-specialty based, prescribers), embedding medication review made visible the fragmented nature of dealing with a patient's medications. Tensions with respect to how work tasks and responsibilities were distributed, therefore, prompted issues of what constitutes purposeful work. As activity systems are conceived as interconnected systems of tools, subjects, the division of work, and the object of work, a change in one element of the system (a new 'rule' to conduct medication review in all patients), this required adaptations in the other elements. That is, besides the creation of new tools (such as the checklist and a reminder in the ED), and a new way of dividing up work, conceptual reconstructions were necessary. Such reconstructions involved, among others, a redefinition of medication- 
related problems in a wider sense, that is, having relevance despite not being connected to the reason for an ED visit. Nevertheless, this entailed 'new' tensions as such a 'universal' orientation was not aligned with the work environment in the ED requiring a constant 'categorization' of patients, for example by using the triage process or following clinical algorithms, according to severity or risk.

\section{Practicing the embedding of medication review}

Revisiting the findings, it becomes evident that aspects of the practice of medication review are tightly entangled with aspects of embedding this practice. Notwithstanding, I will discuss the practicing of this embedding as analytically distinct. In the following subsection, I will discuss several material-discursive practices which function as modes to organize the embedding of medication review by reproducing and stabilizing it; also, I will describe how change and stabilization of medication review and, thus, its embedding was made 'difficult' or were 'resisted'. Turning now to the three modes in which the embedding of medication review evolved or was resisted, these include: Talking about practice, Interconnecting materials and practices, and, Silently legitimizing.

\section{Talking about practice}

First, specifically in the mode of talking about practice, practitioners went beyond what was required in order to merely accomplish the task at hand, which contributed to the practice's reproduction or stabilisation (Gherardi, 2012b). Practitioners negotiated the practice boundaries through discussing what was considered pertaining to the practice of medication review, but also how to perform it competently in the ED. Thus, talk about practice was the mode where practitioners engaged in 'theorizing' about the practice; here, healthcare practitioners offered their practical reasoning about the potential benefits of doing medication review. Also, the normative dimension of the practice was reproduced in and through exchanges about the 'acceptable' conduct of this practice. Further, in practitioners' appraisals of their own actions can be expressed. Both these discursive practices are viewed as mechanisms to perpetuate or stabilize a practice through practitioners' making themselves accountable (Rouse, 2007).

However, talk about practice was less evident in interprofessional situations. As shown in articles 2 and 3, understandings of activities composing medication review, or what was valued or contended in the practice, were not regularly discussed; not making practitioners' own reasonings of their doings 'publicly available' through discourse, can be interpreted as not fully sharing a practice. When the knowing-in-practice could not be shared, or knowledge was 'sticky' (Brown and Duguid, 2001), opportunities for professional and interprofessional learning, but also for changing a 
practice, were not realized. In both settings, healthcare practitioners did not have equal professional standing, also in that discursive practices reflected a medical (physician) dominance. This was evident both in nursephysician interactions in the ED and between pharmacists and surgeons in the surgery wards.

\section{Interconnecting materials and practices}

Second, of further relevance to processes of implementing and embedding a (new) practice were sociomaterial entanglements, or how material entities are and became parts of social phenomena. As shown in articles 1, 2, and 3, implementing medication review and embedding it in routine practice can be understood as occurring through the 'setting up' of interconnections between material entities and practices. Here, materials that are mobilized into and used in the practice of medication review always are also social, that is, they involve 'togetherness and withness of human beings' (Schatzki, 2010: 128). As previously discussed in the section on the practicing of medication review, artifacts such as the pharmacist recommendations came to 'participate' in the practice in the surgery wards as the situated meanings of these artifacts changed over time. This means that embedding medication review requires much more than just making these artifacts to be ready at hand. What is required are sites of social life where practitioners work, interact, and coexist intelligibly (Schatzki, 2005); what is needed, then, for embedding (and perpetuating), for instance, the use of certain artifacts, is to make that material entities and actions 'hang together' in practice (Schatzki, 2010).

In the ED setting, likewise, materials had to be actively mobilized into the 'embedding' of medication review. This was done locally by creating written prompts on dictation sheets in order to remind physicians to systematically document medication activities. Some of the artifacts provided by the regional implementation group, such as a special template to document medication information, were not entered into medication review practices as they were considered 'impractical' in routine use. Still another artifact, a checklist to agree upon how to coordinate tasks among ED teams, was less effective with respect to explicitly dividing up work tasks (as this was vulnerable to how work flow in the ED team developed on each shift); however, the checklist, besides mobilizing 'a sense of teamness', acted as prompt, providing cues to remind team members of the importance of reviewing medication lists.

Finally, a further aspect of the role of sociomaterial entanglements in embedding medication review concerns the ways how patients participate in the practice. As argued by Schatzki (2005), it is through individuals' being incorporated into, and their carrying forward the practice, that the practice is perpetuated. Nevertheless, the findings based on observations 
and interviews conducted in this thesis indicate that patients participate to a very limited extent only in medication review. Rather, their limited participation contributes to upholding a practice that seldom affords them a way to contribute with their knowledge, orientations, or understandings of 'acceptable' practice.

\section{Silently legitimizing}

Third, conducting medication review in a uniform and highly structured way was 'resisted' through silently legitimizing or non-sanctioning (Bjørkeng et al., 2009) a less structured way of practicing or forms that involved adapting medication review. Such adaptations, including not doing medication review at all, were more frequent in situations with high-workload, or, in cases with patients presenting with complex or uncertain health conditions. Adaptations then involved actions such as practitioners redefining a patient's 'need' for receiving medication review or weighing the benefits of conducting medication review against a competing intervention. Although these practices of 'adaptation' often proceeded equally 'silent' (that is, were not made publicly accountable through discourse), perpetuation of not doing or modifying medication review in a specific way occurred through mutual accountability; this meant that not performing medication review in a highly structured way was accountable to other practitioners as sensible, or as conforming to practitioners' shared understanding of appropriate conduct of medication review in these situations.

\section{Methodological contribution}

This thesis makes a methodological contribution by providing an alternative perspective on studying the implementation of a healthcare intervention in routine hospital work. Using ethnographic methods combined with a methodological practice-based sensitivity represents a novel approach to understand and study implementation in healthcare settings in order to better take into account the social accomplishment of such endeavors.

What a practice-theoretical approach offers is a different way to grasp, discuss, examine, challenge, or put into use various ideas and concepts relevant to implementation research. Using ethnographic methods and interrogating the data with several practice-theoretical concepts was useful for critically examining various assumptions and ideas dominating implementation research and broadening the understanding of concepts of knowledge, action, and change, all relevant in implementation research.

\section{Zooming in on practice}

Using a practice-theoretical perspective offers alternative conceptions of knowledge and learning; assuming that knowledge does not have a fixed or 
pre-given meaning, but rather is mobilized and elaborated collectively, directs attention to the ways knowledge is bound up with objects, artifacts, or other actors in a situation (Gherardi, 2006). Knowledge from a practicetheoretical perspective, then, is recast as an epistemology of practice, or as knowing as doing, instead of knowledge as possession (Brown and Duguid, 2001). This focus on the processual character of knowledge, and its practical and situated nature tied to actions, understood as knowing-in-practice, offers a broader view than more traditional, mentalist and individualist conceptions; while the latter rest on representational, rational, calculative, abstract, and cognitive understandings of knowledge, a practice-theoretical conception invites to explore knowledge comprising of broader dimensions. Several examples of the practical and situated knowledge, as well as of the collective knowledgeable doing of medication review in the ED were shown, such as ways of identifying a patient's actual medication use, or the discursive carrying forward in the management of a patient's medication problem at hand. Practicing medication review, then, draws on much more than pharmacological knowledge, as practice can be understood as 'action informed by meaning drawn from a particular group context' (Cook and Brown, 1999: 387).

Schatzki's $(1996,2002)$ theory of practice emphasizes the centrality of practical knowledge as the ability to go on unhindered when carrying out a practice. Particularly the notion of practical intelligibility, that is, what makes sense to do, proved relevant when examining everyday work practices; using this notion directed my attention to the particular circumstances and phenomena of teleology and affectivity, the orientations toward ends, and to why specific things matter in relation to actions; as practical intelligibility is conceived as being not the same as rationality (Schatzki, 2001), using such a practice-theoretical perspective opens up studying practices departing from assumptions of humans as 'rational actors' or doings as behaviour based on reasonings, mental states, or individual decisions. In the above considerations of the knowledge implicated in a practice, the entanglements with material objects and artifacts and action come to the fore. These dynamics were explored and discussed providing illustrations of the sociomaterial coordination of medication review among several professional groups and material entities in the surgery wards.

A practice-theoretical approach, further, emphasizes processes of habituation and repetition, as well as the entrenched nature of practice (Warde, 2005); this, then, led my attention to the often taken-for-granted character of conventions, traditions, or informal rules and how they came to bear on local routines (Feldman, 2000). Using observations of the dayto-day work practices and shadowing various practitioners over a longer period of time made it possible to attend to the variations and iterations of the practices; also, it was possible to follow how practitioners reacted to or 
reflected on specific variations, disruptions, or changes in these routines. This was particularly useful in routines such as handovers, pre-ward round briefings, ward rounds, or discharge planning meetings, where, for instance 'problem-ness' with respect to medications was constructed or negotiated.

Drawing on a practice-based perspective was helpful in exploring the dynamics of embedding medication review. It has been argued that practices themselves are the site of continuing refinement and innovation (Brown and Duguid, 1991; Nicolini, 2011). This directed attention to the entanglements of processes of performing medication review and embedding processes. This rests on the proposition that discursive and reflective practices (such as talking in and about a practice, legitimizing practice standards, explain practice variations) contribute to a practice's continuation or refinement (Gherardi, 2011). This also includes questions of how knowledge is linked to practice, and how knowledge is shared and distributed. The tight coupling between practicing medication review and its embedding was shown. Both in the ED and in the department of surgery, embedding medication review, rather than devising or following 'detailed blueprints for action' (Blackler, 1993: 880), comprised processes of improvising and adjusting, often in reaction to disruptions and uncertainties. Embedding medication review at both sites involved renegotiations of understandings, rules, and the division of work, as well as challenging established codes of conduct and professional roles Also, it required constant repair work in order to adapt plans and routines. These embedding practices were seldom occurring in formal implementation meetings, but rather were accomplished in practicing medication review.

In summary, applying a practice-theoretical perspective was useful as it afforded a different 'practicality'. As suggested by Gergen (1978), the value or the practicality of theories does not lie in their conceptual labels, but rather in the questions they raise. Based on such an understanding, using practice theory was helpful for questioning taken-for-granted ideas and assumptions related to studying implementation. In this manner, this thesis, hopefully, can contribute to offer alternatives for dealing with implementation problems.

\section{Theoretical reflections}

\section{Medication review - a complex undertaking}

It is recommended to conduct medication review in a structured and systematic way (Willeboordse et al., 2017). However, performing medication review is complex as it involves many different, often interdependent, variably demanding tasks. These include the verification and clarification of a 
current medication list, the reconciliation of medicines, the identification of potential medication-related problems, and the recommendation of, or actual accomplishment of any subsequent required medication therapy changes.

Conducting medication review is challenging as it requires assessing the appropriateness of a specific medication for an individual patient, weighing benefits and harms (Mast et al., 2015; Cadogan et al., 2016a); but it also involves the competent use of materials and artifacts, such as tools to conduct safe medication orders or check drug-interactions (Smith et al., 2016; Niehoff et al., 2016; Willeboordse et al., 2018). Added to that, medication reconciliation and medication review also presume effective forms of coordination and collaboration between the different healthcare practitioners involved (Chen and de Almeida Neto, 2007; Kwint et al., 2013) and some form of patient participation (Willeboordse et al., 2014).

Medication review, therefore, is a highly social activity and is organized in and through an ongoing discourse and the use of various tools. Thus, as this research has illustrated, rather than understanding it as a medical or technical intervention, analyzing medication review from a practice perspective broadens the understanding. Rather than seeing it as an intervention, it can be conceptualized as a practice, that is, as 'organised constellation of different people's activities' and as rooted in human activity (Schatzki, 2012: 13).

\section{Medication-related problems in everyday clinical practice}

The empirical findings of this research point to the centrality of dealing with medication-related problems when conducting and embedding medication review. Both practicing and embedding medication review were shaped by how medication-related problems and potential medication harms were constructed, contested, and negotiated in practice. Practitioners' everyday actions and practices revealed different meanings attached to the concept of medication-related problem, both within and, even more so, between professional groups. Interestingly, the technical term itself was rarely used by the healthcare professionals participating in this research. Actions in response to recognizing potential medication-related problems, practitioners' doings and sayings, including written text, differed in how healthcare professionals signalled 'problem-ness' to each other. This included reporting a medication problem, making actions accountable to others by providing a reason for changing a specific medication through documentation, discussing a potential problem with a patient, singling out a specific problem to others, or asking another healthcare professional for advice. Thus, it was shown that healthcare professionals' conceptions of and reactions to medication-related problems had consequences with respect to daily work routines, professional roles, and the division of work. 
Revisiting and discussing the empirical findings, embedding medication review seems to have heightened awareness of potential benefits and harms related to medication use in the settings studied. Nevertheless, it was also shown that practices of dealing with medication-related problems in routine healthcare involve challenges when it comes to making such problems recognizable to others. For example, practitioners were not always observably displaying that they were handling a medication-related problem, nor were they regularly accounting for how they made sense of a potential medication-related problem. This has implications for the provision of healthcare services and strategies to regulate patient safety.

\section{Implications}

\section{Implications for healthcare practice and policy}

It has been argued that conceptions of risk and patient safety, rather than being fixed or preconceived, are being constructed in clinical practice and shaped by professional cultures (Waring, 2009; ). Differing definitions and classifications of patient safety concepts and terms can affect practice, and, as a consequence, healthcare outcomes (Runciman, 2006). It has been shown that different definitions and understandings of medication errors affected the ways in which practitioners made sense of information; this had implications for the conduct of medical documentation and organizational routines of incidence reporting, which in turn compromised medication safety practices and learning (Tamuz et al., 2004). Also, different understandings of medication-related harm between professional groups can affect professional interactions and relations in terms of impeding interprofessional cooperation (van Mil et al., 2016).

Health policy actors have recognized that differing definitions and understandings of patient safety concepts can have impacts on healthcare quality and safety; efforts are, therefore, being directed towards improving the reporting of patient safety incidents with the aim of learning from failures in healthcare (McElroy et al., 2016). Similar work is being conducted in the area of medication safety, with a focus on harmonizing terminology and classification of medication-related harm in order to improve monitoring and reporting (Falconer et al., 2018).

Questions of uniform terminology or classification of medication harms are not within the scope of this thesis. However, other aspects of categorization, such as the ways certain things are singled out by practitioners and the consequences these categorizations have are relevant to issues studied in this thesis. How practitioners react to problems and how professional practices are organized is highly relevant as this can affect the service quality of organizations (Bevan and Hood, 2006). Practitioners co- 
construct medication risk and safety in everyday working practices, and medication safety practices are contextualized in a range of social interactions where medication-related risks are being negotiated (Farre et al., 2017). Also, it was emphasized that frontline clinicians should be engaged in providing input on the differing functional meanings of medication-related terms when developing medication safety improvement strategies (Yu et al., 2005).

This thesis argues that it is consequential how healthcare professionals understand their daily work in terms of recognizing and dealing with medication-related problems. How practitioners understand, but even more so, how they then collectively address and make accountable their actions to deal with medication-related problems, has relevance with respect to the quality and safety of healthcare services.

Rather than attempting to implement medication review as a highly structured and formalized intervention (da Costa et al., 2016; Frankenthal et al., 2017; Lenander et al., 2018), efforts should make use of the sensemaking work involved when practitioners engage with medication-related problems. Sensemaking, here, is not being understood as a mere cognitive interpretative process, but also taking action based on such sensemaking (Sandberg and Tsoukas, 2015). Likewise, when embedding medication review, involving frontline practitioners in reflecting on possibilities for adapting medication review routines to fit the local context makes it possible to learn from implementation processes (Sausman et al., 2016).

\section{Implications for implementation research}

Given the significance of medication-related harm, pushes to implement effective strategies to improve the quality and safety of medication therapy in healthcare settings will continue (WHO, 2017). Implementing and embedding new practices will remain demanding due to the complexity, not only of the practices, but also of the systems these are embedded in (Greenhalgh and Papoutsi, 2018).

However, existent conceptions and ideas in implementation research about how implementation 'works', how knowledge is being used and spread, and how knowledge connects to practice, are not unproblematic. Extant frameworks and concepts can prefigure the ways a phenomenon can be understood, how empirical material about it can be gathered and analyzed, in short, how scientific knowledge is being 'made' (Latour and Woolgar, 1986; Knorr Cetina, 1999; Shotter and Gergen, 1994). Thus, understandings based on extant frameworks not only critically shape how concepts of implementation are being articulated, they also affect how implementation research, the planning and conduct of implementation studies, is organized. The frameworks, models and theories proposed and used in 
implementation research are not just 'cognitive tools'. These frameworks and models not only represent an idea of how implementation works; they also function as knowledge artifacts or epistemic objects (Knorr Cetina, 1999). As epistemic objects they can contribute to knowledge in that they structure epistemic practices, that is, they can be used as ready-made instruments, but also serve as objects of inquiry that invite further exploration and transformation (Knorr Cetina, 2001). But epistemic objects are also consequential with respect to how problem areas are singled out and which problem-solving strategies are mobilized within a professional or research community (Nerland and Jensen, 2012).

Thus, by the continuing application of these implementation frameworks or constructs, specific conceptions and knowledge claims will be 'privileged' and become stabilized, others will be 'bracketed out'. There is a need, then, particularly in qualitative implementation research, to broaden approaches to study implementation processes, not limited to 'identifying' factors or determinants 'out there', and treating them as pre-given categories, ready to be discovered and confirmed (Przyborski and Slunecko, 2009). Drawing on a practice-theoretical perspective brought to the fore alternative views on knowledge and how it can be shared, as well as on the relationship between knowledge and practice. Practice, then, becomes inseparable from examining the knowledge involved, including the practical and ethical judgements, but also the bodies, materials, and discourses bound up with practice. Thus, this calls for approaches in implementation research that, rather than 'bridge the theory-practice gap', explore how theory, or the knowing, and practice hang together.

\section{Concluding remarks}

\section{Future research directions}

Given the complexity of implementation problems, research approaches that allow for sufficient degrees of freedom for studying implementation are required. This means that alternative approaches are needed where concepts, ideas, models or artifacts, such as implementation frameworks, are used in a question-generating way (Knorr Cetina, 2001). In terms of 'turning to practice', future approaches to study implementation in healthcare should enable the development of theory from a perspective of the actors practically involved.

Therefore, 'implementation practitioners', that is, researchers, policy actors, planners, but also frontline practitioners, should be able to engage with and manipulate these ideas and frameworks. Implementation research should, therefore, involve theses practitioners early on in planning 
and throughout embedding a practice. Future endeavours in implementation research should, thus, (re)turn to practice by attending to the practices of these practitioners so that 'practitioners practically turn theoretical, theorists work practice based, practically' (Eikeland and Nicolini, 2011: 170).

With respect to the need for alternative and broadened research approaches, future implementation research would also benefit from the active participation of patients. This also echoes calls for the involvement of patients in the design and implementation of healthcare interventions (Boaz et al., 2016).

\section{Conclusions}

In this thesis, I argued that an alternative perspective is needed to better understand the implementation of healthcare interventions. Drawing on case examples of medication review implementation at two regional hospitals in southeast Sweden, ethnographic methods were used to theorize the practicing of medication review and its embedding into routine hospital work. Empirically, in-depth insight into the everyday practicing of medication review was provided, shedding light on the relevant knowledge involved, the practical concerns, as well as the ends, tasks, and competencies considered acceptable. In doing so, the ways in which medication-related problems were constructed and negotiated in practice were shown, bringing to the fore the contested and conflictual nature of the practice. Also, insight was provided into how practices to embed medication review in routine hospital work unfolded, revealing material-discursive and reflective practices, but also silent modes of legitimizing 'non-practicing' medication review in a highly structured way. Methodologically, employing ethnographic methods and interrogating the data with several practice-theoretical concepts with a so-called toolkit approach were useful for critically examining and broadening the understanding of the concepts of knowledge, action, and change, all central when studying implementation.

This thesis challenges various assumptions underpinning implementation research and, instead, suggests a broadened perspective directing attention to the practical and situated knowing involved, the local processes of negotiating objectives in practice, as well as to the meaning-making required when practitioners engage with a practice. Finally, there are opportunities to learn from implementation processes when frontline practitioners involved in embedding medication review are able to reflect on adapting medication review to make routines better fit the local context. 
Embedding Medication Review in Clinical Practice 


\section{REFERENCES}

Acheampong F, Anto BP and Koffuor GA. (2014) Medication safety strategies in hospitals--a systematic review. Int J Risk Saf Med 26: 117-131.

Albers B, Mildon R, Lyon AR, et al. (2017) Implementation frameworks in child, youth and family services - Results from a scoping review. Children and Youth Services Review 81: 101-116.

Albrecht L, Archibald M, Arseneau D, et al. (2013) Development of a checklist to assess the quality of reporting of knowledge translation interventions using the Workgroup for Intervention Development and Evaluation Research (WIDER) recommendations. 8: 52.

Alvesson M. (2003) Methodology for close up studies - struggling with closeness and closure. Higher Education 46: 167-193.

Alvesson M and Kärreman D. (2007) Constructing Mystery: Empirical Matters in Theory Development. The Academy of Management Review 32: 1265-1281.

Alvesson M and Sandberg J. (2011) Generating research questions through problematization. Academy of Management Review 36: 247-271.

Alvesson M and Sköldberg K. (2009) Reflexive methodology: new vistas for qualitative research. 2. ed., Los Angeles ; London: SAGE.

Anell A, Glenngård AH and Merkur S. (2012) Sweden: Health system review. Health Systems in Transition 14: 1-159.

Angamo MT, Chalmers L, Curtain CM, et al. (2016) Adverse-Drug-ReactionRelated Hospitalisations in Developed and Developing Countries: A Review of Prevalence and Contributing Factors. Drug Safety 39: 847-857.

Antonacopoulou EP, Dehlin E and Zundel M. (2011) The Challenge of Delivering Impact: Making Waves Through the ODC Debate. Journal of Applied Behavioral Science 47: 33-52.

Aronson JK. (2009) Medication errors: what they are, how they happen, and how to avoid them. Qjm-an International Journal of Medicine 102: 513-521.

Atkinson P, Coffey A, Delamont S, et al. (2007) Handbook of Ethnography, London, England: SAGE Publications Ltd.

Avis J. (2009) Transformation or transformism: Engeström's version of activity theory? Educational Review 61: 151-165.

Baker CD and Johnson G. (1998) Interview Talk as Professional Practice. Language and Education 12: 229-242.

Baker R, Camosso-Stefinovic J, Gillies C, et al. (2015) Tailored interventions to address determinants of practice. Cochrane Database Syst Rev 4.

Baker R, Camosso-Stefinovic J, Gillies C, et al. (2010) Tailored interventions to overcome identified barriers to change: effects on professional practice and health care outcomes. The Cochrane database of systematic reviews (3):CDoo5470. doi: CDoo5470.

Bandura A. (1986) Social foundations of thought and action: A social cognitive theory, Englewood Cliffs, NJ: Prentice-Hall.

Barley SR and Kunda G. (2001) Bringing work back in. Organization Science 12: 76-95. 
Barnes B. (2001) Practice as collective action. In: Schatzki TR, Knorr Cetina K and von Savigny E (eds) The Practice Turn in Contemporary Theory. London: Routledge, 25-36.

Bauer MS, Damschroder L, Hagedorn H, et al. (2015) An introduction to implementation science for the non-specialist. BMC psychology 3: 32-32.

Berger PL and Luckmann T. (1966) The Social Construction of Reality: A Treatise in the Sociology of Knowledge, New York City, NY: Anchor Books.

Bevan G and Hood C. (2006) What's measured is what matters: Targets and gaming in the English public health care system. Public Administration 84: 517-538.

Billett S, Smith R and Barker M. (2005) Understanding work, learning and the remaking of cultural practices. Studies in Continuing Education 27: 219-237.

Birken SA, Bunger AC, Powell BJ, et al. (2017a) Organizational theory for dissemination and implementation research. Implementation Science 12: 62.

Birken SA, Powell BJ, Shea CM, et al. (2017b) Criteria for selecting implementation science theories and frameworks: results from an international survey. Implementation Science 12: 9.

Birken SA, Rohweder CL, Powell BJ, et al. (2018) T-CaST: an implementation theory comparison and selection tool. Implementation Science 13: 143.

Bjørkeng K, Clegg S and Pitsis T. (2009) Becoming (a) Practice. Management Learning 40: 145-159.

Blackler F. (1993) Knowledge and the Theory of Organizations: Organizations as Activity Systems and the Reframing of Management Studies. Journal of Management Studies 30: 863-884.

Blackler F. (1995) Knowledge, knowledge work and organizations: An overview and interpretation. Organization Studies 16: 1021-1046.

Blix HS, Viktil KK, Moger TA, et al. (2006) Characteristics of drug-related problems discussed by hospital pharmacists in multidisciplinary teams. Pharm World Sci 28: 152-158.

Blumer H. (1969) Symbolic interactionism : perspective and method, Englewood Cliffs, N.J.: Prentice-Hall.

Boaz A, Robert G, Locock L, et al. (2016) What patients do and their impact on implementation: An ethnographic study of participatory quality improvement projects in English acute hospitals. Journal of Health Organization and Management 30: 258-278.

Bourdieu P. (1977) Outline of a theory of practice, Cambridge: Cambridge Univ. Press.

Braun V and Clarke V. (2006) Using thematic analysis in psychology. Qualitative Research in Psychology 3: 77-101.

Brown CH, Curran G, Palinkas LA, et al. (2017) An Overview of Research and Evaluation Designs for Dissemination and Implementation. Annu Rev Public Health 38: 1-22.

Brown JS and Duguid P. (1991) Organizational Learning and Communities-ofPractice: Toward a Unified View of Working, Learning, and Innovation. Organization Science 2: 40-57.

Brown JS and Duguid P. (2001) Knowledge and Organization: A Social-Practice Perspective. Organization Science 12: 198-213.

Bruni A, Gherardi S and Parolin LL. (2007) Knowing in a System of Fragmented Knowledge. Mind, Culture, and Activity 14: 83-102.

Bulajeva A, Labberton L, Leikola S, et al. (2014) Medication review practices in European countries. Res Social Adm Pharm 10: 731-740. 
Cadogan CA, Ryan C, Francis JJ, et al. (2016b) Development of an intervention to improve appropriate polypharmacy in older people in primary care using a theory-based method. BMC Health Serv Res 16: 661.

Cadogan CA, Ryan C and Hughes CM. (2016a) Appropriate Polypharmacy and Medicine Safety: When Many is not Too Many. Drug Saf 39: 109-116.

Callon M. (1986) Some elements of a sociology of translation: domestication of the scallops and the fishermen of St. Brieuc Bay. In: Law JE (ed) Power, action, and belief: A new sociology of knowledge. London: Routledge.

Canary HE. (2010) Structurating Activity Theory: An Integrative Approach to Policy Knowledge. Communication Theory 20: 21-U61.

Cecez-Kecmanovic D, Galliers RD, Henfridsson O, et al. (2014) The sociomateriality of information systems : current status, future directions MIS Quarterly 38: 809-830.

Charlesworth CJ, Smit E, Lee DSH, et al. (2015) Polypharmacy Among Adults Aged 65 Years and Older in the United States: 1988-2010. The journals of gerontology. Series A, Biological sciences and medical sciences 70: 989-995.

Charmaz K. (2014) Constructing Grounded Theory. 2nd Edition, London: SAGE Publications Ltd.

Cheema E, Alhomoud FK, Kinsara ASA, et al. (2018) The impact of pharmacistsled medicines reconciliation on healthcare outcomes in secondary care: A systematic review and meta-analysis of randomized controlled trials. PLoS One 13: e0193510.

Chen TF and de Almeida Neto AC. (2007) Exploring elements of interprofessional collaboration between pharmacists and physicians in medication review. Pharm World Sci 29: 574-576.

Christensen M and Lundh A. (2016) Medication review in hospitalised patients to reduce morbidity and mortality. Cochrane Database Syst Rev 2: Cdoo8986.

Clay BJ, Halasyamani L, Stucky ER, et al. (2008) Results of a Medication Reconciliation Survey from the 2006 Society of Hospital Medicine National Meeting. Journal of Hospital Medicine 3: 465-472.

Cohen MR, Smetzer JL and Vaida AJ. (2018) ASHP guidelines on preventing medication errors in hospitals: Advancing medication safety to the next level. Am J Health Syst Pharm 75: 1444-1445.

Cohn S. (2014) From health behaviours to health practices: an introduction. Sociology of Health \& Illness 36: 157-162.

Colquhoun H, Leeman J, Michie S, et al. (2014) Towards a common terminology: a simplified framework of interventions to promote and integrate evidence into health practices, systems, and policies. Implementation Science 9: 6.

Cook SDN and Brown JS. (1999) Bridging epistemologies: The generative dance between organizational knowledge and organizational knowing. Organization Science 10: 381-400.

Corradi G, Gherardi S and Verzelloni L. (2010) Through the practice lens: Where is the bandwagon of practice-based studies heading? Management Learning 41: 265-283.

Cossette B, Bergeron J, Ricard G, et al. (2016) Knowledge Translation Strategy to Reduce the Use of Potentially Inappropriate Medications in Hospitalized Elderly Adults. J Am Geriatr Soc 64: 2487-2494.

Craftman AG, Johnell K, Fastbom J, et al. (2016) Time trends in 20 years of medication use in older adults: Findings from three elderly cohorts in Stockholm, Sweden. Arch Gerontol Geriatr 63: 28-35. 
da Costa FA, Silvestre L, Periquito C, et al. (2016) Drug-Related Problems Identified in a Sample of Portuguese Institutionalised Elderly Patients and Pharmacists' Interventions to Improve Safety and Effectiveness of Medicines. Drugs Real World Outcomes 3: 89-97.

Damschroder LJ, Aron DC, Keith RE, et al. (2009) Fostering implementation of health services research findings into practice: a consolidated framework for advancing implementation science. Implementation science : IS 4: 50-59085904-5950.

Davies H, Nutley S and Walter I. (2008) Why 'knowledge transfer' is misconceived for applied social research. Journal of Health Services Research and Policy 13: 188-190.

Davies P, Walker AE and Grimshaw JM. (2010) A systematic review of the use of theory in the design of guideline dissemination and implementation strategies and interpretation of the results of rigorous evaluations. Implementation Science 5: 14.

Dechanont S, Maphanta S, Butthum B, et al. (2014) Hospital admissions/visits associated with drug-drug interactions: a systematic review and metaanalysis. Pharmacoepidemiology and Drug Safety 23: 489-497.

Eccles MP, Armstrong D, Baker R, et al. (2009) An implementation research agenda. Implementation Science 4: 7.

Edwards A and Daniels H. (2012) The knowledge that matters in professional practices. Journal of Education and Work 25: 39-58.

eHälsomyndigheten. (2018) Frågor och svar - Nationella läkemedelslistan [Questions and Answers - The National Medication List]. In: Socialdepartementet (ed). Stockholm: eHälsomyndigheten [Swedish eHealth Agency].

Eikeland O and Nicolini D. (2011) Turning practically: broadening the horizon. Journal of Organizational Change Management 24: 164-174.

Emerson RM. (2009) Ethnography, interaction and ordinary trouble. Ethnography 10: 535-548.

Emerson RM, Fretz RI and Shaw LL. (2011) Writing ethnographic fieldnotes. 2nd ed, Chicago: University of Chicago Press.

Engeström Y. (1995) Objects, contradictions and collaboration in medical cognition: an activity-theoretical perspective. Artificial intelligence in medicine 7: 395-412.

Engeström Y. (2000) Activity theory as a framework for analyzing and redesigning work. Ergonomics 43: 960-974.

Engeström Y. (2001) Expansive Learning at Work: Toward an activity theoretical reconceptualization. Journal of Education and Work 14: 133-156.

Engeström Y and Blackler F. (2005) On the life of the object. Organization 12: 307-330.

Engeström Y and Sannino A. (2010) Studies of expansive learning: Foundations, findings and future challenges. Educational Research Review 5: 1-24.

Engeström Y and Sannino A. (2011) Discursive manifestations of contradictions in organizational change efforts A methodological framework. Journal of Organizational Change Management 24: 368-387.

Falconer N, Barras M, Martin J, et al. (2018) Defining and classifying terminology for medication harm: a call for consensus. Eur J Clin Pharmacol.

Farre A, Shaw K, Heath G, et al. (2017) On doing 'risk work' in the context of successful outcomes: exploring how medication safety is brought into action 
through health professionals' everyday working practices. Health, Risk \& Society 19: 209-225.

Feldman MS. (2000) Organizational routines as a source of continuous change. Organization Science 11: 611-629.

Feldman MS and Orlikowski WJ. (2011) Theorizing Practice and Practicing Theory. Organization Science 22: 1240-1253.

Fenwick T, Nerland M and Jensen K. (2012) Sociomaterial Approaches to Conceptualising Professional Learning and Practice. Journal of Education and Work 25: 1-13.

Fleuren M, Wiefferink K and Paulussen T. (2004) Determinants of innovation within health care organizations - Literature review and Delphi study. International Journal for Quality in Health Care 16: 107-123.

Fleuren MAH, Paulussen T, Van Dommelen P, et al. (2014) Towards a measurement instrument for determinants of innovations. International Journal for Quality in Health Care 26: 501-510.

Flottorp SA, Oxman AD, Krause J, et al. (2013) A checklist for identifying determinants of practice: A systematic review and synthesis of frameworks and taxonomies of factors that prevent or enable improvements in healthcare professional practice. Implementation Science 8: 35 .

Flyvbjerg B. (2006) Five misunderstandings about case-study research. Qualitative Inquiry 12: 219-245.

Franchi C, Tettamanti M, Pasina L, et al. (2014) Changes in drug prescribing to Italian community-dwelling elderly people: the EPIFARM-Elderly Project 2000-2010. European Journal of Clinical Pharmacology 70: 437-443.

Frankenthal D, Israeli A, Caraco Y, et al. (2017) Long-Term Outcomes of Medication Intervention Using the Screening Tool of Older Persons Potentially Inappropriate Prescriptions Screening Tool to Alert Doctors to Right Treatment Criteria. J Am Geriatr Soc 65: e33-e38.

Freyer J, Hueter L, Kasprick L, et al. (2018) Drug-related problems in geriatric rehabilitation patients after discharge - A prevalence analysis and clinical case scenario-based pilot study. Research in Social and Administrative Pharmacy 14: 628-637.

Garfinkel H. (1967) Studies in Ethnomethodology, Englewood Cliffs, NJ: Prentice-Hall.

Geiger D. (2009) Revisiting the Concept of Practice: Toward an Argumentative Understanding of Practicing. Management Learning 40: 129-144.

Gergen KJ. (1978) Toward Generative Theory. Journal of Personality and Social Psychology 36: 1344-1360.

Gherardi S. (2000) Practice-based theorizing on learning and knowing in organizations. Organization 7: 211-223.

Gherardi S. (2001) From organizational learning to practice-based knowing. Human Relations 54: 131-139.

Gherardi S. (2006) Organizational Knowledge: The Texture of Workplace Learning, Malden, MA: Wiley-Blackwell.

Gherardi S. (2008) Situated Knowledge and Situated Action: What do PracticeBased Studies Promise? In: Barry D and Hansen H (eds) The Sage Handbook of New Approaches to Organization Studies. London: Sage, 516-527.

Gherardi S. (2011) Organizational Learning: The Sociology of Practice, Italy, Europe: Blackwell Publishing.

Gherardi S. (2012a) How to Conduct a Practice-based Study. Problems and Methods, Cheltenham, UK, Northampton, MA, USA: Edward Elgar. 
Gherardi S. (2012b) Docta ignorantia: Professional knowing at the core and at the margins of a practice. Journal of Education and Work 25: 15-38.

Gherardi S. (2015) How the Turn to Practice may contribute to Working Life Studies. Nordic Journal of Working Life Studies 5: 13-25.

Gherardi S. (2016) To start practice theorizing anew: The contribution of the concepts of agencement and formativeness. Organization 23: 680-698.

Gherardi S. (2017) One turn ... and now another one: Do the turn to practice and the turn to affect have something in common? Management Learning 48: 345-358.

Giddens A. (1984) The constitution of society : outline of the theory of structuration, Cambridge: Polity Press.

Gill R. (2011) The shadow in organizational ethnography: moving beyond shadowing to spect-acting. Qualitative Research in Organizations and Management: An International Journal 6: 115-133.

Glasgow RE, Klesges LM, Dzewaltowski DA, et al. (2006) Evaluating the impact of health promotion programs: using the RE-AIM framework to form summary measures for decision making involving complex issues. Health Educ Res 21: 688-694.

Glasgow RE, Vogt TM and Boles SM. (1999) Evaluating the public health impact of health promotion interventions: the RE-AIM framework. Am J Public Health 89: 1322-1327.

Goedecke T, Ord K, Newbould V, et al. (2016) Medication Errors: New EU Good Practice Guide on Risk Minimisation and Error Prevention. Drug Safety 39: 491-500.

Government Offices of Sweden - Ministry of Health and Social Affairs and Swedish Association of Local Authorities and Regions. (2015) The National Pharmaceutical Strategy 2016-2018. Stockholm.

Greenhalgh T and Papoutsi C. (2018) Studying complexity in health services research: desperately seeking an overdue paradigm shift. Bmc Medicine 16: 6.

Greenhalgh T and Wieringa S. (2011) Is it time to drop the 'knowledge translation' metaphor? A critical literature review. Journal of the Royal Society of Medicine 104: 501-509.

Greig G, Entwistle VA and Beech N. (2012) Addressing complex healthcare problems in diverse settings: Insights from activity theory. Social Science \& Medicine 74: 305-312.

Greig G, Gilmore C, Patrick H, et al. (2013) Arresting moments in engaged management research. Management Learning 44: 267-285.

Griese-Mammen N, Hersberger KE, Messerli M, et al. (2018) PCNE definition of medication review: reaching agreement. International Journal of Clinical Pharmacy.

Gruman J, Rovner MH, French ME, et al. (2010) From patient education to patient engagement: Implications for the field of patient education. Patient Education and Counseling 78: 350-356.

Guthrie B, Makubate B, Hernandez-Santiago V, et al. (2015) The rising tide of polypharmacy and drug-drug interactions: Population database analysis 1995-2010. BMC Medicine 13.

Hager P, Lee A and Reich A. (2012) Practice, learning and change. practicetheory perspectives on professional learning, Dordrecht, New York: Springer. 
Hammar T, Ekedahl A and Petersson G. (2014) Implementation of a shared medication list: physicians' views on availability, accuracy and confidentiality. International Journal of Clinical Pharmacy 36: 933-942.

Hand M, Shove E and Southerton D. (2005) Explaining showering: a discussion of the material, conventional, and temporal dimensions of practice. Sociological Research Online 10: 22.

Harvey G and Kitson A. (2016) PARIHS revisited: from heuristic to integrated framework for the successful implementation of knowledge into practice. Implementation science 11: 33-33.

Heidegger M. (1978) Being and time, Oxford, UK: Blackwell.

Hermansen H. (2015) Knowledge work in the teaching profession: Opening up the black box of teachers' engagement with Assessment for Learning. Faculty of Educational Sciences, Department of Education. Oslo: University of Oslo

Hohl CM, Wickham ME, Sobolev B, et al. (2015) The effect of early in-hospital medication review on health outcomes: a systematic review. $\mathrm{Br} J$ Clin Pharmacol 80: 51-61.

Huiskes VJB, Burger DM, van den Ende CHM, et al. (2017) Effectiveness of medication review: a systematic review and meta-analysis of randomized controlled trials. BMC Family Practice 18: 5 .

Iedema R. (2007) On the multi-modality, materially and contingency of organization discourse. Organization Studies 28: 931-946.

Jarzabkowski P. (2003) Strategic Practices: An Activity Theory Perspective on Continuity and Change. Journal of Management Studies 40: 23-55.

Johnell K and Klarin I. (2007) The relationship between number of drugs and potential drug-drug interactions in the elderly: a study of over 600,000 elderly patients from the Swedish Prescribed Drug Register. Drug Saf 30: 911918.

Jubraj B, Marvin V, Poots AJ, et al. (2015) A pilot survey of junior doctors' attitudes and awareness around medication review: time to change our educational approach? Eur J Hosp Pharm Sci Pract 22: 243-248.

Juliano A, Lucchetti ALG, Silva J, et al. (2018) Inappropriate Prescribing in Older Hospitalized Adults: A Comparison of Medical Specialties. J Am Geriatr Soc 66: 383-388.

Jäger C, Freund T, Steinhäuser J, et al. (2017) Impact of a tailored program on the implementation of evidence-based recommendations for multimorbid patients with polypharmacy in primary care practices-results of a clusterrandomized controlled trial. Implementation Science 12: 8.

Jäger C, Szecsenyi J and Steinhauser J. (2015) Design and delivery of a tailored intervention to implement recommendations for multimorbid patients receiving polypharmacy into primary care practices. Biomed Res Int 2015: 938069.

Kalkan A, Sandberg J and Garpenby P. (2015) Management by Knowledge in Practice - Implementation of National Healthcare Guidelines in Sweden. Social Policy \& Administration 49: 911-927.

Karthikeyan M and Lalitha D. (2013) A prospective observational study of medication errors in general medicine department in a tertiary care hospital. Drug Metabol Drug Interact 28: 13-21.

Kemmis S. (2009) Understanding Professional Practice: A Synoptic Framework. In: Green B (ed) Understanding and Researching Professional Practice. Rotterdam, The Netherlands: Sense Publishers, 19-38. 
Kerstenetzky L, Birschbach MJ, Beach KF, et al. (2018) Improving medication information transfer between hospitals, skilled-nursing facilities, and longterm-care pharmacies for hospital discharge transitions of care: A targeted needs assessment using the Intervention Mapping framework. Research in Social \& Administrative Pharmacy 14: 138-145.

Kirby EL and Krone KJ. (2002) "The policy exists but you can't really use it": Communication and the structuration of work-family policies. Journal of Applied Communication Research 30: 50-77.

Kirk MA, Kelley C, Yankey N, et al. (2016) A systematic review of the use of the Consolidated Framework for Implementation Research. Implementation science : IS 11: 72-72.

Kitson AL, Rycroft-Malone J, Harvey G, et al. (2008) Evaluating the successful implementation of evidence into practice using the PARiHS framework: theoretical and practical challenges. Implementation Science 3: 1.

Knorr Cetina K. (1999) Epistemic Cultures: How the Sciences Make Knowledge, Cambridge, Mass.: Harvard University Press.

Knorr Cetina K. (2001) Objectual practice. In: Schatzki TR, Knorr Cetina K and von Savigny E (eds) The Practice Turn in Contemporary Theory. London: Routledge, 184-197.

Koschmann T, Kuutti K and Hickman L. (1998) The Concept of Breakdown in Heidegger, Leont'ev, and Dewey and Its Implications for Education. Mind, Culture, and Activity 5: 25-41.

Kwan Y, Fernandes OA, Nagge JJ, et al. (2007) Pharmacist medication assessments in a surgical preadmission clinic. Archives of Internal Medicine 167: 1034-1040.

Kwint HF, Bermingham L, Faber A, et al. (2013) The Relationship between the Extent of Collaboration of General Practitioners and Pharmacists and the Implementation of Recommendations Arising from Medication Review A Systematic Review. Drugs \& Aging 30: 91-102.

Lamy PP. (1991) Physiological changes due to age. Pharmacodynamic changes of drug action and implications for therapy. Drugs \& aging 1: 385-404.

Latour B. (1992) Reassembling the Social: An Introduction to Actor-NetworkTheory, Oxford: Oxford University Press.

Latour B. (1996) On Interobjectivity. Mind, Culture \& Activity 3: 228.

Latour B. (2000) When things strike back: A possible contribution of 'science studies' to the social sciences. British Journal of Sociology 51: 107-123.

Latour B and Woolgar S. (1986) Laboratory Life. The Construction of Scientific Facts, Princeton, New Jersey: Princeton University Press.

Lave J and Wenger E. (1991) Situated learning. Legitimate peripheral participation, Cambridge, MA: Cambridge University Press.

Leape LL, Brennan TA, Laird N, et al. (1991) The nature of adverse events in hospitalized patients. Results of the Harvard Medical Practice Study II. New England Journal of Medicine 324: 377-384.

Lee KP, Hartridge C, Corbett K, et al. (2015) "Whose job is it, really?" Physicians', nurses', and pharmacists' perspectives on completing inpatient medication reconciliation. $J$ Hosp Med 10: 184-186.

Leendertse AJ, Egberts AC, Stoker LJ, et al. (2008) Frequency of and risk factors for preventable medication-related hospital admissions in the Netherlands. Arch Intern Med 168: 1890-1896.

Lenander C, Bondesson A, Viberg N, et al. (2018) Effects of medication reviews on use of potentially inappropriate medications in elderly patients; a cross- 
sectional study in Swedish primary care. Bmc Health Services Research 18: 9 .

Lewis CC, Klasnja P, Powell BJ, et al. (2018a) From classification to causality: Advancing Understanding of Mechanisms of change in implementation science. Frontiers in Public Health 6: 6.

Lim D, Jung K and Shi Y. (2013) National trends in the use of antidepressants between 1997 and 2009 and the role of Medicare Part D implementation. Psychiatr Serv 64: 1038-1042.

Lisby M, Nielsen LP, Brock B, et al. (2010) How are medication errors defined? A systematic literature review of definitions and characteristics. International Journal for Quality in Health Care 22: 507-518.

Lisby M, Nielsen LP and Mainz J. (2005) Errors in the medication process: frequency, type, and potential clinical consequences. Great Britain: Oxford University Press, 15.

Llewellyn N. (2008) Organization in actual episodes of work: Harvey Sacks and organization studies. Organization Studies 29: 763-791.

Lokker C, McKibbon KA, Colquhoun H, et al. (2015) A scoping review of classification schemes of interventions to promote and integrate evidence into practice in healthcare. 10: 27.

Lynch EA, Mudge A, Knowles S, et al. (2018) "There is nothing so practical as a good theory": a pragmatic guide for selecting theoretical approaches for implementation projects. Bmc Health Services Research 18: 11.

Mahler C, Freund T, Baldauf A, et al. (2014) [Structured medication management in primary care - a tool to promote medication safety]. Z Evid Fortbild Qual Gesundhwes 108: 258-269.

Manias E, Rixon S, Williams A, et al. (2014) Barriers and enablers affecting patient engagement in managing medications within specialty hospital settings. Health Expect.

Mast R, Ahmad A, Hoogenboom SC, et al. (2015) Amsterdam tool for clinical medication review: development and testing of a comprehensive tool for pharmacists and general practitioners. BMC Research Notes 8: 642.

May C and Finch T. (2009) Implementing, Embedding, and Integrating Practices: An Outline of Normalization Process Theory. Sociology 43: 535554 .

May C, Finch T, Mair F, et al. (2007) Understanding the implementation of complex interventions in health care: The normalization process model. $B M C$ Health Serv Res 7.

McDonald S. (2005) Studying actions in context: a qualitative shadowing method for organizational research. Qualitative Research 5: 455-473.

McElroy LM, Woods DM, Yanes AF, et al. (2016) Applying the WHO conceptual framework for the International Classification for Patient Safety to a surgical population. Int $J$ Qual Health Care 28: 166-174.

McNab D, Bowie P, Ross A, et al. (2018) Systematic review and meta-analysis of the effectiveness of pharmacist-led medication reconciliation in the community after hospital discharge. BMJ Qual Saf 27: 308-320.

McTier L, Botti M and Duke M. (2015) Patient participation in medication safety during an acute care admission. Health Expectations 18: 1744-1756.

Meier F, Maas R, Sonst A, et al. (2015) Adverse drug events in patients admitted to an emergency department: an analysis of direct costs. Pharmacoepidemiology and Drug Safety 24: 176-186. 
Mekonnen AB, McLachlan AJ and Brien JE. (2016) Effectiveness of pharmacistled medication reconciliation programmes on clinical outcomes at hospital transitions: a systematic review and meta-analysis. BMJ Open 6.

Metz A and Bartley L. (2012) Active Implementation Frameworks for Program Success: How to Use Implementation Science to Improve Outcomes for Children. Zero to Three 32: 11-18.

Meyboom RH, Lindquist M and Egberts AC. (2000) An ABC of drug-related problems. Drug Saf 22: 415-423.

Michie S, Johnston M, Abraham C, et al. (2005) Making psychological theory useful for implementing evidence based practice: a consensus approach. Qual Saf Health Care 14: 26-33.

Michie S, van Stralen MM and West R. (2011) The behaviour change wheel: a new method for characterising and designing behaviour change interventions. Implementation Science 6: 42.

Miettinen R and Virkkunen J. (2005) Epistemic objects, artefacts and organizational change. Organization 12: 437-456.

Monahan T and Fisher JA. (2010) Benefits of "Observer Effects": Lessons from the Field. Qualitative research : $Q R$ 10: 357-376.

Moullin JC, Sabater-Hernández D, Fernandez-Llimos F, et al. (2015) A systematic review of implementation frameworks of innovations in healthcare and resulting generic implementation framework. Health Research Policy and Systems 13.

Murphy E and Dingwall R. (2007) Informed consent, anticipatory regulation and ethnographic practice. Soc Sci Med 65: 2223-2234.

Muth C, Uhlmann L, Haefeli WE, et al. (2018) Effectiveness of a complex intervention on Prioritising Multimedication in Multimorbidity (PRIMUM) in primary care: results of a pragmatic cluster randomised controlled trial. BMJ Open 8: e017740.

Nerland M and Jensen K. (2012) Epistemic practices and object relations in professional work. Journal of Education and Work 25: 101-120.

Nicolini D. (2006) The work to make telemedicine work: A social and articulative view. Social Science \& Medicine 62: 2754-2767.

Nicolini D. (2009) Zooming In and Out: Studying Practices by Switching Theoretical Lenses and Trailing Connections. Organization Studies 30: 13911418.

Nicolini D. (2011) Practice as the site of knowing: Insights from the field of telemedicine. Organization Science 22: 602-620.

Nicolini D. (2012) Practice Theory, Work, and Organization. An Introduction, Oxford, United Kingdom: Oxford University Press.

Nicolini D. (2017) Practice Theory as a Package of Theory, Method and Vocabulary: Affordances and Limitations. In: Jonas M, Littig B and Wroblewski A (eds) Methodological Reflections on Practice Oriented Theories. Cham, Switzerland: Springer 19-34.

Niehoff KM, Rajeevan N, Charpentier PA, et al. (2016) Development of the Tool to Reduce Inappropriate Medications (TRIM): A Clinical Decision Support System to Improve Medication Prescribing for Older Adults. Pharmacotherapy 36: 694-701.

Nilsen P, Ståhl C, Roback K, et al. (2013) Never the twain shall meet? - a comparison of implementation science and policy implementation research. Implementation Science 8: 63. 
O'Mahony D, O'Sullivan D, Byrne S, et al. (2015) STOPP/START criteria for potentially inappropriate prescribing in older people: version 2. Age Ageing 44: 213-218.

O'Toole LJ. (2000) Research on Policy Implementation: Assessment and Prospects. Journal of Public Administration Research and Theory: J-PART 10: 263-288.

Ocampo CC, Garcia-Cardenas V, Martinez-Martinez F, et al. (2015) Implementation of medication review with follow-up in a Spanish community pharmacy and its achieved outcomes. Int J Clin Pharm 37: 931-940.

OECD. (2018) Health at a Glance. OECD Indicators Paris: OECD Publishing.

Orlikowski WJ. (2000) Using Technology and Constituting Structures: A Practice Lens for Studying Technology in Organizations. Organization Science 11: 404-428.

Ortner SB. (1984) Theory in Anthropology since the Sixties. Comparative Studies in Society and History 26: 126-166.

Palinkas LA. (2014) Qualitative and Mixed Methods in Mental Health Services and Implementation Research. Journal of Clinical Child \& Adolescent Psychology 43: 851-861.

Palinkas LA and Zatzick D. (2018) Rapid Assessment Procedure Informed Clinical Ethnography (RAPICE) in Pragmatic Clinical Trials of Mental Health Services Implementation: Methods and Applied Case Study. Administration and Policy in Mental Health and Mental Health Services Research https://doi.org/10.1007/s10488-018-0909-3.

Patel TK and Patel PB. (2018) Mortality among patients due to adverse drug reactions that lead to hospitalization: a meta-analysis. European Journal of Clinical Pharmacology 74: 819-832.

Patey AM, Hurt CS, Grimshaw JM, et al. (2018) Changing behaviour 'more or less'-do theories of behaviour inform strategies for implementation and deimplementation? A critical interpretive synthesis. Implement Sci 13: 134.

Polanyi M. (1958) Personal Knowledge. Towards a Post-Critical Philosophy, Chicago, London: University of Chicago Press.

Powell BJ, McMillen JC, Proctor EK, et al. (2012) A compilation of strategies for implementing clinical innovations in health and mental health. Med Care Res Rev 69: 123-157.

Prince MJ, Wu F, Guo Y, et al. (2015) The burden of disease in older people and implications for health policy and practice. The Lancet 385: 549-562.

Prochaska JO and DiClemente CC. (1983) Stages and Processes of Self-Change of Smoking: Toward An Integrative Model of Change. Journal of Consulting and Clinical Psychology 51: 390-395.

Proctor E, Silmere H, Raghavan R, et al. (2011) Outcomes for implementation research: conceptual distinctions, measurement challenges, and research agenda. Administration and Policy in Mental Health 38: 65-76.

Proctor EK, Powell BJ and McMillen JC. (2013) Implementation strategies: recommendations for specifying and reporting. Implementation Science 8: 139.

Przyborski A and Slunecko T. (2009) Against reification! Praxeological methodology and its benefits. In: Valsiner J, Molenaar P, Lyra M, et al. (eds) Dynamic Process Methodology in the Social and Developmental Sciences. New York, NY: Springer 141-170.

Reckwitz A. (2002) Toward a Theory of Social Practices: A Development in Culturalist Theorizing. European Journal of Social Theory 5: 243-263. 
Redmond P, Grimes TC, McDonnell R, et al. (2018) Impact of medication reconciliation for improving transitions of care. Cochrane Database of Systematic Reviews: 150.

Region Östergötland. (2014) Läkemedelsgenomgång, enkel- och fördjupad samt läkemedelsberättelse (riktlinjer) [Medication review, basic and advanced, dicharge summary report (Guideline)]. Available at: https://vardgivarwebb.regionostergotland.se/Startsida/PM-medicinska-ovardadm/PM-dokument/Ledningsstab/Lakemedelsgenomgang-enkel--ochfordjupad-samt-lakemedelsberattelse-riktlinjer/.

Region Östergötland. (2015) Slutrapport Rätt läkemedel [Final report: the right drug]. Linköping, Sweden: Region Östergötland.

Rosenstock IM. (1990) The health belief model: Explaining health behavior through expectancies. Health behavior and health education: Theory, research, and practice. San Francisco, CA, US: Jossey-Bass, 39-62.

Rouse J. (2001) Two concepts of practices. In: Schatzki TR, Knorr Cetina K and von Savigny E (eds) The Practice Turn in Contemporary Theory. London: Routledge, 198-208.

Rouse J. (2007) Social Practices and Normativity. Philosophy of the Social Sciences 37: 46-56.

Ruiz-Millo O, Climente-Marti M, Galbis-Bernacer AM, et al. (2017) Clinical impact of an interdisciplinary patient safety program for managing drugrelated problems in a long-term care hospital. International Journal of Clinical Pharmacy 39: 1201-1210.

Runciman WB. (2006) Shared meanings: preferred terms and definitions for safety and quality concepts. Med $J$ Aust 184: S41-43.

Rycroft-Malone J, Kitson A, Harvey G, et al. (2002) Ingredients for change: revisiting a conceptual framework. Quality \& safety in health care 11: 174180.

Salter C, Holland R, Harvey I, et al. (2007) "I haven't even phoned my doctor yet." The advice giving role of the pharmacist during consultations for medication review with patients aged 80 or more: qualitative discourse analysis. $B M J$ 334: 1101.

Sanchez SH, Sethi SS, Santos SL, et al. (2014) Implementing medication reconciliation from the planner's perspective: a qualitative study. $B M C$ Health Services Research 14: 290-290.

Sandberg J and Tsoukas H. (2011) Grasping the Logic of Practice: Theorizing Through Practical Rationality. The Academy of Management Review 36: 338-36o.

Sandberg J and Tsoukas H. (2015) Making sense of the sensemaking perspective: Its constituents, limitations, and opportunities for further development. Journal of Organizational Behavior 36: S6-S32.

Sausman C, Oborn E and Barrett M. (2016) Policy translation through localisation: implementing national policy in the UK. Policy and Politics 44: 563-589.

Schatzki TR. (1996) Social practices: a Wittgensteinian approach to human activity and the social, Cambridge: Cambridge University Press.

Schatzki TR. (2001) Introduction: practice theory. In: Schatzki TR, Knorr Cetina $\mathrm{K}$ and von Savigny E (eds) The Practice Turn in Contemporary Theory. London: Routledge, 10-23. 
Schatzki TR. (2002) The Site of the Social: A Philosophical Account of the Constitution of Social Life and Change, University Park, PA: Pennsylvania State University Press.

Schatzki TR. (2005) The Sites of Organizations. Organization Studies (o1708406) 26: 465-484.

Schatzki TR. (2009) Timespace and the Organization of Social Life. In: Shove E, Trentmann F and Wilk R (eds) Time, Consumption and Everyday Life. Practice, Materiality and Culture London Oxford: Berg Publishers, 35-48.

Schatzki TR. (2010) Materiality and Social Life. Nature and Culture 5: 123-149.

Schatzki TR. (2012) A Primer on Practices. Theory and Research. In: Higgs J (ed) Practice-Based Education: Perspectives and Strategies. Rotterdam: Sense Publishers, 13-26.

Schatzki TR. (2017) Practices and Learning. In: Grootenboer P, Edwards-Groves $\mathrm{C}$ and Choy S (eds) Practice Theory Perspectives on Pedagogy \& Education. Praxis, Diversity and Contestation. Singapore: Springer, 23-43.

Schmidt K. (2018) "Practice theory": A critique. In: Wulf V, Pipek V, Randall D, et al. (eds) Socio-informatics: A practice-based perspective on the design and use of IT artifacts. Oxford: Oxford University Press, 105-137.

Schmidt R. (2017) Sociology of Social Practices: Theory or Modus Operandi of Empirical Research? In: Jonas M, Littig B and Wroblewski A (eds) Methodological Reflections on Practice Oriented Theories. Cham, Switzerland: Springer, 3-17.

Schmidt R and Volbers J. (2011) Siting praxeology. The methodological significance of "public" in theories of social practices. Journal for the Theory of Social Behaviour 41: 419-440.

Schütz A. (1980) The phenomenology of the social world, London, UK: Heinemann.

Sedlačko M. (2017) Conducting Ethnography with a Sensibility for Practice. In: Jonas M, Littig B and Wroblewski A (eds) Methodological Reflections on Practice Oriented Theories. Cham, Switzerland: Springer, 47-60.

Sennesael AL, Dalleur O, Henrard S, et al. (2018) Implementing a screening tool to improve prescribing in hospitalized older patients: a pilot study. Int J Clin Pharm 40: 15-19.

Shah BM and Hajjar ER. (2012) Polypharmacy, adverse drug reactions, and geriatric syndromes. Clin Geriatr Med 28: 173-186.

Shotter J and Gergen KJ. (1994) Social Construction: Knowledge, Self, Others, and Continuing the Conversation. Communication Yearbook 17: 3 .

Shove E and Pantzar M. (2007) Recruitment and Reproduction: The Careers and Carriers of Digital Photography and Floorball. Human Affairs 17: 154.

Shove E, Pantzar M and Watson M. (2012) The Dynamics of Social Practice. Everyday Life and how it Changes, Thousand Oaks, CA: SAGE Publications.

Sinnott C, Byrne M and Bradley CP. (2017) Improving medication management for patients with multimorbidity in primary care: a qualitative feasibility study of the MY COMRADE implementation intervention. Pilot Feasibility Stud 3: 14.

Sjöberg C and Wallerstedt SM. (2013) Effects of Medication Reviews Performed by a Physician on Treatment with Fracture-Preventing and Fall-RiskIncreasing Drugs in Older Adults with Hip Fracture?A Randomized Controlled Study. Journal of the American Geriatrics Society 61: 1464-1472.

Skolarus TA, Lehmann T, Tabak RG, et al. (2017) Assessing citation networks for dissemination and implementation research frameworks. 12: 97. 
Slaughter SE, Zimmermann GL, Nuspl M, et al. (2017) Classification schemes for knowledge translation interventions: a practical resource for researchers. Bmc Medical Research Methodology 17: 11.

Smith DE. (2006) Institutional ethnography as practice, Lanham, Md.: Rowman $\&$ Littlefield.

Smith KJ, Handler SM, Kapoor WN, et al. (2016) Automated communication tools and computer-based medication reconciliation to decrease hospital discharge medication errors. American journal of medical quality : the official journal of the American College of Medical Quality 31: 315-322.

Socialstyrelsen. (2012) Ändring i föreskrifterna och allmänna råden (SOSFS 200O:1) om läkemedelshantering $i$ hälso- och sjukvården [Changes in the provisions and general guidelines on medication management in health care], Stockholm.

Socialstyrelsen. (2013a) Läkemedelsgenomgångar för äldre ordinerade fem eller fler läkemedel - en vägledning för hälso- och sjukvården [Medication review for elderly patients with five or more prescribed medications guidance for health care], Stockholm.

Socialstyrelsen. (2013b) Webbutbildning om Läkemedelsgenomgångar för äldre [Web-based training on medication review in the eldelry].

Southam-Gerow MA and Dorsey S. (2014) Qualitative and mixed methods research in dissemination and implementation science: introduction to the special issue. J Clin Child Adolesc Psychol 43: 845-850.

Spradley J. (1980) Participant observation, Orlando, FL: Harcourt Brace Jovanovich.

Strifler L, Cardoso R, McGowan J, et al. (2018) Scoping review identifies significant number of knowledge translation theories, models, and frameworks with limited use. Journal of Clinical Epidemiology 100: 92-102.

Suchman L, Blomberg J, Orr J, et al. (1999) Reconstructing Technologies as Social Practice. American Behavioral Scientist 43: 392-408.

Sutcliffe KM. (2004) Defining and classifying medical error: lessons for learning. Quality \& Safety in Health Care 13: 8-9.

Swedberg R. (2016) Before theory comes theorizing or how to make social science more interesting. British Journal of Sociology 67: 5-22.

Sveriges läkarförbund. (2016) Nationell läkemedelslista nu! En kvalitativ studie av läkarnas behov av en nationell läkemedelslista [National medication list now! A qualitative study exploring physicians' view on a national medication list]. Stockholm.

Tabak RG, Khoong EC, Chambers DA, et al. (2012) Bridging research and practice: models for dissemination and implementation research. American journal of preventive medicine 43: 337-350.

Tamuz M, Thomas EJ and Franchois KE. (2004) Defining and classifying medical error: lessons for patient safety reporting systems. Quality \& Safety in Health Care 13: 13-20.

Thomas DC, Berry A, Djuricich AM, et al. (2017) What Is Implementation Science and What Forces Are Driving a Change in Medical Education? American Journal of Medical Quality 32: 438-444.

Timmermans S and Tavory I. (2012) Theory Construction in Qualitative Research: From Grounded Theory to Abductive Analysis. Sociological Theory 30: 167-186.

Turner S. (1994) The Social Theory of Practices: Tradition, Tacit Knowledge, and Presuppositions, Chicago, IL University Of Chicago Press. 
Uhl MC, Muth C, Gerlach FM, et al. (2018) Patient-perceived barriers and facilitators to the implementation of a medication review in primary care: a qualitative thematic analysis. Bmc Family Practice 19: 9.

Waeraas A and Nielsen JA. (2016) Translation Theory 'Translated': Three Perspectives on Translation in Organizational Research. International Journal of Management Reviews 18: 236-270.

van der Geest S and Finkler K. (2004) Hospital ethnography: introduction. Social Science \& Medicine 59: 1995-2001.

van Mil JWF, Westerlund T, Brown L, et al. (2016) Medical care and drug-related problems: Do doctors and pharmacists speak the same language? International Journal of Clinical Pharmacy 38: 191-194.

van Sluisveld N, Zegers M, Natsch S, et al. (2012) Medication reconciliation at hospital admission and discharge: insufficient knowledge, unclear task reallocation and lack of collaboration as major barriers to medication safety. BMC Health Serv Res 12: 170.

Wandersman A, Chien VH and Katz J. (2012) Toward an Evidence-Based System for Innovation Support for Implementing Innovations with Quality: Tools, Training, Technical Assistance, and Quality Assurance/Quality Improvement. American Journal of Community Psychology 50: 445-459.

Warde A. (2005) Consumption and theories of practice. Journal of Consumer Culture 5: 131-153.

Warde A. (2014) After taste: culture, consumption and theories of practice. Journal of Consumer Culture 14: :279-303.

Waring JJ. (2009) Constructing and re-constructing narratives of patient safety. Social Science \& Medicine 69: 1722-1731.

Warren CAB. (2012) Interviewing as Social Interaction. In: Gubrium JF, Holstein JA, Marvasti AB, et al. (eds) The SAGE Handbook of Interview Research.The Complexity of the Craft 2ed. Thousand Oaks, California: SAGE Publications, Inc., 129-142.

Watts JH. (2011) Ethical and practical challenges of participant observation in sensitive health research. International Journal of Social Research Methodology 14: 301-312.

WHO. (2002) Safety of medicines. A guide to detecting and reporting adverse drug reactions, Geneva: World Health Organization.

WHO. (2016) Medication Errors: Technical Series on Safer Primary Care, Geneva: World Health Organization.

WHO. (2017) Medication Without Harm - Global Patient Safety Challenge on Medication Safety. Geneva: World Health Organization.

Willeboordse F, Hugtenburg JG, Schellevis FG, et al. (2014) Patient participation in medication reviews is desirable but not evidence-based: a systematic literature review. British Journal of Clinical Pharmacology 78: 1201-1216.

Willeboordse F, Schellevis FG, Chau SH, et al. (2017) The effectiveness of optimised clinical medication reviews for geriatric patients: Opti-Meda cluster randomised controlled trial. Family Practice 34: 437-445.

Willeboordse F, Schellevis FG, Meulendijk MC, et al. (2018) Implementation fidelity of a clinical medication review intervention: process evaluation. International Journal of Clinical Pharmacy.

Wind G. (2008) Negotiated interactive observation: Doing fieldwork in hospital settings. Anthropology \& Medicine 15: 79-89.

Wittgenstein L. (1967) Philosophical investigations, Oxford, UK: Blackwell. 
Vogelsmeier A, Pepper GA, Oderda L, et al. (2013) Medication reconciliation: A qualitative analysis of clinicians' perceptions. Research in Social and Administrative Pharmacy 9: 419-430.

Wolfinger NH. (2002) On writing fieldnotes: Collection strategies and background expectancies. Qualitative Research 2: 85-93.

Vygotskij LS and Cole M. (1978) Mind in Society. The Development of Higher Psychological Processes, Cambridge, Mass.: Harvard U.P.

Yanow D and Schwartz-Shea P. (2014) Interpretation and method: empirical research methods and the interpretive turn. 2nd ed., Oxford: Routledge.

Ybema S, Yanow D, Wels H, et al. (2009) Organizational Ethnography: Studying the Complexities of Everyday Life, London, United Kingdom: SAGE Publications, Ltd.

Yu KH, Nation RL and Dooley MJ. (2005) Multiplicity of medication safety terms, definitions and functional meanings: when is enough enough? Qual Saf Health Care 14: 358-363.

Zhou LN and Rupa AP. (2018) Categorization and association analysis of risk factors for adverse drug events. European Journal of Clinical Pharmacology 74: 389-404.

Zimmerman KM, Salgado TM and Dixon DL. (2017) Medication reconciliation vs medication review. JAMA 318: 965-966.

Zundel M and Kokkalis P. (2010) Theorizing as Engaged Practice. Organization Studies 31: 1209-1227. 


\section{APPENDIX}

\section{Interview topic guide healthcare staff}

\section{Background information}

Gender, speciality (approx. duration), working at unit since (years), type of work position

Brief introduction of research project, relevance of interviews

\section{Current professional work and medications}

- Describe current work activities and work tasks, describe typical work shift

- Can you recall a recent situation where it felt really important to ask a patient about his/her medications?

- Can you recall a recent situation where you were alarmed (very concerned) with respect to a patient's medications?

\section{Conduct of medication-review}

- Own definition of medication review

Probe: in what ways differs medication review from previous routines with respect to medications?

- According to you, what is the main purpose of medication review?

Probes: What is the benefit of doing medication review?

Are there any harms of doing medication review?

How would you know that you did a good job/did not accomplish what you planned?

- What does it take to perform medication review appropriately?

- When considering your usual work context (e.g. workload, competing demands, patient groups), describe a suitable/practicable way to conduct medication review?

Probe: In what ways would that impact potential benefits of medication review? How do you go about to make medication review fit (adapt) to local context? 
- What does medication review mean to you with respect to the documentation required?

- With whom would you work together/have contact with respect to medications?

- What does medication review mean to you with respect to the task distribution vis-à-vis other healthcare professionals (physician, nurse, pharmacists)?

Probe: Can you briefly describe your responsibilities (work task boundaries) vis-à-vis other healthcare professionals at this department?

\section{Implementation and embedding of medication-review}

- Describe (previous/ongoing) activities to further embed medication review in local context

Probes: describe own involvement

Are you aware of any implementation objectives?

How was introduction/initial implementation met locally?

How would you consider implementation 'success' so far?

\section{Medication-related harms}

- Are you confident in the ways patient (medication) safety is being dealt with at this department?

Probes: What are the processes available to you in order to contribute to learning for improving medication safety?

Do you receive any feedback when sharing (reporting) medication safety concerns?

- Describe (define) medication-related problem

Probes: Can you remember a specific situation where you were dealing with a medication-related problem?

In what ways did this impact on your later work practices? Describe consequences (e.g. reporting routines)? 


\section{Interview topic guide patients}

Background information

Gender, age, occupation

Brief introduction research project, relevance of interviews

\section{Recent hospital stay (ED visit)}

- Describe reason for hospitalization (ED visit, respectively)

\section{Medication use (ongoing, previous)}

- Describe use of medicines (regular therapy, since when, type of medicines, as ordered?)

- Occasional medicine use

Probes: Use (occasional, regular) of other types of medicines (e.g. alternative or complementary)?

What kind of support do you need most? Did you receive the support you expected/felt you needed?

How do you feel about the effects of your medicines?

How do you go about judging whether you have the expected effects from your medicines?

\section{Medication-related activities connected to hospitalization (ED visit)}

- Describe: in what ways were medicines relevant (e.g. talked about, describe actions) at admission to hospital (ED visit, respectively)

Probes: In what ways did you actively bring up medicines in this context?

(specific to surgery/orthopaedic wards): do you remember talking about medicines with any specific healthcare professional (probe for clinical pharmacist, nurse, physician, other professional)?

- Describe: in what ways were medicines relevant (e.g. talked about, describe actions) during the hospital stay?

- Describe: in what ways were medicines relevant (e.g. talked about, describe actions) at discharge from the hospital (ED, respectively)?

Probes: type of healthcare professional involved 
How was the discharge medication list discussed?

Was it possible to discuss own questions or concerns? Please describe...

- Do you recall receiving any new medications in connection to your hospital stay (ED visit, respectively)?

If yes, please describe

- If yes: in what way were these new medications discussed with you?

Probes: In what ways were the expected effects of your medicines discussed?

Were any unintended effects/side effects discussed?

How did you go about judging whether you had the expected effects from your medicines?

- Did you have any concerns related to medicines in connection to your hospital stay (ED visit, respectively)?

If yes, please describe....

- How did you go about taking your new (or changed) medications after discharge from hospital?

Probe: Did you require (receive) any specific support?

Did you experience any problems?

If yes, please describe 


\section{Articles}

The articles associated with this thesis have been removed for copyright reasons. For more details about these see:

http://urn.kb.se/resolve?urn=urn:nbn:se:liu:diva-156274 



\section{FACULTY OF MEDICINE AND HEALTH SCIENCES}

Linköping University Medical Dissertation No. 1684, 2019

Department of Medical and Health Sciences

Linköping University

SE-581 83 Linköping, Sweden

www.liu.se 